\title{
Can Wage Dynamics in Long-term Employment Relationships Help Mitigate Financial Shocks?
}

\author{
Yicheng Wang* \\ Economics, University of Rochester
}

Job Market Paper

This version: January 10, 2015

\begin{abstract}
Evidence suggests that financially constrained firms may offer lower wages, coupled with faster wage growth. If these constrained firms can tilt wages, cutting current wages in exchange for later increases, this potentially mitigates the impact of financial frictions or shocks. This paper studies the aggregate implications of this mitigating effect with an application to the 2008 financial crisis. I provide a new, tractable equilibrium model of wage dynamics for heterogeneous firms-some are financially constrained, some not. Risk-neutral firms post optimal long-term wage contracts to attract risk-averse workers through competitive search. When applied to the 2008 financial crisis, the model predicts that small firms, being more likely to be constrained, tend to temporarily cut workers' wages, while for large firms wages are quite smooth and stable. Counterfactual experiments in the model show that the mitigating effect can be important. For instance, if the wages within a contract were more rigid (e.g., by raising workers' risk aversion parameter from 2 to 10), the aggregate output would have been even lower in the crisis by about $2 \%$ and the unemployment rate higher by about a third of a percentage point. Lastly, I find that the model has empirical support along several dimensions. The model is consistent with cyclical behavior in wage data (including new hires and job stayers' wage behavior). Its prediction that small firms cut wages much more than large firms is also consistent with micro-level data during the Great Recession.
\end{abstract}

Classification: E2, J3, G3.

Keywords: Implicit contracts, financial frictions, firm dynamics, labor market dynamics.

*E-mail address: yicheng.wang@rochester.edu. I would like to thank Mark Bils for his invaluable advice and encouragement throughout the course of this project. For helpful comments and suggestions, I am also grateful to George Alessandria, Yan Bai, Saki Bigio, Yongsung Chang, Gabriel Chodorow-Reich, Francois Gourio, Baris Kaymak, Dan Lu, Ryan Michaels, Jon Steinsson, Vincent Sterk, Robert Wilson, and other seminar participants at Rochester, Tsinghua University Macroeconomics Workshop 2014, and Econometric Society China Meeting 2014. All errors are my own. 


\section{Introduction}

The 2008 financial crisis in the United States and the subsequent recession have raised much emphasis on the macroeconomic implications of how firms respond to financial shocks. ${ }^{1}$ This paper provides a new perspective on this topic, asking how firms and workers as a whole respond to financial shocks within long-term employment relationships. In particular, as evidence suggests, financially constrained firms may "tilt" workers' wages, cutting current wages in exchange for faster wage growth in the future. Using the proceeds from wage cuts, firms can mitigate the constraints on investment and production that arise from limited credit market access. Importantly, this wage profile adjustment toward backloading is mutually beneficial for both firms and workers, since financially constrained firms have a higher shadow value of current dollars. ${ }^{2}$ Consequently, when firms face financial constraints, wage dynamics may have important macroeconomic implications, which have not yet been explored in the literature. This paper studies, quantitatively and empirically, the aggregate implications of this mitigating effect with an application to the 2008 financial crisis. ${ }^{3}$ I show that the mitigating effect is important and sizable.

Empirically, several pieces of evidence suggest that financially constrained firms actively use wage dynamics to help mitigate their constraints. Guiso et al. (2013) use matched bank-employer-employee data from Italy and show that firms that operate in less financially developed markets, being more likely to be liquidity constrained, offer lower entry wages but with faster wage growth than firms in more financially developed markets. ${ }^{4}$ In Section 6, I document new evidence during the 2008 financial crisis period: small firms, which are more likely to be financially constrained, cut workers' wages when financial markets were disrupted, and gradually increased wages when market conditions improved. By contrast, at large firms, wages were quite stable and smooth. That is, during the crisis period, financially constrained firms appeared to tilt the wage profiles. Additionally, Core and Guay (2001), Hall and Murphy (2003), and Blasi et al. (2003) find that it is more common for liquidity constrained firms to use stock options/grants as a labor payment to non-executive, ordinary workers, instead of using cash as a payment. ${ }^{5}$ Benmelech et al. (2012) find that constrained firms in the airline industry negotiated with the labor union to obtain wage concessions (about

\footnotetext{
${ }^{1}$ For detailed research along these lines, see the literature review section.

${ }^{2}$ This is because firms may have high productivity, or high marginal product of capital, which is typically higher than the risk-free interest rate.

${ }^{3}$ The 2008 financial crisis is particularly relevant, since in this period, the financial market was disrupted and many firms were financially constrained. Among other evidence, Chodorow-Reich (2014) uses matched bank-employer data, Gilchrist et al. (2012) use firm-level borrowing costs, Hadlock and Pierce (2010) use survey data, and Campello et al. (2010) use surveys of CFOs to find that firms faced much more difficulty in financing during this period.

${ }^{4} \mathrm{As}$ the authors claim in the paper, this is probably the first one to have a systematic, empirical evaluation about the role of employment relationship as an implicit credit relation. They estimate that the amount of credit generated by implicit lending within the firm is economically important and can be as large as $30 \%$ of bank lending.

${ }^{5}$ Stock options may also provide incentives for executives. However, just as argued in Core and Guay (2001), stock options to non-executives, secretaries, and clerks can hardly be justified as providing incentives versus mitigating the firm's liquidity constraints.
} 
$10 \%$ of wages annually). By doing this, firms could mitigate their financial constraints and remain competitive. ${ }^{6}$

These facts are in contrast to the traditional understanding of wage behaviors: real wages within employment matches are typically sticky and smoothed. ${ }^{7,8}$ The classical rationale from the implicit contract literature for wage smoothness is that unconstrained risk-neutral firms provide full insurance to risk-averse workers. ${ }^{9}$ However, when firms themselves are financially constrained, the tilted and non-smoothed wage profile could help firms mitigate their constraints.

Motivated by the aforementioned facts, I explore the role of wage dynamics within longterm contracts in mitigating financial frictions, as well as the aggregate implications. I provide a new, tractable equilibrium model of wage dynamics for heterogeneous firms. The model has two key elements: risk-neutral firms post long-term labor contracts to attract risk-averse workers; firms face credit market frictions, and some of them may be financially constrained. The model allows me not only to study wage and firm dynamics at the micro-level, but also to analyze aggregate wage behavior across business cycles and the aggregate implications of mitigating effects.

When applying the quantitative model to study the 2008 financial crisis, I find that the model helps account for wage dynamics in this period. Specifically, the model predicts that, in response to unanticipated financial shocks, liquidity-constrained firms cut workers' wages and gradually increase pay to workers, while for unconstrained firms wages remain quite smooth and stable. The key intuition is that constrained firms have a higher shadow value of current dollars, i.e., firms can create surplus more than the amount of wage cuts. Empirically, the model's predictions regarding differential wage dynamics across firms are consistent with micro-level data from the Survey of Income and Program Participation (SIPP): small firms, which are more likely to be financially constrained, cut wages much more than large firms during the Great Recession.

How important in the aggregate is the impact of constrained firms tilting wages? To explore this, I perform counterfactual experiments. I make the wage path endogenously much more rigid by raising workers' risk aversion parameter from 2 to 10 (with CRRA utility). Intuitively, if wages are too rigid, then it is extremely costly for financially constrained firms to cut wages. They have to operate at an even more suboptimal scale. Thus aggregate output declines more. Through general equilibrium effects, potential new entrants are now more

\footnotetext{
${ }^{6}$ There are some other related case studies. An interesting example is Energy Services Group International, an energy-services engineering and construction company in Williamsburg, VA. The company got a new contract from an electric utility in Florida but it could not persuade banks to lend. Only employees came forward with wage cuts and explicit savings in the company that ranged from $\$ 200$ to $\$ 74,000$ in exchange for promissory notes (Inc. Magazine, January 1992).

${ }^{7}$ For instance, see Bils (1985), Pissarides (2009), and the references therein.

${ }^{8}$ There is also ample evidence about nominal wage stickiness, such as Barattieri et al. (2014). They find that the average quarterly probability of a nominal wage change is between 21.1 and 26.6 percent, implying an expected duration for nominal wages about a year. My paper focuses only on real wages.

${ }^{9}$ Theoretical works include Knight (2002), Azariadis (1975), Baily (1974) and Gordon (1974); empirical support includes Beaudry and DiNardo (1991). For more details, see the literature review section.
} 
cautious to enter, since they anticipate the increased difficulty of borrowing from workers if they are constrained in the future after entry. This reduced hiring incentive results in a higher unemployment rate in the counterfactual economy. Quantitative results show that the aggregate output would have been even lower in the crisis period, by about $2 \%$, and the unemployment rate would have been higher by about a third of a percentage point. These results suggest that the mitigating effects from wage dynamics can be important.

Lastly, the model mechanism also helps account for cyclical wage behavior across business cycles. Specifically, I find that the cyclicality of average wages, both for job stayers and new hires, is fairly consistent with empirical estimates. The two key elements in the modelfinancial frictions and firm insurance to workers-are essential for yielding these consistencies. The model performs better with respect to wages than those without firm insurance (e.g., standard business cycle models such as King and Rebelo (1999) and Shimer (2005)), and better than those with full insurance (e.g., Rudanko (2009)). ${ }^{10}$

The contribution of this paper is to explore the aggregate implications of workers lending to constrained firms in long-term employment relationships that would typically smooth workers' wages. To my knowledge, this paper is the first to study how these wage dynamics respond to financial shocks and mitigate firms' constraints.

The structure of this paper is as follows. After discussing related literature, in section 2 I lay out the model's details and discuss the model's assumptions, intuitions and solution. The model is calibrated in section 3 . In section 4, I investigate firm and wage dynamics at the firm level. In section 5, I apply the model to study wage and firm dynamics in 2008 financial crisis. I perform counterfactual experiments to highlight the mitigating effects. In section 6, I provide some empirical support for the model's cross-sectional and cyclical wage predictions. In the appendix, I document all related data constructions, numerical analysis results, empirical analysis results, and mathematical proofs.

\subsection{Related Literature}

This paper is closely related to several different strands of literature. Most importantly, it builds on the implicit contract literature, from static implicit contract theory by Baily (1974), Gordon (1974), and Azariadis (1975) to long-term contract theory such as Harris and Holmstrom (1982) and Thomas and Worrall (1988). Similar to Rudanko (2009, 2011), this paper explicitly embeds a dynamic contract into a competitive search environment. In contrast, though, I focus on the interactions between financial frictions and firm insurance, whereas there is no financial friction in Rudanko's papers. Implicit contract models, empirically supported by a large body of literature (Beaudry and DiNardo (1991), Kudlyak (2014), Macis (2006), and Bellou and Kaymak (2012)), essentially capture the idea that a firm is not merely just a place of production; when outside insurance and credit markets for workers

\footnotetext{
${ }^{10}$ More precisely, my model performs better than the full commitment case in Rudanko (2009).
} 
do not work well due to moral hazard or informational frictions, relatively risk-neutral entrepreneurs optimally help smooth consumption for risk-averse workers. In the same spirit, when the outside credit markets limit firms' optimal investment and production, workers may help provide implicit internal credit through wage dynamics to the entrepreneurs. ${ }^{11}$

I employ the process of competitive search in labor markets, following Moen (1997), Acemoglu and Shimer (1999), and Menzio and Shi (2011). By doing this, we can endogenously determine the firm's hiring efforts as well as the value of dynamic wage contracts. The value of the contract and the level of wage bills have important influences on firm dynamics, especially for those firms without much financial strength. The assumption of a competitive search process, in contrast to a random search process, allows firms with different financial strength to post differentiated contracts upon entry and allows workers to fully direct their search toward their desired contracts in the decentralized labor market. ${ }^{12,13}$

This paper also belongs to a large and growing literature on financial market frictions, from earlier developments (Bernanke and Gertler (1989), Bernanke et al. (1999), Carlstrom and Fuerst (1997), Gertler and Gilchrist (1994)) to recent extensions with heterogeneous firms (Cooley and Quadrin (2001), Cooley et al. (2004), Arellano et al. (2012), Khan and Thomas (2013)). ${ }^{14}$ Closely related, Michelacci and Quadrini (2009) also assume that firms sign optimal long-term contracts to workers, and firms face an enforcement condition for the financial contract with investors. Their focus is explaining facts from Finnish longitudinal data: wage growth is positively related to firm growth and starting wages are negatively related to future firm growth. In contrast, my main contribution is studying the aggregate implications of contract mitigating financial shocks through wage profile adjustments in a dynamic equilibrium model. At the same time, the wage dynamics from my model are consistent with micro-level facts, including those described in Michelacci and Quadrini (2009) and those identified in Guiso et al. (2013).

\footnotetext{
${ }^{11}$ One may ask why firms can implicitly borrow from workers while cannot borrow from banks. In principal, this could be related to the facts that workers know more and/or better about firms than outside banks do. Also, it is possible that the job-specific capital and worker-specific human capital accumulated within the employment relationship can serve as implicit collateral. In this paper, I don't particularly model these elements, instead I focus on the wage dynamics when the outside credit for firms is exogenously limited and fluctuates.

${ }^{12}$ Random search is used, for instance, in the Diamond-Mortensen-Pissarides framework (Diamond (1982) and Mortensen and Pissarides (1994)), and also in Shimer (2005).

${ }^{13}$ This helps to capture the idea that a worker can choose to work for a contract posted by a firm with limited financial resources, or another firm with financial strength.

${ }^{14}$ This strand of research mostly focuses on studying whether and how a financial market disruption can have a large and lasting impact on the real economy. They also study why and how the presence of financial frictions can help amplify and propagate the original shocks, such as productivity shocks, demand shocks, capital depreciation shocks and others. Another strand (such as Buera and Shin (2013) Buera et al. (2011)) attempts to explain the impact of financial frictions on resource misallocations and endogenous TFP losses.
} 


\section{Model}

In this section I provide a new, dynamic equilibrium model to study the role of wage dynamics when firms face financial friction. After introducing each element for the model, I illustrate the intuition behind the model, discuss the model's characterizations and solutions, and finally comment on the model's assumptions.

\subsection{Model Details}

\section{Environment}

Consider an economy with two types of agents, a continuum of workers with measure 1 and a continuum of entrepreneurs (firms) with a large measure. ${ }^{15}$ There are three important elements in the model: Risk-neutral firms post long-term labor contracts to attract riskaverse workers; ${ }^{16}$ firms face credit market friction; and new firms and workers are matched through a competitive search labor market.

\section{Timing}

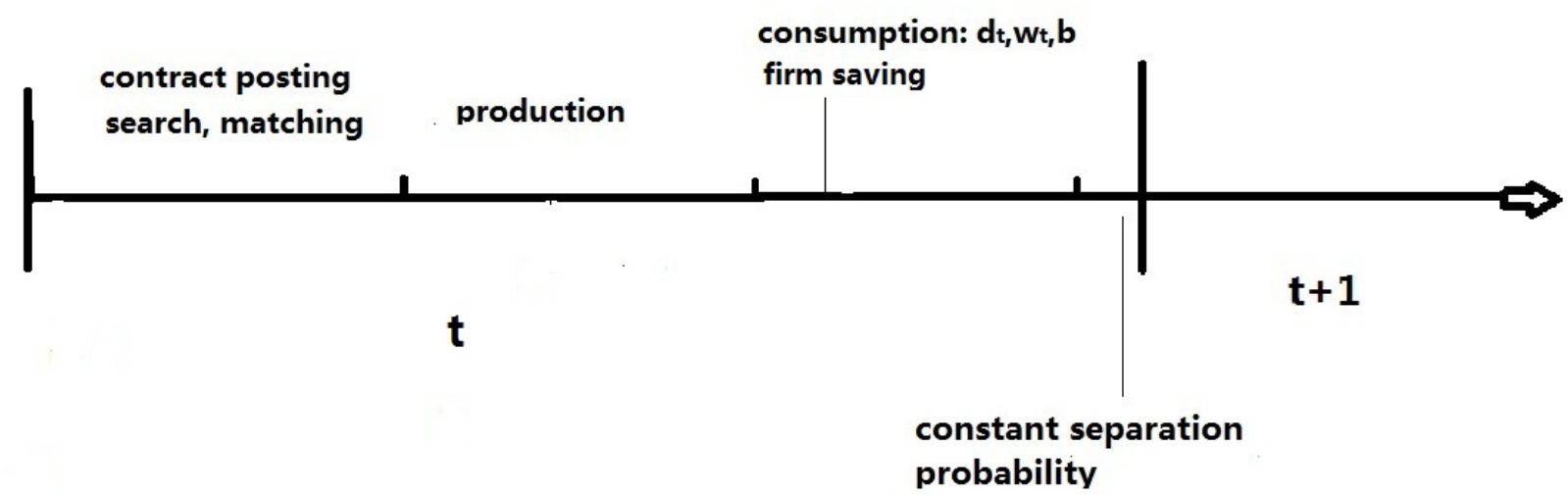

Figure 1: Timing of the model.

Time is discrete and infinite. For each period $t$, the timing is as follows:

1 Aggregate states are realized. ${ }^{17}$ The idiosyncratic productivity shock is also realized for each entrepreneur.

2 Matching. Unemployed workers and opened vacancies are brought together through

\footnotetext{
${ }^{15}$ The measure of entrepreneurs is greater than 1 and need not to be specified, since we only need to track the matched and unmatched (unemployed) workers.

${ }^{16}$ Essentially, we only need firms to be relatively less risk averse than workers.

${ }^{17}$ Aggregate states include aggregate productivity $X$ and aggregate financial shocks $\lambda$.
} 
competitive search in the labor market. The probability of matching is derived from a matching function to be specified below.

3 Production. For new matches and all existing matches, the firm-worker pair follows an optimally designed contract. The firm's investment, saving for the next period, the worker's current wage, and continuation utilities are determined at this stage.

4 Consumption. Employed workers consume their labor compensations. Entrepreneurs consume dividends and unemployed workers enjoy unemployment benefits.

5 Separation. At the last stage of period $t$, for each matched pair, there is a constant, exogenous probability of separation. ${ }^{18}$ Separated workers do not search in this period and are counted as unemployed at the beginning of the next period. ${ }^{19}$

6 Period $t+1$ begins.

\section{Hand-to-Mouth Workers}

The worker derives utility from goods consumption, with the following lifetime utility function:

$$
E_{t} \sum_{s \geq 0} \beta^{s}\left[u\left(c_{t+s}\right)\right]
$$

where $u$ is strictly increasing, concave, and satisfies the usual Inada conditions. Assume workers have no access to any form of financial markets, including any saving technology. That is, workers are hand-to-mouth. I will come back to this point later in the remarks subsection.

Employed workers have no choices to make; they simply consume their contemporaneous wages. ${ }^{20}$ However, unemployed workers must make choices as they optimally search in the frictional labor market. We now turn to discuss the optimization problem for the unemployed.

\section{Labor Market: Competitive Search}

Assume the search process in the frictional labor market is competitive search (Moen (1997) and Acemoglu and Shimer (1999)). ${ }^{21}$ At the beginning of each period, each vacant entrepreneur (firm) chooses whether to post an employment contract. Different contracts will deliver different lifetime promised utility $v$ to workers. The unemployed worker optimally

\footnotetext{
${ }^{18}$ In the literature for studying heterogeneous firms and firm dynamics in equilibrium and across business cycles, some methods and concepts are proposed to deal with the problem of large dimensionality, "to forecast infinite other firms' behavior": the Krusell-Smith method by using finite-moment approximations and forecasting, and Block recursive equilibria proposed by Menzio and Shi (2010) and Menzio and Shi (2011). I do not use these methods. The key feature in model allowing me to obtain tractability is the assumption of constant separation probability across any matched pair.

${ }^{19}$ Notice that there is no severance payment for the separated worker. Since separation is at the last stage for each period, the separated worker still enjoys wage compensation at the consumption stage in this period.

${ }^{20}$ For simplicity, I assume that a worker cannot apply for a job if he is employed, that is, there is no on-the-job search in the model.

${ }^{21}$ It is also called directed search in the search literature.
} 
chooses which contract to apply for (equivalently speaking, chooses which submarket to visit). For the submarket $v$, denote $\theta(v)$ as the queue length, or the ratio of applicants to vacancies in that submarket (following Acemoglu and Shimer (1999)). If the unemployed worker applies for job $v$, his application is successful with probability $f(\theta(v))$, where $f(\theta)$ a strictly decreasing function of $\theta$ such that $f(0)=1, f(\infty)=0$. Symmetrically, the firm finds a successful applicant for a job $v$ with probability $q(\theta(v))$, where $q(\theta)$ is a strictly increasing function such that $q(0)=0, q(\infty)=1$ and $q(\theta)=f(\theta) \theta .^{22}$

The unemployed worker searches across different open submarkets $i$, with $v_{i t}$ promised in that submarket. His optimization problem is as follows:

$$
V^{U}\left(S_{t}\right) \equiv \operatorname{Max}_{\{i\}} f\left(\theta_{i t}\right) v_{i t}+\left(1-f\left(\theta_{i t}\right)\right)\left[u(b)+\beta E_{t} V^{U}\left(S_{t+1}\right)\right],
$$

where $V^{U}\left(S_{t}\right)$ is the value of being unemployed at the beginning of $t$ with aggregate state $S_{t}$. Intuitively, he finds a job with probability $f\left(\theta_{i t}\right)$ from submarket $i$ and receives a lifetime promised utility $v_{i t}$. With probability $1-f\left(\theta_{i t}\right)$ he does not find a job; then he can consume unemployment benefit $b$ in this period and has a continuation utility $V^{U}\left(S_{t+1}\right)$ in the next period.

The competitive search means, in equilibrium, if there are two submarkets opened, (e.g., $\left.\theta_{i}^{*}>0, \theta_{j}^{*}>0\right)$, then for identical workers we must have:

$$
\begin{aligned}
V^{U}\left(S_{t}\right) & =f\left(\theta_{i t}^{*}\right) v_{i t}^{*}+\left(1-f\left(\theta_{i t}^{*}\right)\right)\left[u(b)+\beta E_{t} V^{U}\left(S_{t+1}\right)\right] . \\
& =f\left(\theta_{j t}^{*}\right) v_{j t}^{*}+\left(1-f\left(\theta_{j t}^{*}\right)\right)\left[u(b)+\beta E_{t} V^{U}\left(S_{t+1}\right)\right] .
\end{aligned}
$$

$V^{U}\left(S_{t}\right)$ is typically called market utility (Moen (1997) and Acemoglu and Shimer (1999)) and is essentially determined by workers' optimal search across different potential submarkets. This is important for the model, since we want to capture the idea that firms may post different contracts due to different financial conditions (and productivity), and that the unemployed worker can fully direct himself to whichever contract is optimal for him. In practice, a worker may choose to work for a start-up, or for a large and more mature firm. ${ }^{23}$

Finally, for any newly matched pair, the lifetime value $v$ will become a part of the firm's state variables. We now turn to the firm's problem.

\section{Firm Productivity and Production}

A firm is associated with a vector of idiosyncratic state variables $(z, a, v)$ at the beginning of each period, where $z$ is the idiosyncratic productivity, $a$ is the firm's net worth, and $v$ is the utility promised to the firm's worker determined in the prior period. $z$ takes its value from a finite set, $z \in\left\{z_{1}, z_{2}, \ldots, z_{N}\right\}$, and follows a common stationary and increasing Markov

\footnotetext{
${ }^{22} \mathrm{I}$ also assume the elasticity of $q$ with respect to $\theta, \varepsilon_{q}(\theta)$ is restricted such that $q(\theta) \frac{\varepsilon_{q}(\theta)}{1-\varepsilon_{q}(\theta)}$ as a whole is a decreasing function of $\theta$. This property will be used later when equilibrium conditions are derived.

${ }^{23}$ Presumably, these firms will have different financial strengths and offer different wage paths.
} 
transition function $Q\left(z_{t} \mid z_{t-1}\right)$ that satisfies the Feller property. $z$ is independent across firms.

The firm's production function is given by

$$
e^{X+z} f(k), \quad k \geq 0
$$

where $X$ is aggregate productivity which follows the same assumption of finiteness and has the same Markov properties as $z$. There is decreasing return to scale for the production, $f(k)=k^{\alpha}$, with $\alpha<1$. This assumption will enable us to obtain a non-trivial firm size distribution at the steady state and across business cycles. This is important, since we need enough firm heterogeneity to study our mechanism. Firms are endogenously heterogeneoussome of them may be financially constrained and some may not-and will react differently when they face the same aggregate shock, such as a financial shock.

\section{Financial Market Friction}

The financial market is not frictionless for firms. I assume the firm is subject to a collateral constraint when it needs to borrow. The form of the constraint is as follows:

$$
k \leq \lambda a, \lambda \geq 1
$$

The constraint $k \leq \lambda a$ says the value of rented capital cannot exceed a certain point, which is determined by the value of current firm net worth $a$ and the collateral constraint parameter $\lambda .{ }^{24}$ Different underlying frictions can give rise to such collateral constraints. ${ }^{25} \lambda$ is related to leverage since if $k>a$, then the leverage ratio $\frac{k-a}{a}$ is limited to $\lambda-1$. One can see that $\lambda$ measures the degree of credit market frictions, with $\lambda=\infty$ corresponding to the case of perfect credit markets and $\lambda=1$ to financial autarky where all capital rentals have to be selffinanced by the entrepreneur. I assume $\lambda$ is the same for all entrepreneurs in the economy and rule out the case that $\lambda$ may be differentiated for different firms. ${ }^{26}$ Finally, this specification captures the essential spirit and the common prediction from models of limited enforcement in the financial friction literature: the amount of credit available is limited by an individual

\footnotetext{
${ }^{24}$ This specification follows from the financial friction literature, such as Buera and Shin (2013), Moll (2014), Buera et al. (2011).

${ }^{25}$ As a very simple example, this constraint can be motivated as arising from a limited enforcement problem. Suppose an entrepreneur, with net north $a$, rents $k$ units of capital from a lender. The entrepreneur can steal $\frac{1}{\lambda}$ fraction of the rented capital. Imagine an environment where the borrowers are anonymous, or it is too costly for a lender to detect private stealing and collect back all the loans. At most, he can confiscate the borrower's net worth $a$. In anticipation of this possible stealing behavior, the lender will endogenously limit the lending in the first place. That is, the lending is limited by $k \frac{1}{\lambda} \leq a$. Notice that this constraint is essentially static and optimal long-term contracts are not considered here. If there were multiple periods, in principle there could be a repeated relationship between borrowers and lenders. In that case, an entrepreneur, when tempted to steal, has to take into account of the consequence of stealing in the future periods. If he can costlessly find a new lender (the anonymity assumption) and not being identified, then again, he will face the "static" limit. However, when the assumptions are different, generally put, a longer relationship would serve as a discipline for borrowers, such as in Hart and Moore (1994) and Kiyotaki and Moore (1997).

${ }^{26}$ For example, if the financial contract between borrower and lender is conditional on the firm's individual characteristics, then possibly the price and quantity of debt will differ across firms, such as in Arellano et al. (2012).
} 
entrepreneur's wealth. At the same time, this form of modeling and the parsimoniousness of using just one parameter enable us to analyze the qualitative and the quantitative effects of financial friction on aggregate dynamics without losing tractability. ${ }^{27}$

The assumptions of production function concavity and the collateral constraint imply that firms will have an incentive to accumulate net worth when they are small, while for large firms this incentive vanishes as $a$ is sufficiently large and the constraint is not binding.

\section{Promise Keeping to Workers}

For any matched pair, suppose the promised lifetime utility to the worker at the beginning of period $t$ is given by $v_{t}$. Formally, we should have

$$
\begin{aligned}
v_{t} & \equiv E_{t} \sum_{s \geq 0} \beta^{s}\left[u\left(c_{t+s}\right)\right]=u\left(w_{t}\right)+\beta E_{t}\left[\rho V_{t+1}^{U}+(1-\rho) E_{t+1} \sum_{s \geq 0} \beta^{s} u\left(c_{t+1+s}\right)\right] \\
& =u\left(w_{t}\right)+\beta E_{t}\left[\rho V_{t+1}^{U}+(1-\rho) v_{t+1}\right]
\end{aligned}
$$

This recursion says that the current promised lifetime utility to workers, $v_{t}$, is the sum of contemporaneous flow utility $u\left(w_{t}\right)$, and discounted next period's continuation value. If at the end of period $t$, the worker is separated with probability $\rho,(0<\rho<1),{ }^{28}$ then his continuation value is the value of being unemployed in the next period, $V_{t+1}^{U}$. With probability $1-\rho$ of not being separated, the worker receives continuation value $v_{t+1}$ from the firm. Note that since $v_{t}$ is predetermined and is one of the firm's individual state variables, $v_{t+1}$ will become a state variable in the next period. ${ }^{29}$ The contract is complete in the sense that for each individual state and each aggregate state, the continuation utility should be specified, as can be seen from below:

$$
v(s ; S)=u(w)+\beta E\left\{\left[\rho V^{U}\left(S^{\prime}\right)+(1-\rho) v^{\prime}\left(s, z^{\prime}, S^{\prime}\right)\right] \mid(s, S)\right\},
$$

where the $v^{\prime}$ is a function of this period's state variables $(s ; S)$ and also $\left(z^{\prime}, S^{\prime}\right)$ in the next period. While it is possible to add other frictions or more complect elements, I use complete contract as a starting point from a first principle and focus on understanding the key mitigating mechanism.

\section{Firm's Dynamic Optimization Problem}

We are now ready to describe the firm's optimization problem. For given state variables $(z, a, v ; S)$, denote the firm's value as $J(z, a, v ; S)$. The firm maximizes its expected discounted

\footnotetext{
${ }^{27}$ By doing this, the capital investment is essentially safe, not subject to any other risk or irreversibility like in Khan and Thomas (2013). If we add capital stock as a state variable and capital depreciates over time, the exact formulation of collateral constraint will change (Kiyotaki and Moore (1997)) and the fromulation may become complicated. However, the key mechanism in this paper can still go through even if we do that.

${ }^{28}$ This shock could be interpreted as the worker's health shock, or any other type of shock that incurs termination of the job.

${ }^{29}$ Using promised utility to worker as a state variable is quite common in the dynamic contract literature, such as Thomas and Worrall (1988), Rudanko (2009).
} 
present value of dividend streams, subject to a set of constraints: the dividend should be non-negative; renting physical capital is limited by the collateral constraint; and the worker's utility should be promise-keeping. Formally, we have the following recursive form:

$$
\begin{aligned}
J(z, a, v ; S)= & \operatorname{Max}_{\left\{w, k, a^{\prime}, v^{\prime}\left(s, z^{\prime}, S^{\prime}\right)\right\}} \\
& e^{X+z} f(k)-(r+\delta) k-w+a(1+r)-a^{\prime} \\
& +\beta(1-\rho) E J\left(z^{\prime}, a^{\prime}, v^{\prime}\left(s, z^{\prime}, S^{\prime}\right) ; S^{\prime}\right) \mid(s, S) \\
& +\beta \rho\left(a^{\prime}(1+r)\right) \\
\text { s.t. }: \quad & d=e^{X+z} f(k)-(r+\delta) k-w+a(1+r)-a^{\prime} \geq 0 \\
& k \leq \lambda a \\
& v=u(w)+\beta E\left\{\left[\rho V^{U}\left(S^{\prime}\right)+(1-\rho) v^{\prime}\left(s, z^{\prime}, S^{\prime}\right)\right] \mid(s, S)\right\} .
\end{aligned}
$$

Specifically, the firm optimally chooses physical capital $k$ to rent, saving $a^{\prime}$ for the next period, the contemporaneous wage $w$, and also the continuation utility function $v^{\prime}\left(s, z^{\prime}, S^{\prime}\right)$. The entrepreneur receives the contemporaneous dividend $d$ and continues his business with probability of $1-\rho$. If he is separated from the worker with a probability of $\rho$, he will receive only his asset $a^{\prime}(1+r)$ in the next period and exit. In that case, the separated worker returns to the unemployed pool.

\section{Entry of New Firms}

The above optimization problem is for a matched pair. For a potential new firm entrant, I assume that the new firm is associated with individual productivity of $z_{0} \equiv E z$, and an initial net worth $a_{0}$. Entrant are subject to a one-time fixed cost of $\kappa$, in units of the consumption good. ${ }^{30}$ The new firm's problem then is to choose which type of contract to post, or which level of promised utility $v$ to post in the contract:

$$
\operatorname{Max}_{\{v\}}-\kappa+q(\theta(v)) J\left(z_{0}, a_{0}, v ; S\right) .
$$

If the entrant chooses to post $v$, then the market queue length for this job will be $\theta(v)$ and $q(\theta(v))$ is the probability that the firm will find a worker. On the equilibrium path, we must have a zero-profit condition for the new entrant, that is,

$$
0=-\kappa+q\left(\theta\left(v^{*}\right)\right) J\left(z_{0}, a_{0}, v^{*} ; S\right)
$$

\section{Asset Market}

\footnotetext{
${ }^{30}$ Here I assume the cost has to be paid at the time of entry and there is no finance for this entry cost. In Petrosky-Nadeau and Wasmer (2013), they assume the recruitment cost should be financed. In Chugh (2013), they assume all operating costs, including wage payments, capital costs and recruiting costs, should be financed. As a comparison, our model focuses on the constraints on capital to be rented and that the dividend should be non-negative (no equity finance).
} 
To complete the model, for the asset market I assume the interest rate is fixed (small open economy) and entrepreneurs are impatient:

$$
\beta(1+r)<1
$$

This assumption ensures that in the cross-sectional distribution, a fraction of firms are financially constrained. That is, firms do not have strong incentives to accumulate unlimited buffer stock. $^{31}$ The assumption of fixed interest rate simplify the model. This allows us to focus more on the wage dynamics, firm dynamics, and labor market equilibrium.

\subsection{Definition of Recursive Competitive Search Equilibrium}

Now we are in the position to define a notion of recursive equilibrium. The Recursive Competitive Search Equilibrium consists of a list of functions: $V^{U}(S), u(S), v(S), f(\theta ; S), \theta(v ; S)$ where $v \in W$ and the equilibrium set of $W^{*} \sqsubseteq W \sqsubseteq \mathbb{R}, J(s ; S)$ and optimal decision functions $w(s ; S), a^{\prime}(s ; S), k(s ; S), d(s ; S), v^{\prime}\left(s, z^{\prime} ; S, S^{\prime}\right)$ such that:

(1) Unemployed workers optimally choose among different submarkets.

(2) Existing firms sign optimal contracts with workers and choose optimal investment, saving, wages, and continuation utilities.

(3) Vacancy posting for the new entrant is optimal and the free entry condition is satisfied.

(4) The $\theta$ function is defined on $W$ with the following complementary slackness condition:

$$
\begin{aligned}
0 & =\theta(v)\left\{\kappa-q(\theta(v)) J\left(z_{0}, a_{0}, v ; S\right)\right\}, \forall S . \\
\theta(v) & \geq 0 .
\end{aligned}
$$

(5) The aggregate unemployment rate dynamics are given by:

$$
u_{t+1}=u_{t}\left(1-f_{t}\right)+\left(1-u_{t}+u_{t} f_{t}\right) \rho .
$$

(6) The distribution of firms, represented by the density function $\mu(z, a, v ; S)$ at the beginning of each period, evolves as follows:

$$
\begin{aligned}
\mu\left(z^{\prime}, a^{\prime}, v^{\prime} ; S^{\prime}\right)= & {\left[\left(1-u_{t}\right) \int_{\left(v^{\prime}\left(s, z^{\prime} ; S, S^{\prime}\right)=v^{\prime} ; a^{\prime}(z, a, v ; S)=a^{\prime}\right)} \pi\left(z, z^{\prime}\right) \mu(z, a, v ; S) d z d a d v\right.} \\
& +u_{t} f_{t} \pi\left(z_{0}, z^{\prime}\right) I_{\left.\left(v^{\prime}\left(s, z^{\prime} ; S, S^{\prime}\right)=v^{\prime} ; a^{\prime}\left(z_{0}, a_{0}, v^{*} ; S\right)=a^{\prime}\right)\right] /\left(1-u_{t}+u_{t} f_{t}\right) .}
\end{aligned}
$$

\footnotetext{
${ }^{31}$ This assumption is commonly used in the literature. See a discussion in Arellano et al. (2012). To see this clearly, we can look at the first-order conditions for the firm's saving as in section 4 .
} 


\subsection{Intuition behind the Model}

Before I present formal analytical characterizations and numerical exercises, it is helpful to illustrate the mechanism intuitively here by using simple graphs.

Let us focus on a matched firm-worker pair. The firm tries to provide insurance to the worker with smoothed wages $w_{t}$, and the firm consumes dividends $d_{t}$. In each period the firm's flow of budget equation reads as

$$
d_{t}=\underbrace{y_{t}+a_{t}(1+r)-a_{t+1}}-\underbrace{w_{t}}
$$

where $y_{t} \equiv e^{X_{t}+z_{t}} f(k)-(r+\delta) k$. Notice that $y_{t}$ will be affected by productivity shocks and financial shocks $\lambda_{t}$ since $k \leq \lambda_{t} a_{t}$. Also the firm faces the non-negative dividend constraint:

$$
d_{t} \geq 0
$$

Call the first part $y_{t}+a_{t}(1+r)-a_{t+1}$ the available funds after saving. To provide insurance to workers, firms try to make wages as smooth as possible; however, there will be fluctuations in the available funds due to individual productivity shocks and aggregate shocks. Graphically, I use a fluctuating curve to represent roughly the available funds and a flat line to represent the wages. I discuss different cases below. In Figure 17, the non-negative dividend constraint is not binding, and the firm can always provide perfect insurance to workers (perfectly flat wages). However, hypothetically, in some states, the fluctuations in the available funds are too large to satisfy the dividend constraint when the firm wants to keep wages flat (as in figure 18). What would be the optimal choices of wages and dividends in this situation? In figure 19, intuitively, the firm could cut worker's wages, pay zero dividends when the situation is so severe and pay back workers later when financial conditions improve. Importantly, when firms are constrained, they have higher shadow value of current dollars, and tilting wages is optimal for both firms and workers. This case summarizes the essential point in those empirical facts discussed in the introduction.

These graphs are an extreme simplification and only intuitively illustrate the firm's problem. For example, the choice of capital and firm's saving will be endogenously determined in the model, but not here. The next sections provide rigorous analysis and numerical solutions.

\subsection{Model's Characterizations and Solutions}

In this section, I simplify and analyze the firm's optimization problem. Since the choice of capital is static, first define the following simple problem:

$$
\begin{aligned}
F(a, z ; S) \equiv & \operatorname{Max}_{\{k\}} e^{X+z} f(k)-(r+\delta) k+a(1+r) \\
& \text { s.t. : } \quad k \leq \lambda a,
\end{aligned}
$$


where $F(a, z ; S)$ is defined as the maximal value by choosing optimal capital $k$, for given current firm net worth and productivity. It is easy to show that $F$ is increasing in $a$, first concave and then linear in $a$. When the constraint is not binding, the marginal value of $a$ is just the gross interest rate.

Then the firm's problem can be simplified to:

$$
\begin{aligned}
& J(z, a, v ; S)= \operatorname{Max}_{\left\{w, a^{\prime}, v^{\prime}\left(s, z^{\prime}, S^{\prime}\right)\right\}} \\
& d+\beta(1-\rho) E J\left(z^{\prime}, a^{\prime}, v^{\prime}\left(s, z^{\prime}, S^{\prime}\right) ; S^{\prime}\right) \mid(s, S) \\
&+\beta \rho\left(a^{\prime}(1+r)\right) \\
& \mu \geq 0: d=F(a, z ; S)-w-a^{\prime} \geq 0, \\
& \xi \geq 0: u(w)+\beta E\left\{\left[\rho V^{U}\left(S^{\prime}\right)+(1-\rho) v^{\prime}\left(s, z^{\prime}, S^{\prime}\right)\right] \mid(s, S)\right\}-v=0,
\end{aligned}
$$

where I denote the Lagrangian multiplier $\mu$ for the dividend constraint and $\xi$ for the worker's promising keeping constraint.

I state the following properties and leave the formal proof to the appendix. The value function $J$ is differentiable, decreasing, and strictly concave in the worker's promised utility $v ; J$ is increasing and concave in the firm's net worth $a$; and $J$ is increasing in productivity $z$ under the assumption of the Feller property for the process $z$.

After establishing the concavity of the value function, we can use first-order conditions to characterize the optimization problem. Other F.O.Cs and the envelope conditions are left to the appendix, but I state here one condition that must be satisfied :

$$
\frac{\partial J(s ; S)}{\partial v}=\frac{\partial J\left(s^{\prime} ; S^{\prime}\right)}{\partial v^{\prime}}
$$

Intuitively, this condition says that the firm optimally allocates the worker's lifetime utility such that it is smoothed across states and time (notice that the above equation holds for any $s^{\prime}$ and any $S^{\prime}$ in the next period). Technically, this is because the firm's value function $J$ is concave in $v$. Another way is through the following condition about the worker's wage smoothing:

$$
\frac{u^{\prime}(w(s ; S))}{1+\mu(s ; S)}=\frac{u^{\prime}\left(w\left(s^{\prime} ; S^{\prime}\right)\right)}{1+\mu\left(s^{\prime} ; S^{\prime}\right)} .
$$

The intuition here is that the firm tries to provide insurance and smooth the worker's wages (and hence consumption) as much as possible. The firm uses the weight $\mu$, which is the shadow value of the dividend, or the value of an additional dollar to the firm. This equation clearly illustrates that if the firm has a higher shadow value for current dollars, it will lower current wages, relative to a perfectly smoothed case with $\mu=0$.

To solve the firm's optimization problem, one has to solve the continuation utility function $v^{\prime}\left(s, z^{\prime}, S^{\prime}\right)$ for the current and next period state. This becomes infeasible when the dimension of the state space is reasonably large. However, we can utilize the first-order condition in 
equation 5, which links the choice of continuation utility across time and across states. The basic idea then is to search over the marginal utility space, which is just one dimension. Essentially, we can do this because the firm always tries to insure workers as much as possible, and does this by keeping the weighted marginal utility constant, just as in equation 6 . To implement this idea, we define a new function $\Psi(z, a, \omega ; S)$ to be a weighted summation of two parties' values. ${ }^{32}$

$$
\begin{aligned}
\Psi(z, a, \omega ; S) \equiv & \operatorname{Sup}_{v} J(z, a, v ; S)+\omega v \\
= & \operatorname{Max}_{\left\{w, a^{\prime}\right\}} \\
& F(a, z ; S)-w-a^{\prime} \\
& +\omega\left[u(w)+\beta \rho E V^{U}\left(S^{\prime}\right)\right]+\beta \rho a^{\prime}(1+r) \\
& +\beta(1-\rho)\left(E \Psi\left(z^{\prime}, a^{\prime}, \omega ; S^{\prime}\right)\right) \\
\text { s.t. }: \quad & d=F(a, z ; S)-w-a^{\prime} \geq 0 .
\end{aligned}
$$

Note that the state variable $\omega$ now does not change in the next period's value function and now it is much easier to compute for $\Psi(z, a ; \omega, S)$. The original firm value $J$ can be recovered by $J(z, a, v ; S)=\Psi\left(z, a ; \omega^{*}, S\right)-\omega^{*} v$ with a search for $\omega^{*}$ such that $\frac{\partial \Psi\left(z, a ; \omega^{*}, S\right)}{\partial \omega^{*}}=v$. The following graph shows the transformed function $\Psi$ and the value function for $J$. For more details about the derivation and properties of $\Psi$, please see the appendix.
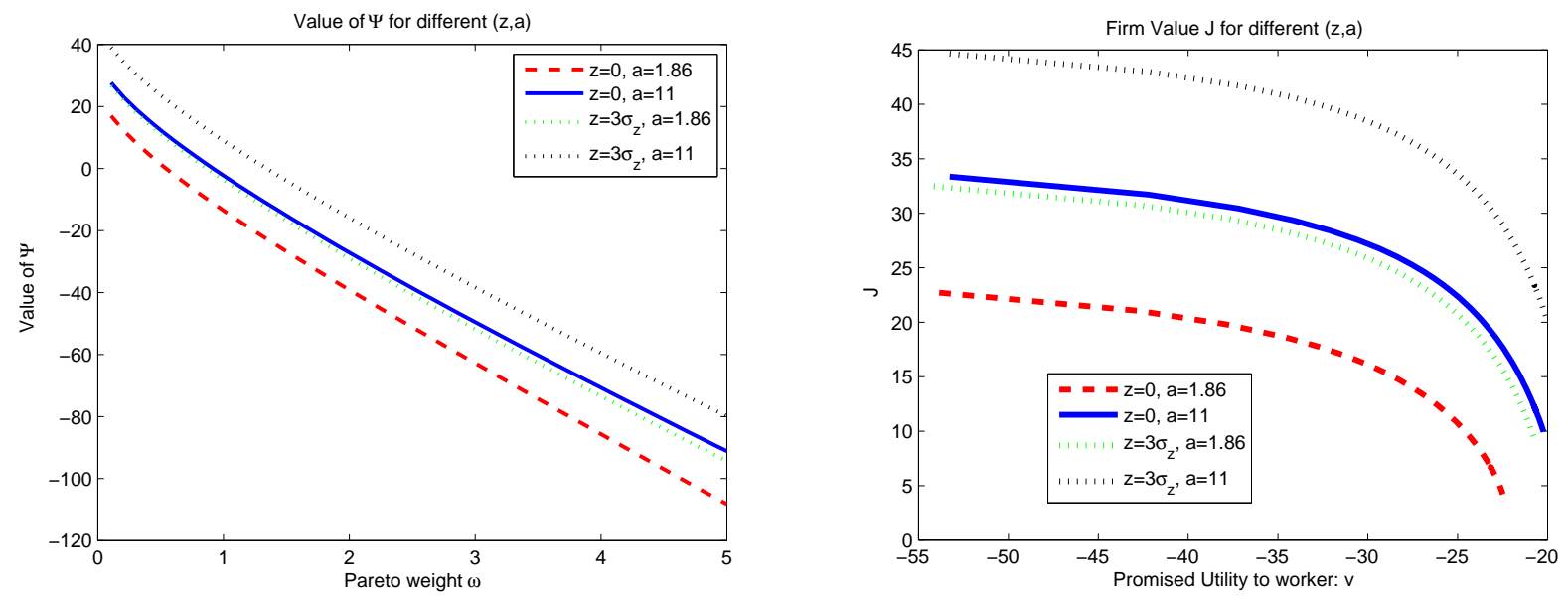

Figure 2: $\Psi(z, a, \omega ; S)$ and $J(z, a, v ; S)$

\subsection{Remarks on Model's Assumptions}

Several remarks on the model's assumptions and details are in order.

\footnotetext{
${ }^{32}$ Mathematically, this is so called Legendre-Fenchel transform. The method that uses the marginal utility in the state space is known as the recursive Lagrangian approach (see also Kocherlakota(1996), Cole and Kubler (2012)).
} 
First, I assume that workers do not have access to the financial markets and are handto-mouth. This is based on several considerations. (1) Limiting workers' access to financial markets matters for the model's mechanism. In the model, firms face borrowing constraints; if workers could borrow freely, then firms could implicitly borrow from workers and workers could borrow from outside financial markets. Therefore limiting workers' access serves as a conservative consideration here. Also as will be clearer later, the worker's wage profile is typically backloading; therefore even if we allow workers to save, it would not be optimal for them to do that. (2) Empirical work shows that this assumption may be realistic. For example, Chetty (2008) documents that approximately half of unemployment benefit claimants in the U.S. held no liquid wealth at the time of job loss, and exhibit liquidity-constrained behavior. Browning and Crossley (2001) and Gruber (1997) provide related evidence on the lack of consumption smoothing in the face of unemployment shocks. Jappelli (1990) documents that the unemployed are less likely to have access to credit than the average consumer. In addition, recently Kaplan et al. (2014) documents that a significant fraction of households are liquidity constrained and live "hand-to-mouth." (3) Finally, this assumption greatly simplifies the computation for the optimal contract problem. Suppose workers had access to financial markets; then in the contract, firms would have to take workers' optimal consumption and saving behavior into account, and the optimal contract design would be much more complicated. Based on these considerations, I assume workers have no access to financial markets.

Second, the separation probability is assumed to be constant and exogenous for each matched pair. By doing this, I push the firm's adjustment along the extensive margin to the hiring action. In equilibrium, at the time of entry, new firms will take into account future shocks and possible constraints, and this will affect their hiring incentives. ${ }^{33}$ Importantly, when a firm is hit by an adverse financial shock, if the magnitude of the shock is unexpectedly large, then the surplus for the match could become negative and they will separate. In the present model, I limit the size of shocks (through the assumption of a finite Markov process) and ensure that there is always positive surplus for each match. Empirically, as shown in figure 26, I find that the separation probabilities for small and large firms have similar patterns in the financial crisis period as well as in the 2001 recession. ${ }^{34}$ Since one of the main focuses here is to study the differential wage responses of different firms (small vs. large, constrained vs. unconstrained), I think this assumption is innocuous. Technically, this assumption makes the model tractable. I do not have to track the whole distribution of individual firms regarding separation decisions when calculating the evolution of aggregate variables, such as the unemployment rate and the value of being unemployed. ${ }^{35}$ Admittedly,

\footnotetext{
${ }^{33}$ Several other papers have a similar treatment, such as Shimer (2005), Gertler and Trigari (2009) and Bils et al. (2014).

${ }^{34}$ This actually is consistent with Moscarini and Postel-Vinay (2012) and Haltiwangera, Hyattb, and McEntarferb (2014), who find that the cyclical patterns of hiring and separation across large and small firms almost do not change in 2008 recession and in previous recessions.

${ }^{35}$ In addition, in the current model, there is only one worker for each firm. One could view the notion of firm size as capital or asset per worker. Alternatively, one could think there is a continuum of identical worker for each firm. Again, the main reason for this assumption is for simplicity and it does not hurt our
} 
it's important and more realistic to introduce endogenous separations and I leave this for future studies.

Finally, I assume that firms and workers can commit to the dynamic labor contract. ${ }^{36}$ Workers typically have backloading wage payments in the model. Therefore even if we allow workers to walk away freely without punishment, most of time the workers would not choose to do that. However, if workers are limited committed and there is a sufficiently unfavorable shock, the firm then cannot lower the current wages and the continuation utility as they could when workers fully commit. That is, there would be a form of downward wage stickiness. Therefore, the exact quantitative "mitigating" effects may be dampened a bit, though the mechanism still goes through in that case. ${ }^{37}$ On the firm's side, the firm may commit to the contract based on several considerations. The firm needs to incur firing costs and other legal costs to replace workers who had implicitly lent to him for non-performance reasons. Second, the firm may invest in worker-specific human capital and also job-specific capital. The capital accumulated during the employment relationship will be lost if the contract is breached. Finally, in today's society, the firm's reputation is very important for it to continue and thrive, especially when firms are relatively large.

\section{Calibration}

I calibrate the model at the steady state. We assume model periods are quarters. Workers have CRRA utility $\frac{c^{1-\sigma}}{1-\sigma}$. Firms and workers have the same subjective discount factor $\beta$ as 0.98 and the risk-free interest rate is 0.005 for a quarter. ${ }^{38}$ The production function is assumed to be $f(k)=k^{\alpha}$. For the firm's idiosyncratic productivity and also the aggregate productivity processes, $z$ and $X$, as already mentioned, I assume they follow $A R(1)$. In computation, I use the finite Markov chain method of Tauchen (1986) to discretize the productivity space into 15 and 7 points, respectively. The means of productivity are normalized to 1 . For the labor market matching function, following Menzio and Moen (2010), Menzio and Shi (2011), and Schaal (2012), I assume the matching function has the form such that a worker's probability

main mechanism. With multiple workers within each firm, we could have a richer firm dynamics to match firm-level data. However, in that case, we would have to track the within-firm distributions over individual firm characteristics and multiple workers' promised utilities, which is too complicated for computation.

${ }^{36}$ In the contract literature there is a concern that the contract may not be enforceable, especially when the contract is implicit. Some party may renege on the contract; that is, the contract will have limited commitment. Models with imperfect enforceability and limited commitment have been studied in dynamic environments by several authors, including Thomas and Worrall (1988), Kocherlakota (1996), and Alvarez and Jermann (2000). The combination of implicit labor contract and limited commitment has been studied by Rudanko (2009) and Menzio and Moen (2010).

${ }^{37}$ If instead we adopt the assumption of limited commitment for workers, on the equilibrium path we should have that $v_{i, t+1} \geq V_{t+1}^{U}, v_{i t} \geq V_{t}^{U}$. In the literature, this assumption is shown to be successful in generating a form of endogenous downward wage stickiness. (See the excellent review paper Thomas and Worrall (2007), also Rudanko (2009).)

${ }^{38}$ If firms and workers have different discounting factors, on average, the path of wages will have a frontloading or backloading trend, depending on who is more patient/impatient. However, what matters for our purpose is that, when there is an adverse shock, the deviation of wage relative to its path without shocks. 
of finding a job vacancy is given by $f(\theta)=\theta\left(1+\theta^{\gamma}\right)^{\frac{-1}{\gamma}}$, and the probability that a firm will find a worker is $q(\theta)=\frac{f(\theta)}{\theta}=\left(1+\theta^{\gamma}\right)^{\frac{-1}{\gamma}}$. This form ensures us a unique submarket opened on the equilibrium path. ${ }^{39}$ The parameter $\gamma$ is taken from Schaal (2012) and is obtained from a nonlinear optimal fitting estimation. The separation rate is assumed to be about 5 percent each quarter as in Shimer (2005).

The calibration results are in table 2 . The individual productivity process has parameters $\left(\rho_{z}, \sigma_{z}\right)=(0.89 .0 .18)$, which are consistent with various sources: Khan and Thomas (2013), Lee and Mukoyama (2008), and Clementi and Palazzo (2014). The value of $\lambda$ is calibrated to 1.3 and is important to determine the debt-to-asset ratio. ${ }^{40}$ Since the calibration is done at the steady state, I do not have its persistence parameter calibration here. I discuss the details when performing business cycle analysis. Finally, I calibrate entry cost $\kappa$ such that the steady state unemployment rate is about $6 \%$. The finding probability implied by the model is about 0.82 , which is consistent with Shimer (2005). The parameter $b$ is chosen such that the ratio of the unemployment benefit to the average labor income is about $50 \%$ in the model. ${ }^{41}$ Overall, the calibration shows that the model can fit the data in a number of dimensions, as shown in table 3, including untargeted moments. I will perform the quantitative analysis based on these parameters.

\section{Model's Properties}

In this section I examine the model's properties from several perspectives. I first study individual firms' optimal decisions, and then the wage and firm dynamics for an individual firm over time. I also relate the wage dynamics from the model to empirical studies. By doing this, we can ensure us that the model's implications for wage and firm dynamics are consistent with empirical patterns, and therefore suitable for further applications in section 5.

\footnotetext{
${ }^{39}$ In addition, this form can ensure that the matching probability is bounded by 0 and 1 . If instead we use the traditional Cobb-Douglas form, we probably need to assume the model period is a month, or even a week (see Rudanko (2009)).

${ }^{40}$ In practice, many moments are determined by all parameters simultaneously. Here I just emphasize the most important and most relevant moment for a particular target.

${ }^{41}$ As noted in Shimer (2005) and also in Hall and Milgrom (2008), Rudanko (2009), this ratio is in the range of empirical estimations (e.g., $40 \%$ in Shimer (2005) to $70 \%$ in Hall and Milgrom (2008) ). In the search literature, there is no consensus about the size of the replacement ratio.
} 


\subsection{Individual Firm's Optimal Decisions}
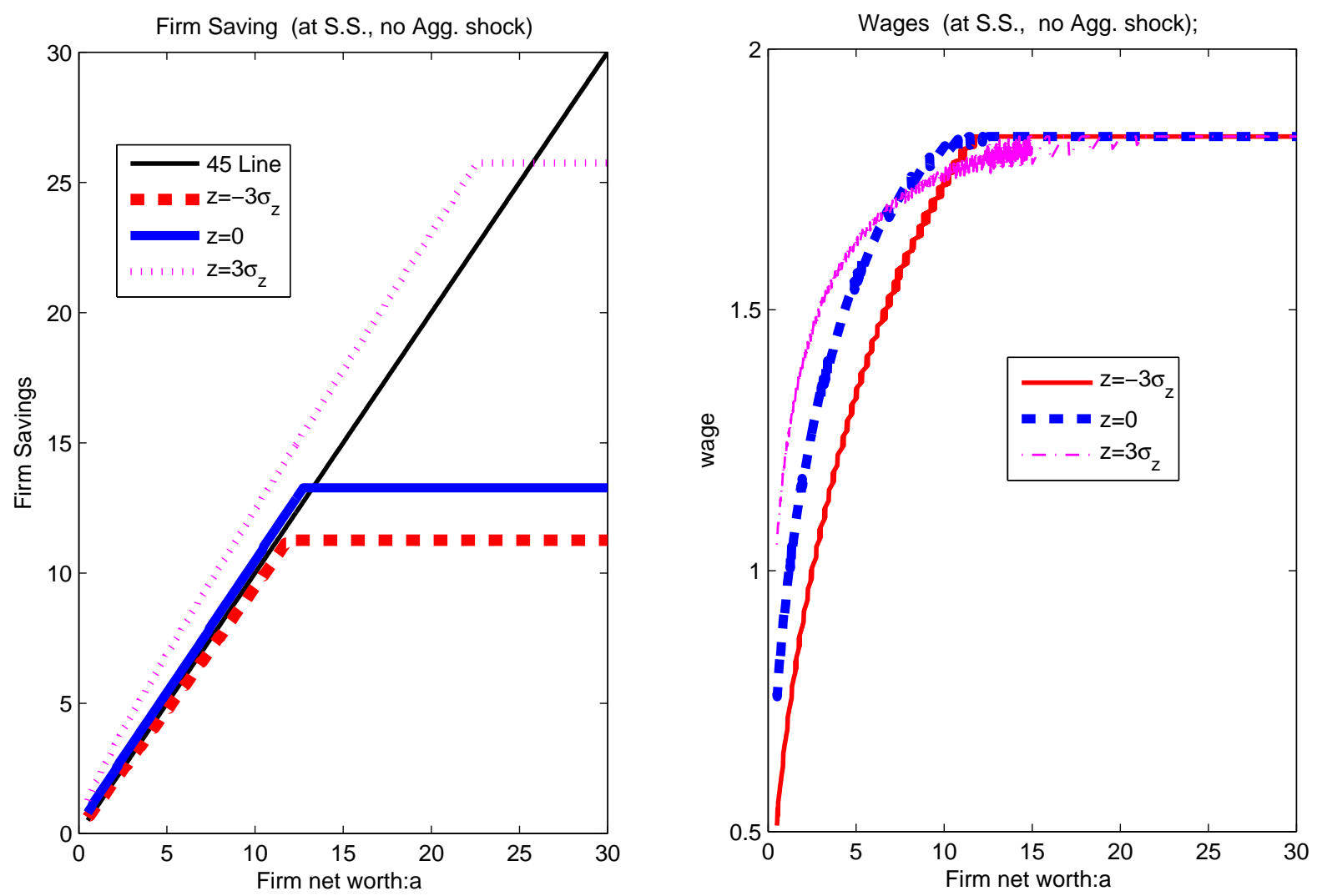

Figure 3: Optimal Firm Decisions: Saving and Wages

Figure 3 plots firms' optimal saving (left panel) and optimal wages (right panel) for a given state of $(z, a)$ at the steady state. For each line, the individual productivity is constant along that line. For instance, in the left panel, along the thinly dashed line, we always have $z=3 \sigma_{z}$. To understand firms' decisions, recall the optimal F.O.C for saving is given by:

$$
1+\mu=\beta \rho(1+r)+\beta(1-\rho) E\left(1+\mu^{\prime}\right) F_{a^{\prime}}\left(z^{\prime}, a^{\prime}\right),
$$

where $1+\mu$ is the shadow value for one additional unit of net worth today, and the right-hand side is the expected return for saving one more unit. In the next period, the firm's net worth could be used to purchase physical capital for production, and hence we have $F_{a^{\prime}}\left(z^{\prime}, a^{\prime}\right)$ in the equation. Along an optimal path, this condition dictates that firms can do no better by giving up one more unit of dividend on the margin in period $t$, saving it, and collecting the corresponding proceeds in $t+1$. Typically, when current net worth $a$ is small or the productivity $z$ is high, the firm will have a strong incentive to save since the marginal return $F_{a^{\prime}}\left(z^{\prime}, a^{\prime}\right)$ is high. As the firm's net worth is large enough, the incentive to save diminishes and the saving stays at a constant level. The 45 degree line (the black solid line), intersected with other curves at some different bounded levels, ensures us that in the dynamic economy firm sizes are bounded and there is a non-trivial distribution over firm productivity and firm 
sizes.

The right-hand panel displays optimal wage policies. First, it should be clear that at steady state, ${ }^{42}$ it automatically implies that when firms are not financially constrained, they will provide the same "unconstrained" wages, even though they may have different productivity or net worth. ${ }^{43}$ This is shown in the graph(e.g., when firms' net worth $a$ is larger than 20). However, when firms are small, the wage policies are different. For instance, tracking along the bold dashed line (productivity constant with $z=0$ ), the firm offers lower wages when it is small. Wages will grow to a stable level as the firm's net worth is large enough (e.g., when $a$ is larger than 15 for $z=0$ ). Also, a firm with higher productivity pays relatively higher wages than a firm with lower productivity, holding their net worth small and the same (e.g., fix $a=5$ and compare the wages across the three lines).
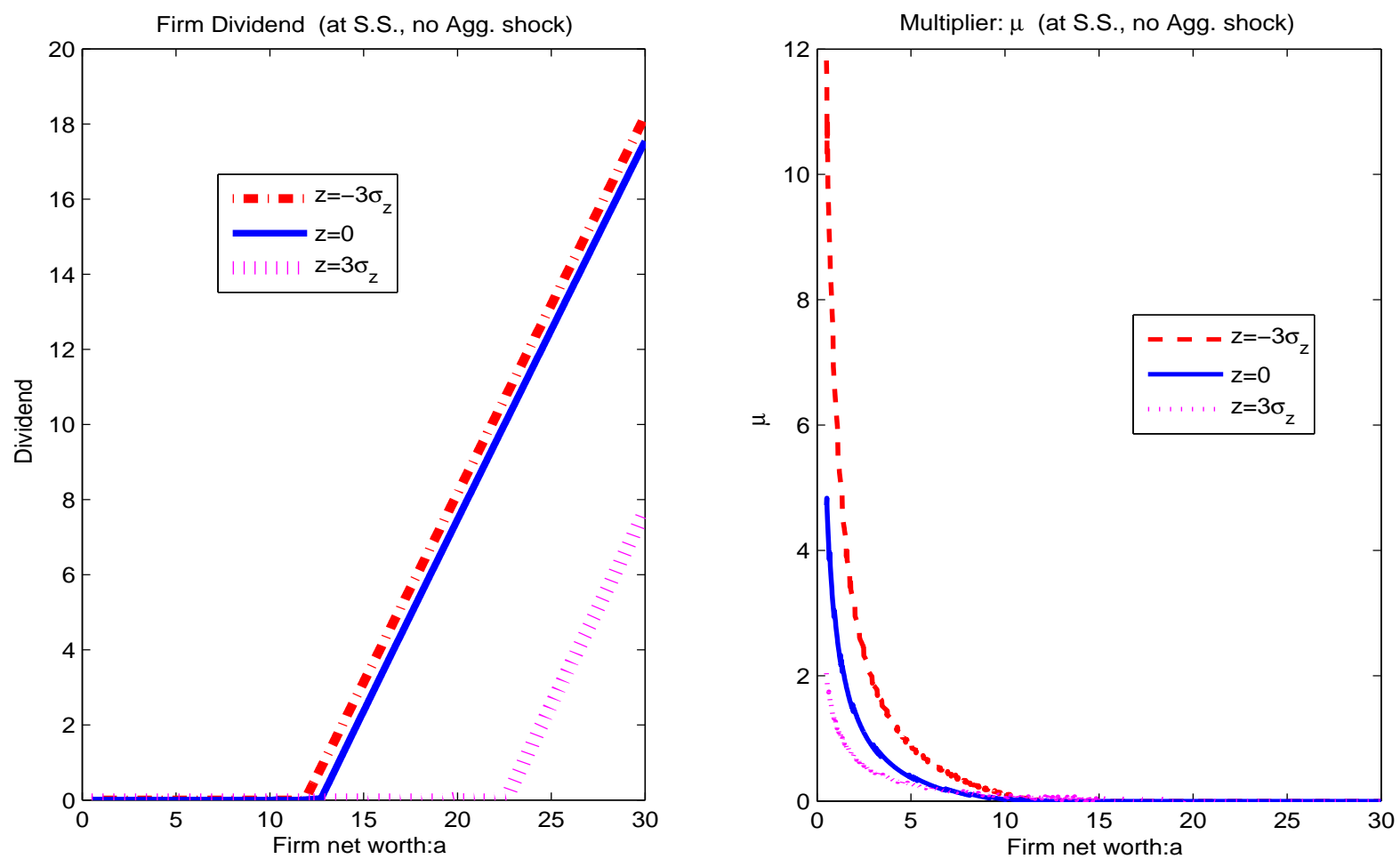

Figure 4: Firm Dividends and Shadow Value for Dividends

Figure 4 indicates that different firms have different dividend policies. There are two main opposite forces in determining dividend payout and hence asset accumulation in firms' optimal decisions: the assumption that firms are impatient, $\beta(1+r)<1$, will drive firms to pay out dividends and dissave whenever optimal; the possibility of being financially constrained tends to make firms save more. Smaller firms do not pay out dividends until they are sufficiently

\footnotetext{
${ }^{42}$ At the steady state, all new entrant post the same contracts with promised utility $v_{S S}^{*}$. Also recall that in the transformed value function $\Psi(z, a ; \omega, S)$, the state $\omega$ (the Pareto weight on the worker's lifetime utility) should be constant for all firms at the steady state. Across business cycles, new entrants entering at different aggregate states are with different $\omega$.

${ }^{43}$ That is, $\omega u^{\prime}(w)=1$ and $\omega$ is the same for all firms at the steady state.
} 
large and not financially constrained (when the multiplier $\mu$ in the right panel is no longer positive). Conditional on the same net worth, high-productivity firms typically have lower shadow values than low-productivity firms (e.g., when $a=5$ in the right panel). ${ }^{44}$ However, at the same time, high-productivity firms will try their best to explore growth opportunity since high productivity is persistent. Hence they will delay dividend payout and keep the retained earnings. For instance, in the left panel when $a$ is around 15 to 20, the firm with highest productivity $z=3 \sigma_{z}$ pays much lower dividends than other firms.

\subsection{Tracking a New Entrant}

Here I study firm and wage dynamics for a given firm over time. Doing this makes it easier to see the effects of financial constraints on wage paths. In figure 5 I track a new entrant and plot time series for the firm's net worth, wages, and shadow values. For illustration, there is no aggregate shock or idiosyncratic productivity shock here.
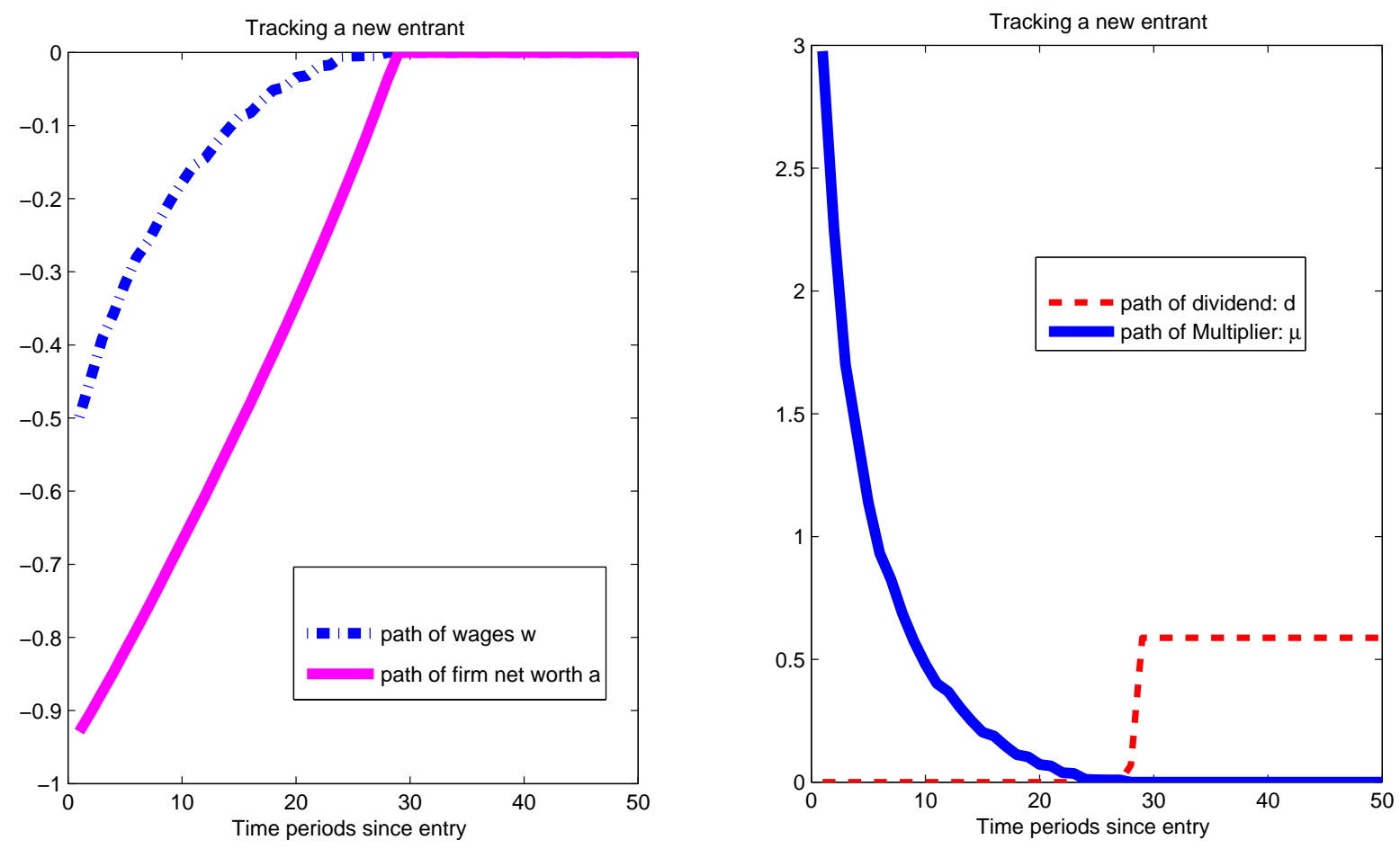

Figure 5: Along firm growth path: wages, net worth, and shadow values

Notes: This graph tracks a new entrant. In the left panel, for the purpose of comparison I plot each variable relative to its steady state level in percentage deviation. There is no change of aggregate state variables along firm growth path. For simplicity, I let the idiosyncratic productivity $z$ always at its mean.

Upon entry, the firm has very low net worth and is financially constrained. The multiplier $\mu$ for the dividend constraint is strictly positive, indicating that the firm has a high shadow value of current dollar. As the firm grows, the multiplier gradually decreases to 0 , and

\footnotetext{
${ }^{44}$ This is mainly because high productivity means high output in the current period; therefore they have lower shadow values and also relatively higher worker wages (see figure 3).
} 
eventually, the firm is not financially constrained any more. Over time, we observe the growth of firm size (in terms of net worth $a$, or closely related, the physical capital $k$ in production) and also growth of wages within the firm. The growth path for $a$ is almost linear, mainly because there is no adjustment cost for the accumulation of net worth or physical capital. Wage growth is gradual and smooth, which reflects the fact that workers are risk averse and value smoothed wages whenever possible. The initial wage is lowered by about 40 percent relative to the level of wage when the firm is unconstrained, indicating that the "implicit credit" from the worker to the firm may be sizable.

\subsection{Measuring Implicit Credit in the Model}

As we just saw financially constrained firms tilt wage profiles; so we want to have a sense about the size of "implicit credit" from workers to firms in the model. This could help us understand the role of wage dynamics in mitigating financial constraints from another perspective. Assume the economy is at its steady state. I define the internal credit as the difference between expected discounted present value of actual wages and its frictionless counterpart. Formally, it is defined as

$$
E_{0} \Sigma_{0 \leq t \leq T^{*}} \frac{(1-\rho)^{t}}{(1+r)^{t}}\left[w_{t}^{*}-w_{t}\right]
$$

where $w_{t}^{*}$ is defined as the wage level when the financial constraint is no longer binding (i.e., $\omega u^{\prime}(w)=1$; see the subsection on model solution and the appendix for first-order conditions). Correspondingly, $T^{*}$ is the stochastic stopping period when the firm grows out of its financial constraints. The internal credit is defined starting from period 0 and taking into account possible separation shocks. The results are reported in table 4. For comparison, I also vary several primitive parameters in the model, recalibrate for each case, and calculate the corresponding internal credit. Two points are worth noting. First, on average, the internal credit is sizable. For instance, it is in the order of about 40 percent to 80 percent of average capital in the steady state. Second, two parameters are crucial for the size of internal credit: the financial constraint parameter $\lambda$ and workers' risk aversion parameter $\sigma$. Intuitively, it is easy to see that internal credit decreases as financial constraint is relaxed (as $\lambda$ increases ) or workers become more risk averse (as $\sigma$ increases). Roughly, we can view $\lambda$ as a measure of development for the outside credit market, and $\sigma$ as a measure of how much internal credit is available.

\subsection{Discussion}

Lastly, I should point out that the model's generated wage and firm dynamics at the steady state are consistent with several empirical studies. For instance, Brown and Medoff (1989), Oi and Idson (1999), and Abowd et al. (1999) document a robust positive relation between 
firm size and wages. My model can generate this pattern (see figure 20 for a positive relation between firm wage and firm size (capital) from model and also from Compustat data). Also, Bronars and Famulari (1997), Hanka (1998), and Guiso et al. (2013) report that fast growing firms on average pay lower wages. Hall and Hall (1993) and Cooley and Quadrini (2001) (and the references therein) empirically show that smaller firms typically do not pay out dividends. Particularly, in Guiso et al. (2013), they identify the liquidity effects on wage growth and find that when firms are more likely to be constrained, they tend to offer lower entry wages but with faster wage growth in the future, all else being equal. Our model is consistent with these observations. As a further check, I conduct a simple regression analysis on the modelgenerated data and on the Compustat sample. I find wage growth is positively correlated with firm growth, negatively correlated with firm size and firm's liquidity conditions. These relations are true both in the model and in the sample data. The regression results are documented in table 5 (for model-generated data) and tables 6,7 (for Compustat data). In short, at the steady state, wage and firm dynamics from the simple model structure are qualitatively consistent with empirical facts.

\section{Application: 2008 Financial Crisis}

In this section I apply the model to the 2008 financial crisis. In this exercise, on the one hand, we can further understand and test the model's predictions regarding wage dynamics in the crisis period; on the other hand, I perform counterfactual experiments and further highlight the role of wage dynamics for mitigating financial shocks in this period.

\subsection{Model Predictions: Differential Wage Responses for Small and Large Firms}

To begin the exercise, I first feed in the model a series of unanticipated aggregate financial shocks. I focus on the wage responses across different firms, since I want to examine and compare the wage dynamics at the micro-level from the model and from the data. Specifically, I choose a realized path of $\left\{\lambda_{t}\right\}^{45}$ to minimize the distance between model-generated output, aggregate debt, and the data counterparts. That is, we have

$$
\operatorname{Min}_{\left\{\lambda_{t}\right\}} \quad m^{\top}\left(\left\{\lambda_{t}\right\}\right) W^{-1} m\left(\left\{\lambda_{t}\right\}\right),
$$

where the vector $m_{t}$ represents the distance between model and data for $\left(y_{t}\right.$, Debt $\left._{t}\right)$ at time $t, m=\frac{1}{T} \sum_{t} m_{t}, W=\frac{1}{T} \sum_{t} m_{t} m_{t}^{\top} \cdot{ }^{46}$ Finally, the stochastic process of $\lambda$ is associ-

\footnotetext{
${ }^{45}$ One could interpret this as saying that in the financial crisis, the financial intermediation sector increased the lending standard. This way of modeling financial shocks is adopted frequently in the literature. (e.g., Monacelli et al. (2011), Khan and Thomas (2013)).

${ }^{46}$ For robustness, when the weighting matrix is singular or close to singular, I simply replace it with an identical matrix.
} 
ated with parameters $\rho_{\lambda}=0.95$ and $\sigma_{\lambda}=0.04$, which are chosen to be consistent with Jermann and Quadrini (2012) and Gilchrist et al. (2009). Note that the agents in the economy are forward looking, taking into account the stochastic structure of $\lambda$; the financial shocks are unanticipated. I then find the optimal path of $\left\{\lambda_{t}\right\}$. The fitted model matches the data very well and the results are reported in figure 6 .
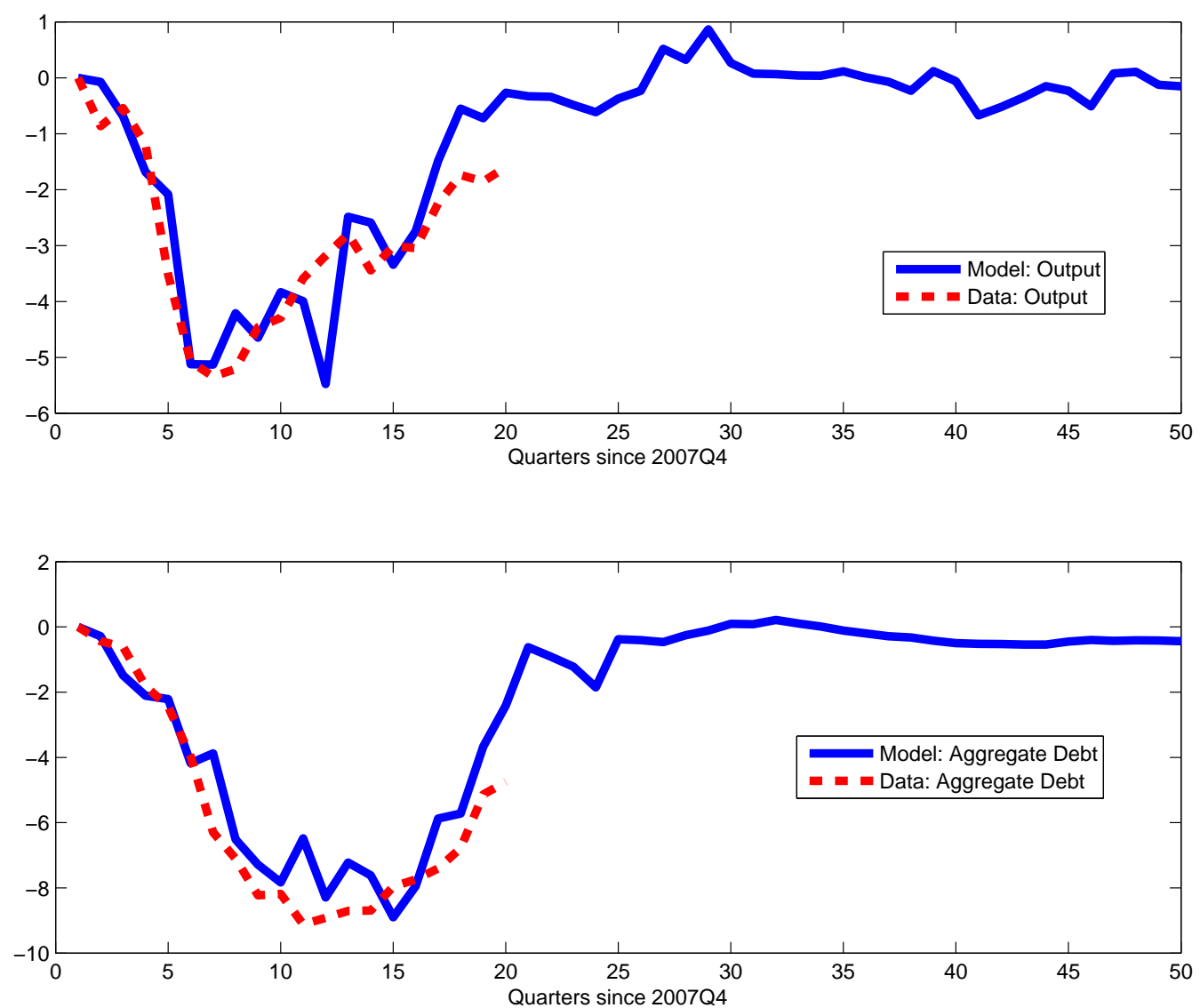

Figure 6: Fitted Model and Data

Notes: This graph displays the output and aggregate debt from the fitted model and data. For data details, see the data appendix. I use a GMM type criterion to do the best-fitting.

Now we can investigate the wage responses across different firms in the face of financial shocks. Fundamentally, firms will have differential responses since some of them are financially constrained, and some are not. Unconstrained firms will not be affected by the financial shocks. In the model, small firms, with limited net worth, are more likely to be constrained. ${ }^{47}$ Also, to relate the model responses to the later empirical analysis in which I only observe firm size and do not observe the firm' financial conditions, in the following exercise I look at responses for small versus large firms in the model. Specifically, at time $t=0$, the model economy starts from its steady state and I divide firms from the cross-sectional distribution into small and large firms. Small firms have capital $k<=3.4793$ and large firms have $k>=4.6614$. These numbers are chosen so that the output share for each category in

\footnotetext{
${ }^{47}$ If a small firm is associated with extremely low productivity, then it may not be constrained, since its demand for capital will be extremely low.
} 
the model best matches with its empirical counterpart. ${ }^{48}$ For each firm, I compute the wage deviations relative to its no-shock path. ${ }^{49}$ The comparison of wage responses across firms is given in figure 7 .

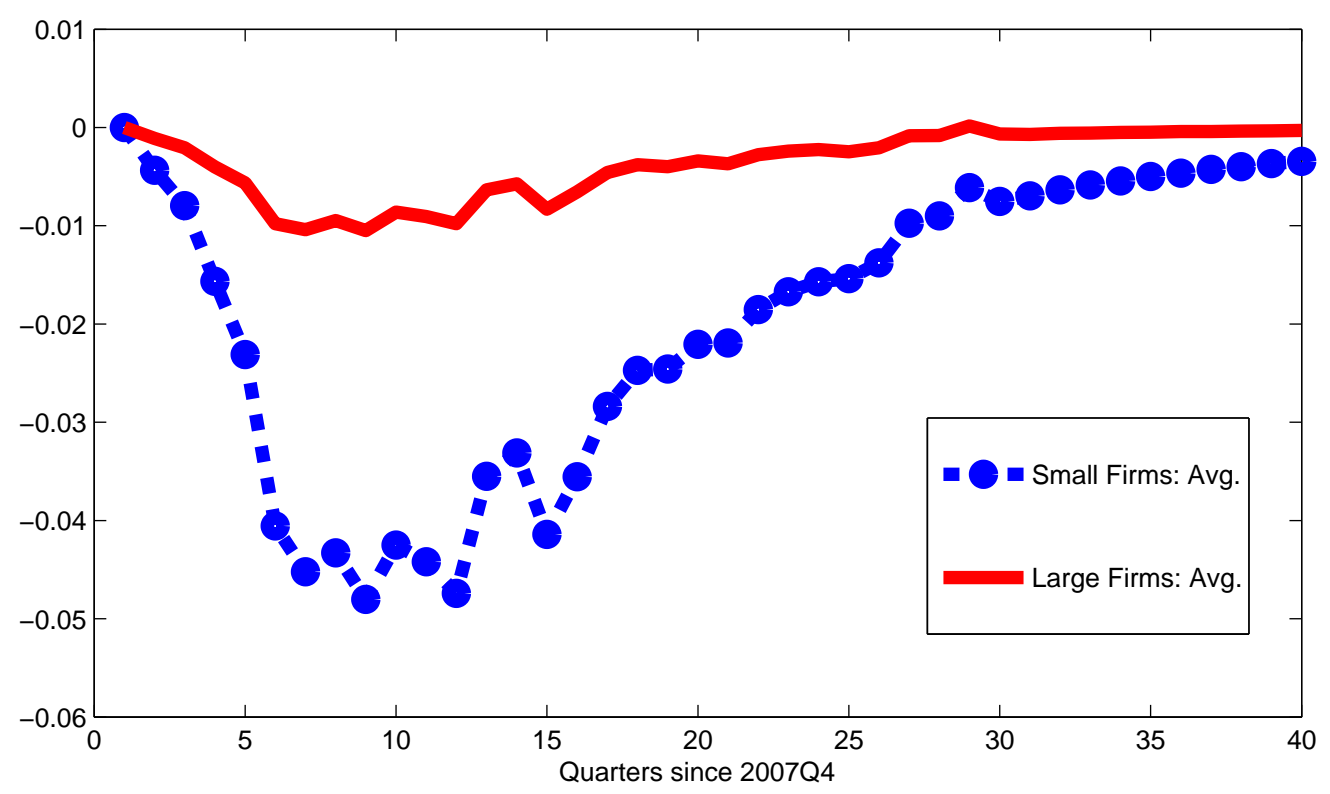

Figure 7: Wage Responses for Small vs. Large Firm under Aggregate Financial Shock

Several points are worth noting in figure 7. First, in response to the financial shocks, small firms on average cut wages by about 5 percent around 2009 and 2010, and then gradually paid wages back to the workers. This is in sharp contrast with large firms, where workers' wages are quite stable and smoothed throughout the financial crisis period. The main reason for this difference is that small firms are endogenously more vulnerable than large firms when facing common financial shocks. Cutting wages is desirable for small firms, since they have higher shadow value of dollars at the time of financial distress. Each dollar from wage cuts can be used for investment and production, which is associated with high marginal returns. The cost of bending the wage (consumption) path is outweighed by the benefit of increased output and accumulating additional buffer stocks. However, the wage cuts can not undo all the effects of financial shocks. Indeed, as shown in figure 8, the output drops more than 10

\footnotetext{
${ }^{48}$ The firm sizes are chosen according to the distributions presented in the two panels in figure 21 . For a comparison of firm size categories used for the numerical exercise and those used in the SIPP data, see table 8. I should point out that the link of firm size categories from the model to the SIPP data is not perfect. In the model I use physical capital to divide firms. In the data, I only observe number of employees. However, as suggested in table 8, this comparison is reasonably good. Admittedly, the comparison of the differential wage dynamics in the model and in the data is more in a qualitative sense.

${ }^{49}$ To be more precise, for each firm, I simulate two paths: path $\mathrm{A}$ is $\left\{\left(z_{t}, \rho_{t}, \bar{\lambda}\right)\right\}$, with idiosyncratic productivity draws, separation shock draws, and no aggregate financial shocks; path B is with the same idiosyncratic productivity and separation shock draws, but with fitted financial shocks, $\left\{\left(z_{t}, \rho_{t}, \lambda_{t}\right)\right\}$. Then I calculate the percent of deviation path B relative to path A. Alternatively, I did another closely related exercise: assume there is no firm exit and entry. That is, the realized path of separation shock is always not to separate, but the firm fully takes into account of the stochastic structure of separation shocks. The results are very similar and hence not reported here.
} 
percent for small firms, almost twice as large as the average drop for large firms. ${ }^{50,51}$ This is because workers are risk averse and the wage profile cannot be adjusted arbitrarily. In the empirical part, I will show that the model's predictions about the pattern of wage dynamics are consistent with SIPP data in the crisis period.

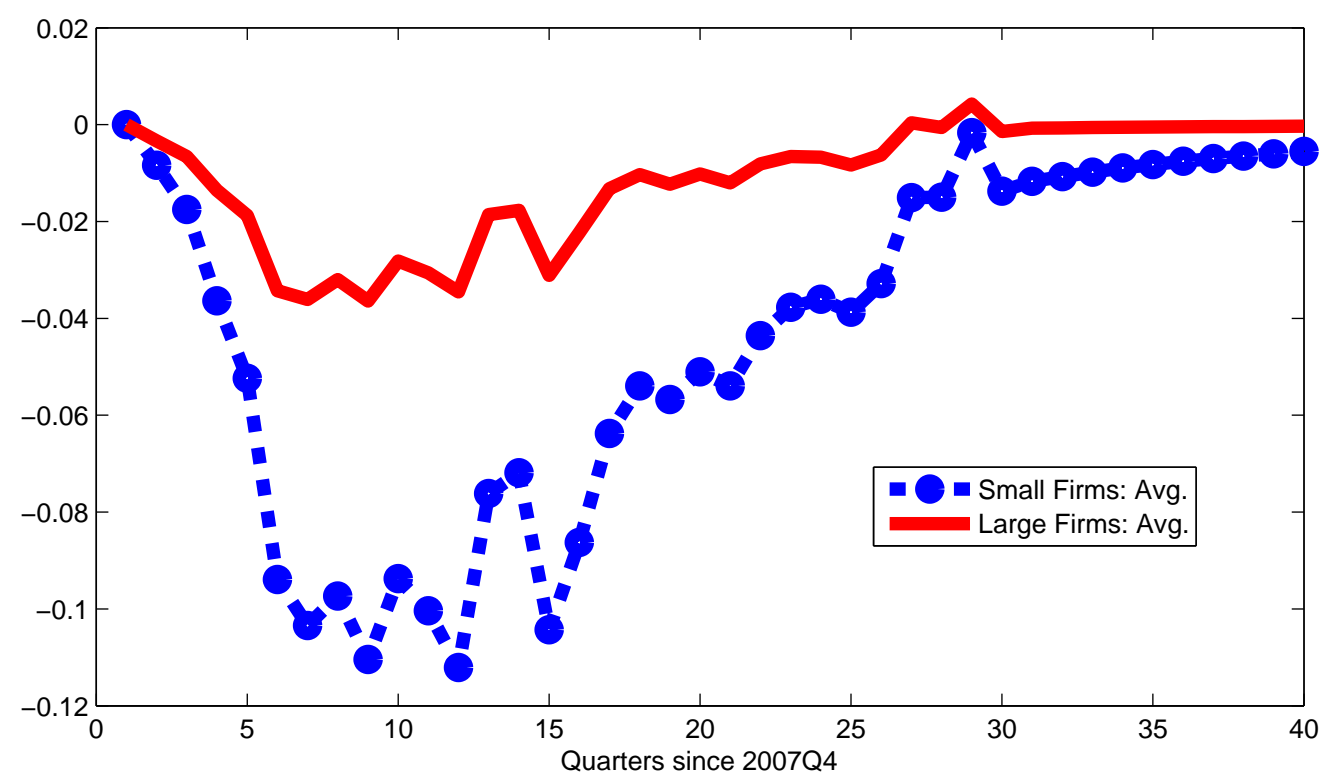

Figure 8: Output Responses for Small vs. Large Firm under Aggregate Financial Shock

\subsection{Counterfactual Experiments: The Mitigating Effect Is Sizable}

To further understand the role of wage dynamics in helping firms mitigate financial shocks, I consider counterfactual situations where it's impossible or too difficult to borrow from workers. While presumably there are many other reasons to prevent "implicit lending," 52 in this exercise, I make the wage path endogenously more rigid, and it's more difficult (costly) for workers to have wage adjustments. Specifically, I raise workers' risk aversion parameter $\sigma$, from $\sigma=2$ in the benchmark case to $\sigma=10$ (with CRRA utility). I perform the exercise as follows: Let the new economy start from its steady state. ${ }^{53}$ From $t=1$ and onward, it experiences exactly the same aggregate financial shock as the benchmark economy and the

\footnotetext{
${ }^{50} \mathrm{I}$ do not have direct micro-level evidence of output dynamics by firm size in the crisis period. Campello et al. (2010) and Chodorow-Reich (2014) suggest that financially constrained firms reduce investment, market expenditures, and employment much more than unconstrained firms. Moscarini and Postel-Vinay (2012) also point out that small firms are hit particularly harder in the crisis period.

${ }^{51}$ The present model just uses a common aggregate financial shock and it is able to generate larger output drops for small firms. I think this is more satisfactory than using two shocks (or size-dependent shocks) to explain why output drops are larger for small firms than large firms.

${ }^{52}$ For instance, the contract duration is too short, or the industry is associated with too much risk, or workers are very poor.

${ }^{53}$ I recalibrate the new economy such that it has the same unemployment rate at the steady state as the benchmark economy.
} 
shocks are, again, unanticipated. I then compute wage and output responses for small and large firms, as shown in figure 9.
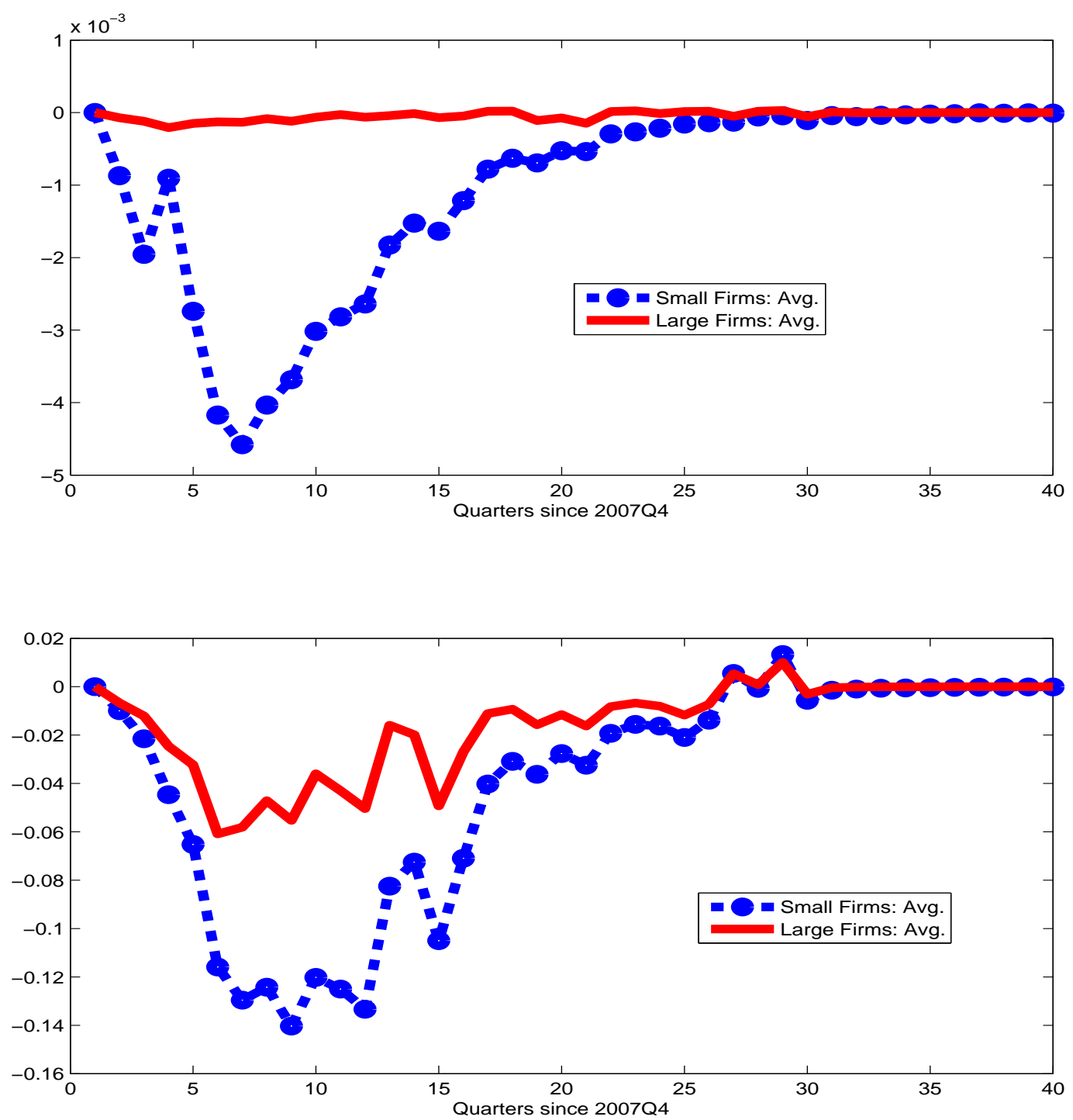

Figure 9: Wage (upper panel) and Output (lower panel) responses: $\sigma=10$

Intuitively, when workers are more risk averse, they prefer a more smoothed wage path. How does this affect firms' behavior? When there is an adverse financial shock, the firm's incentive to cut wages would not be as strong as in the benchmark case. This is because the cost of bending the wage path is larger now in the $\sigma=10$ economy, holding the firm's characteristics the same across the two economies. Comparing this with the benchmark case, this will make firms more vulnerable, and firms have to produce at an even more suboptimal scale when constrained. This is shown in figure 9. Small and large firms still have differential reactions. However, compared with the benchmark case, the wage responses for all firms are much smoother and dampened, and the output responses for all firms are now larger. As shown in the left panel of figure 10, the total output would have been even lower by about $2 \%$ in the counterfactual economy in the financial crisis period. 

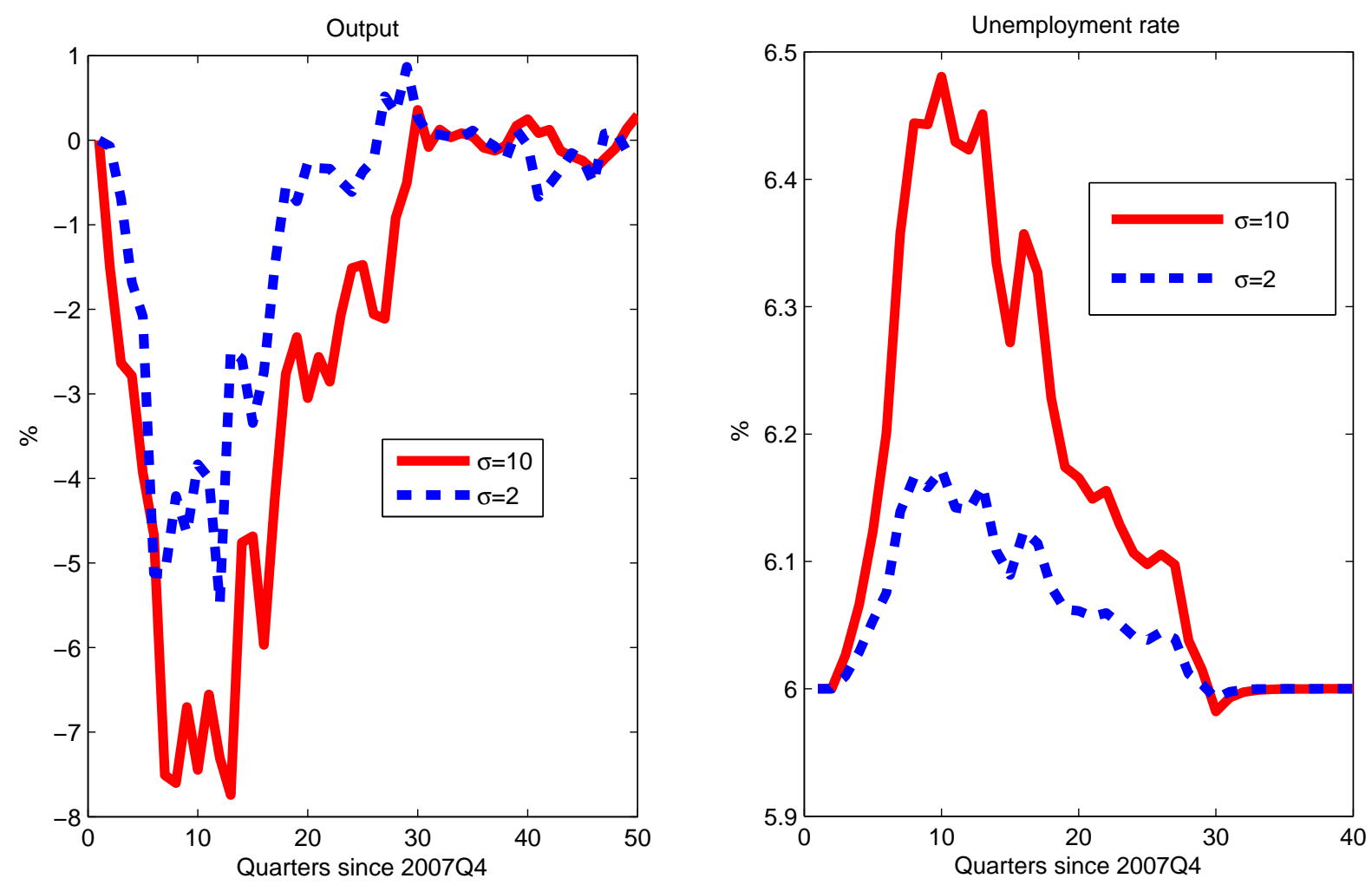

Figure 10: Experiments: Output (left panel) and unemployment rate (right panel)in benchmark economy $(\sigma=2)$ and in the counterfactual economy $(\sigma=10)$.

I can also look at the effects on job creation and the unemployment rate. Before entering, the potential new entrant takes into account possible future financial constraints and the increased difficulty of cutting wages. The firm's incentive to post vacancies and hire will be reduced, and therefore, the unemployment rate would be higher when $\sigma=10$. As shown in the right panel of figure 10, it is higher by about a third of a percentage point. ${ }^{54}$ In summary, if the wages within a contract are made too rigid, then the wage dynamics cannot help firms mitigate financial shocks as much as in the benchmark case, and we would see even lower output and an even higher unemployment rate in the financial crisis period. This exercise suggests that the mitigating effect from wage dynamics is important and sizable.

\footnotetext{
${ }^{54} \mathrm{As}$ in the benchmark case when $b=0.8$, the ratio of $b$ to average labor income in the model is about 50 percent, which is a conservative calibration. Shimer (2005) calibrates the replacement rate of unemployment insurance to labor income about 40 percent and there is little amplification. Our results also reflects this point. Hagedorn and Manovskii (2008) have argued that we should have a high replacement rate, since high unemployment volatility means workers' utility from non-market activity should be very close to the utility obtained from market activity. There is no consensus in the literature yet; neither do I take a stand on the replacement rate. Moreover, the focus of this paper is not to address unemployment volatility, but rather, focus on the differences when $\sigma$ are different.
} 


\section{Empirical Support}

\subsection{Differential Wage Dynamics Consistent with the SIPP Data}

In the previous section, we analyzed firms' differential wage responses to aggregate financial shocks during the crisis period in the model. In this subsection, the main purpose is to study whether and to what extent the model's implications are consistent with actual micro-level data. I use household survey data, the Survey of Income and Program Participation (SIPP), to study wage dynamics across small and large firms in the 2008 financial crisis period. ${ }^{55}$ For details on sample selection and definition of variables, please see the data appendix.

\section{1: Job Stayer's Earnings and Wages in the 2008 Financial Crisis Period}

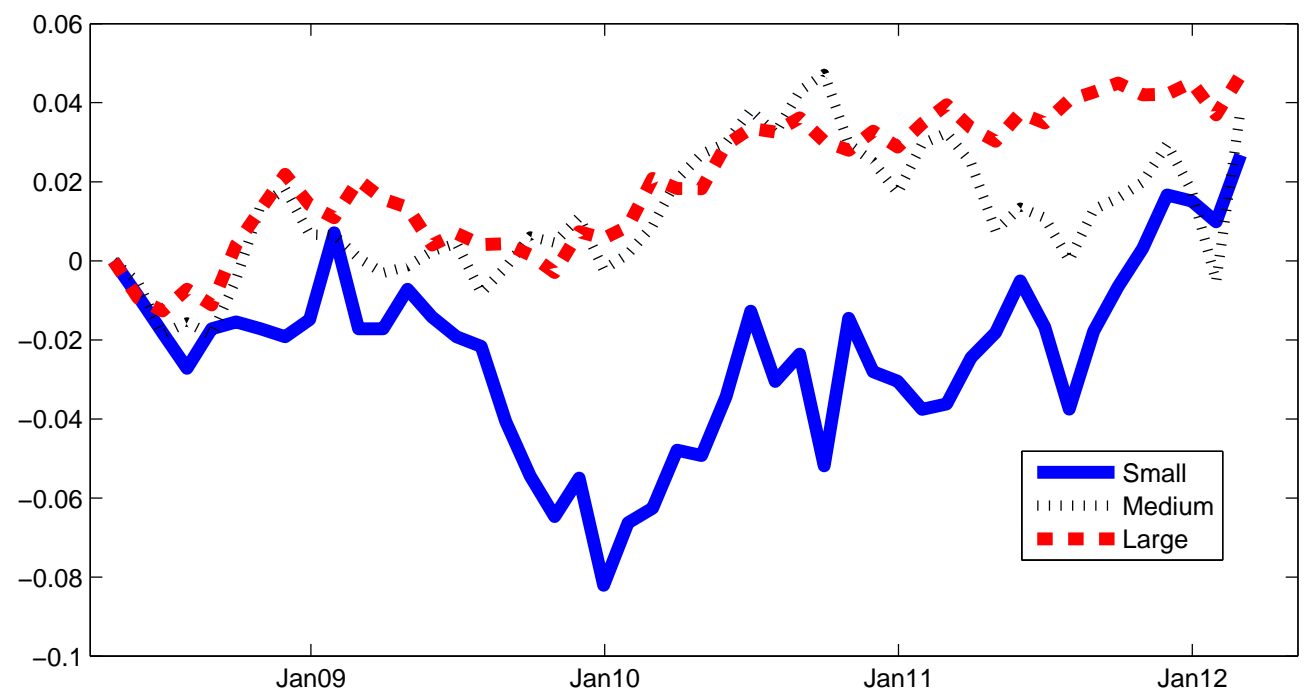

Figure 11: Earnings Dynamics for Small vs. Large Firms

Notes: This figure shows job stayers' real earnings dynamics. "Small firm" refers to firms with few than 25 employees. "Large firm" refers to firms with more than 100 employees. Since the data is an unbalanced panel, for each series, the calculation is very similar to the calculation of CPI index over a set of goods with sampling weights, that is, earnings (wage) changes $W_{g, t}=\sum_{i}\left(\log w_{i, t}-\log w_{i, t-1}\right) g_{i t}$. The first month data point for each series is normalized to 0 for comparison purposes.

Figure 11 shows job stayers' logged real earnings across different firm sizes in the 2008 financial crisis period. Generally, different firms have different patterns of earnings dynamics during this period. Specifically, large firms (number of employees $>100$ ) have relatively stable and smoothed earnings in this period, while small firms (number of employees $<25$ )

\footnotetext{
${ }^{55}$ The main advantage of using SIPP data is that, among other things, it provides a large nationally representative panel data at high frequencies. This particularly fits into our main purpose of examining wage dynamics for job stayers almost monthly during the crisis period. In addition, SIPP asks a number of questions regarding workers' employers. Other data sets, like PSID, CPS, or NLSY, are not as ideal as SIPP for our studies.
} 
cut workers' earnings in the heyday of the crisis period around 2009 and gradually paid wages back to workers when the financial turmoil calmed down. Real earnings in large firms dropped only slightly in the third quarter of 2008 and have been increasing steadily along an almost linear trend. For small firms, the real earnings dropped much more in the second half of 2008 and there was a sharp decline in 2009. The timing with large earnings cuts was coincident with when the financial market was most disrupted throughout $2009 .{ }^{56}$ The comparison of earnings dynamics across different firms is clearer in figure 23, where the three data series are detrended and smoothed. Compared to large firms, the change of real earnings in small firms were on average about 2 percent lower in January 2009 and this gap continued to spread throughout 2009. It was about 7 percent lower in January 2010. After that, small firms gradually increased their workers' earnings and the gap started to shrink.

\section{2: Further Analysis}

One may be concerned that some workers' working hours may have undergone a large drop even if hourly wages have not changed very much. Therefore, it is also important to check the intensive margins. I look at real earnings per hour. ${ }^{57}$ The results are displayed in figure 12 (figure 24 for smoothed and detrended series). The pattern is still very similar to what we just found for real earnings, though the quantitative magnitude has changed a little bit. For instance, the largest gap for real wage changes between small and large firms throughout the financial crisis period was about 4 percent. At the beginning of 2012, real wages in small firms have recovered surprisingly and grown faster than those in large firms.

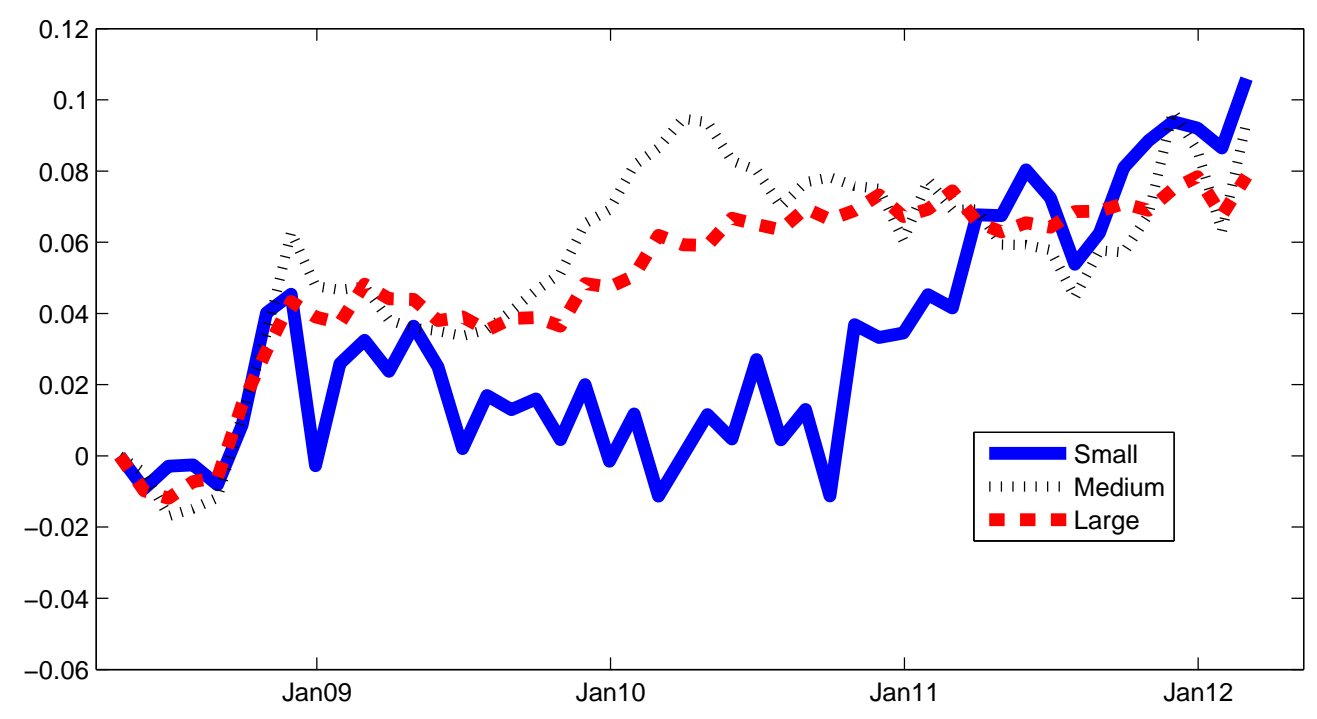

Figure 12: Dynamics of Real Earnings per Hour for Small vs. Large Firms

\footnotetext{
${ }^{56}$ See figure 22 in the appendix. Notice that in the figure 22, I use the interest rate spread, the Bank of America Merrill Lynch U.S. Corporate Option-Adjusted bond rates over the spot treasury rate, as a proxy to measure the aggregate credit market conditions.

${ }^{57}$ Working hours are calculated as weekly hours times working weeks. Some workers did not report hours or working weeks and effectively the sample size is reduced by about 12 percent.
} 
A further analysis is conducted here. Workers may work in the private sector or in the public sector. The basic idea is that, compared to the private sector, especially those small and vulnerable firms in the private sector, financial pressure and the likelihood of being liquidity constrained should be arguably of less concern for the government sector. I distinguish workers by sector and then compare the earnings dynamics. In figure 13 (figure 25 for smoothed and detrended series), two points are worth noting. First, the earnings dynamics for the government sector are very similar to those for large firms, both with a stable and smoothly growing path. This confirms our prior belief that the impact of financial shocks on workers' earnings in the government sector is negligible. Second, the difference between earnings for the small firms and those for the government sector is still large and substantive during the crisis period. Overall, this analysis further suggests that for the earnings dynamics in small firms, financial shocks are likely to be important.

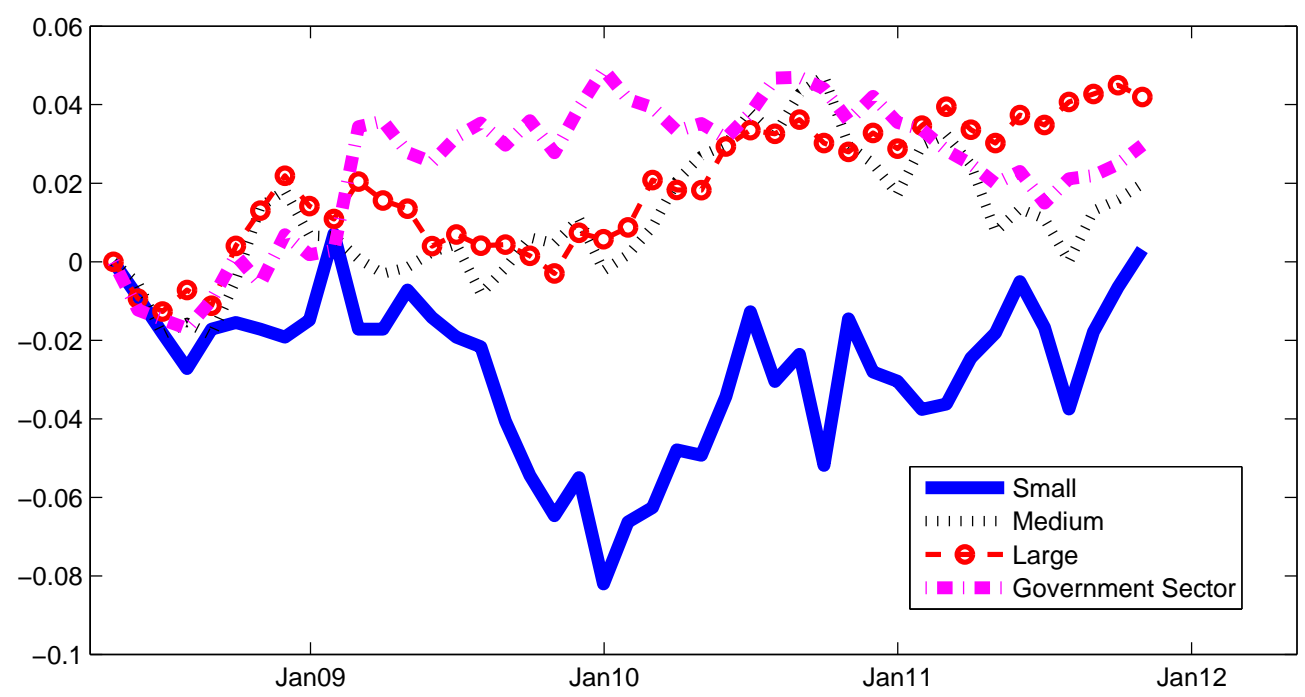

Figure 13: Earnings Dynamics for Small, Medium, Large Firms, and the Government Sector

\section{3: Comparing 2008 and 2001 Pattern}

In addition to the preceding analysis, I investigate the earnings patterns from a different perspective. The 2008 financial crisis and the subsequent Great Recession highlight the importance of financial market disruptions. In contrast, the 2001 recession is a mild recession, and the conventional wisdom generally does not think that financial shocks played a major role (see the financial spread around 2001 in figure 22). Therefore, a natural exercise is to examine the earnings pattern in 2001 and compare it with the pattern in 2008. As shown in figure 14, in the peak to thorough period of the 2001 recession (from March 2001 to November 2001), the earnings dynamics across different firms are very similar, which is in contrast to the pattern in 2008. For instance, both large and small firms have slightly dropped real earnings at the beginning of 2001 (about 0.5 percent) and quickly recovered their earnings almost within the same year of 2001. From this comparison, we therefore again highlight 
the importance of financial shocks in 2008 on workers' earnings dynamics. However, I should admit that further rigorous analysis of sources of business cycles in 2001 and in 2008 could provide more insight and discipline to my analysis.

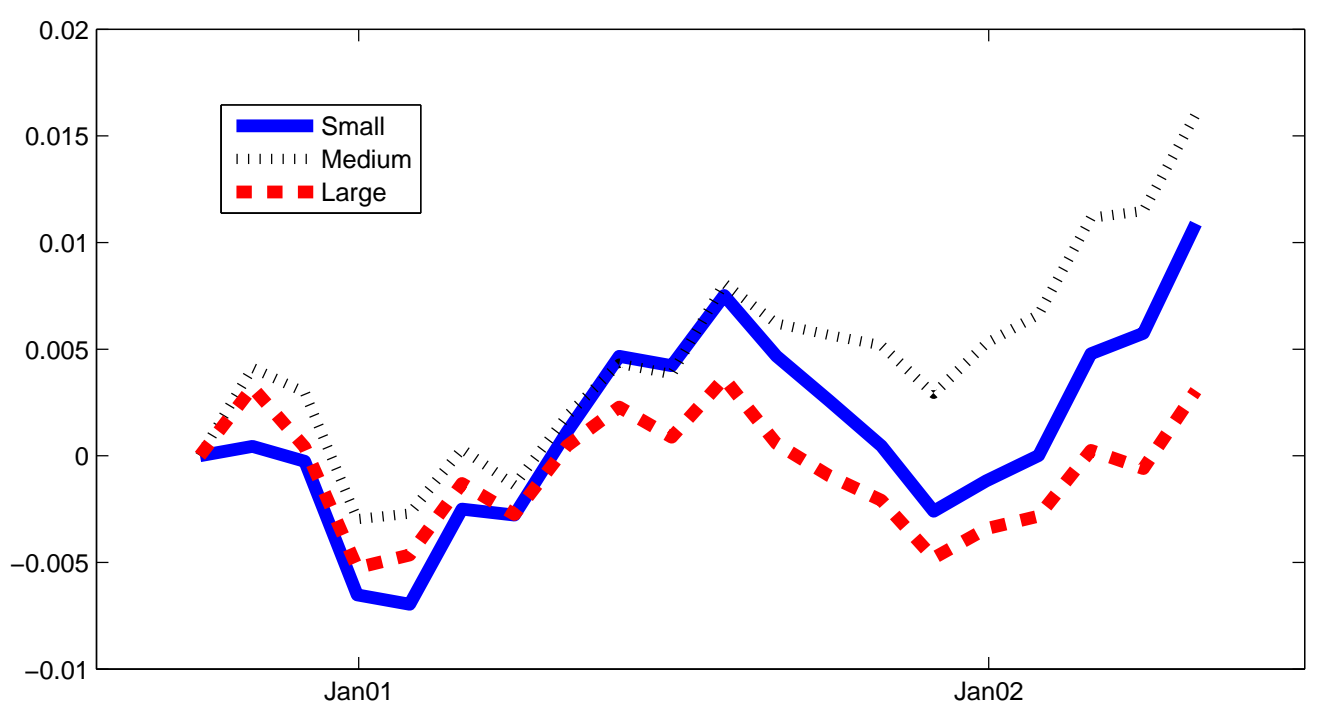

Figure 14: Earnings Dynamics for Small vs. Large Firms in 2001

Notes: This figure shows job stayer's real earnings dynamics in 2001 recession. All series are linearly detrended by using the trend for large firms. Definitions for small and large firms and the calculation of earnings are the same as in figure 11.

\section{4: Comments and Summary}

In sum, the empirical facts and analysis suggest that in the recent financial crisis, small firms were hit harder and they cut worker's earnings (wages) much more than large firms. This pattern is consistent with the model's implications as in figure 7. In the model exercise, the exogenous driving force is an aggregate financial shock. Small firms in the model are hit harder because of limited financial net worth when the credit market is disrupted. The fact that small firms are financially more vulnerable and more likely to face liquidity constraints than large firms has been stressed frequently in the literature of financial friction at least since Gertler and Hubbard (1989) and Gertler and Gilchrist (1994). This line of literature suggests a strong correlation between firm size and likelihood of being financial constrained. Therefore, firm size could be used as a reasonable proxy for firms' liquidity constraints. Empirically, Gilchrist et al. (2012), Chodorow-Reich (2014), and Hadlock and Pierce (2010) use different detailed data sets, ${ }^{58}$ and found in the 2008 financial crisis that smaller firms indeed faced higher borrowing costs, more limited credits, and were more likely to be financially constrained. Admittedly, firm size per se is not a direct determinant of financial market access, but it is strongly correlated with the primitive factors that do matter, e.g., smaller firms typically are young, not well collateralized, and associated with high monitoring cost

\footnotetext{
${ }^{58}$ Gilchrist et al. (2012) uses firm-level borrowing costs, Chodorow-Reich (2014) uses matched bank-firm data and Hadlock and Pierce (2010) uses survey data.
} 
for credit lenders. One caveat in my empirical analysis is that, due to data limitations, I cannot rigorously and convincingly identify that the cause for the differential wage dynamics is the financial shock alone. However, as long as financial shocks have played a major role in the crisis period, we can still validly conclude that the model's implications are consistent with actual data.

\subsection{Cyclical Wage Behavior: Two Key Elements in the Model}

Previously we have found that in the crisis period, the model's predictions regarding wage dynamics across firms are consistent with the data. The two key elements in the modelfinancial friction and firm insurance- are important to account for that. In this section, I examine the model's implications from a different perspective and look at cyclical wage behaviors across long time-series. I find that these two key elements are also crucial for the model to be consistent with data. This could be viewed as a further discipline of the model.

Specifically, assume that in the model economy, the aggregate shock only includes productivity shock with $\rho_{X}=0.95, \sigma_{X}=0.02$, as in standard business cycle literature. ${ }^{59}$ Consider the elasticity of average wages with respect to output per worker (labor productivity) across many different lags. Formally, I compute $\frac{\operatorname{Cov}\left(w_{t}, y_{t-j}\right)}{\operatorname{Var}\left(y_{t}\right)}$ for $-8 \leq j \leq 8$ from the model-generated data and actual data.

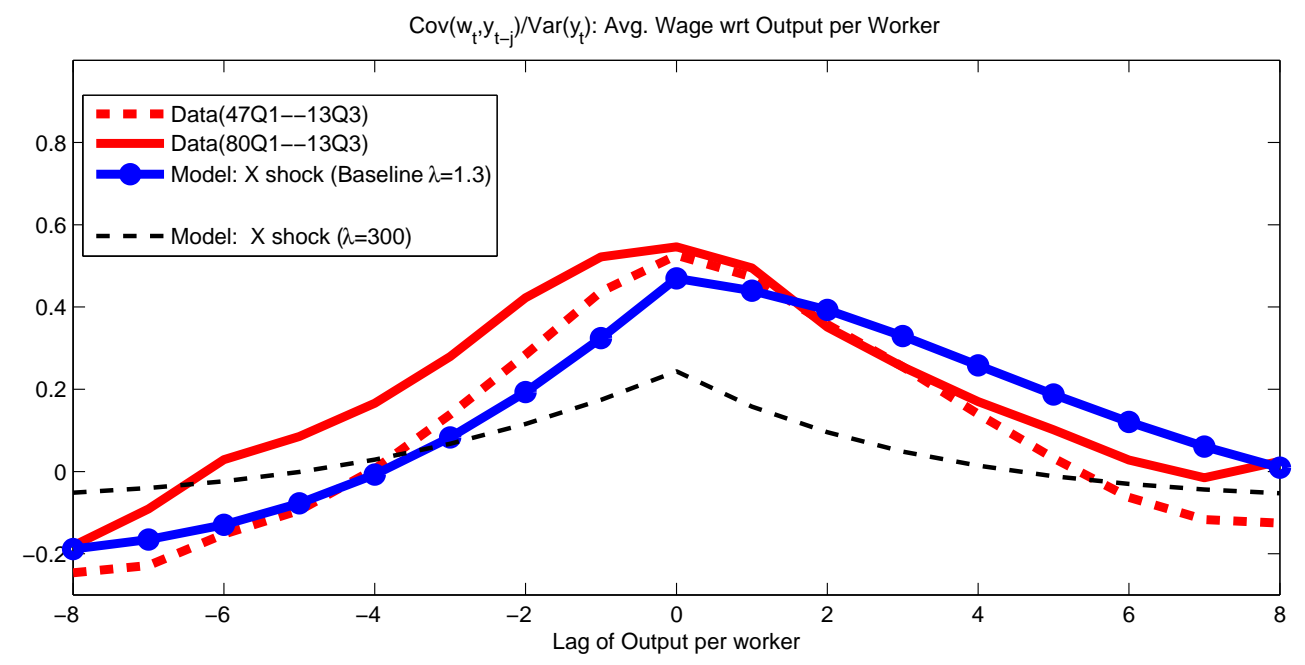

Figure 15: Elasticity of Average Wage w.r.t. Output per Worker: Data and Model

Notes: This graph displays the elasticities of average wages w.r.t. output per worker, from the data and from the model. All series (model and data) are logged and HP filtered with smoothing parameter 1600. The model is simulated for 100,268 periods, and I only take the last 268 periods. I simulate the model 1000 times and calculate the average statistics.

In figure 15, first, we can see that the baseline model can generate a pattern of elasticities very similar to the data. Second, when there is almost no financial constraint (by increasing

\footnotetext{
${ }^{59}$ Such as Cooley and Prescott (1995) and King and Rebelo (1999).
} 
$\lambda$ from 1.3 to 300) and firms can provide full insurance to workers, the contemporaneous elasticity of wages to productivity then becomes too small. This highlights the importance of financial friction. Moreover, it is well known that in standard business cycle models without firm insurance (such as standard RBC model, or Shimer (2005)), the contemporaneous elasticity will be too high and around 1. In contrast, with both firm insurance and financial frictions, the baseline model can successfully be consistent with the data.

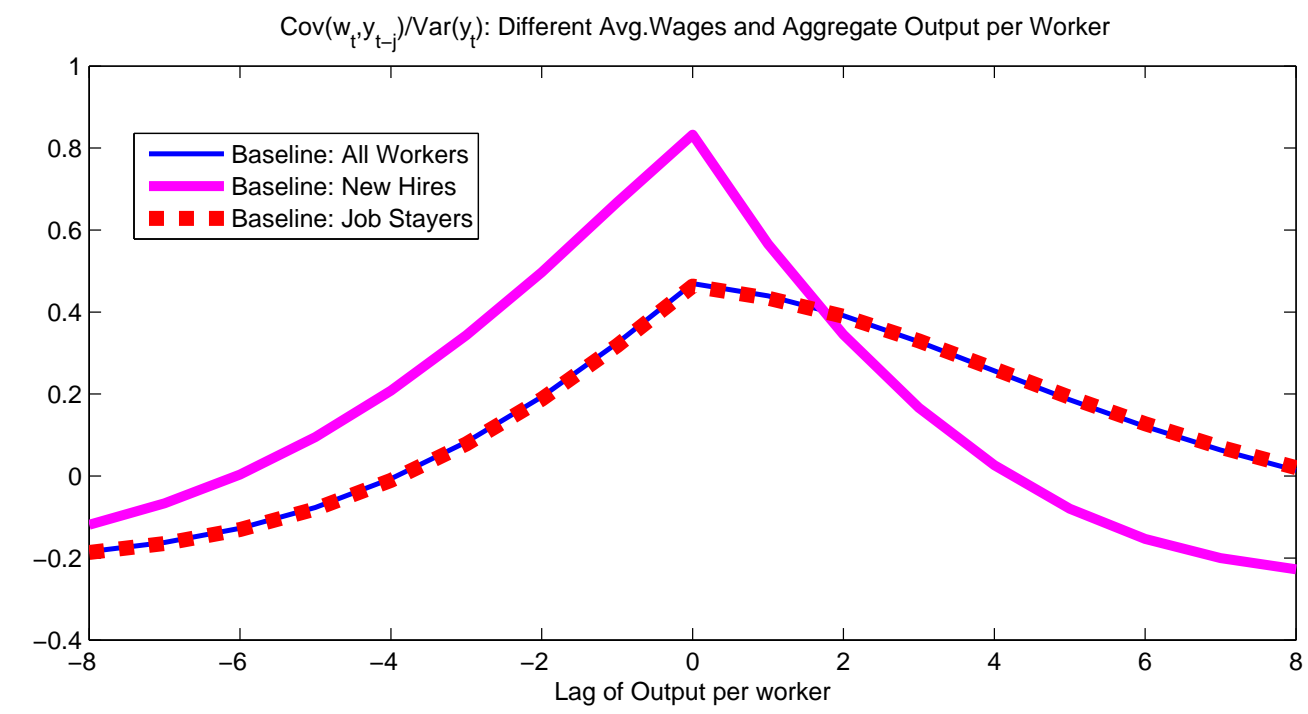

Figure 16: Elasticity of Different Average Wages w.r.t. Output per Worker

To further understand why the baseline model can reproduce the data pattern, I decompose workers into new hires and job stayers, and compute their elasticities respectively as in figure 16. We can observe several points here. First, for new hires, their contemporaneous $($ lag $=0)$ elasticity is much higher than job stayers. This just reflects the fact that newly hired workers choose the wage contract (and hence the starting wage) at each aggregate state, and the value of the wage contract flexibly moves as the aggregate state changes. Also we can see that new hires' elasticities across other lags are almost symmetric, which inherits the decaying pattern of the AR(1) productivity process. Second, since more than $95 \%$ of workers are job stayers, the aggregate elasticities are basically the same with those for job stayers. For job stayers, the contemporaneous elasticity is about 0.4 , suggesting that most job stayers' wages are sticky as productivity changes. Also there is a notable lag in the elasticities of current wages responding to past productivity (e.g., when $j>0$ ). This is because most job stayers's current wages are smoothed to some extent, highly correlated with past wages and hence past productivity. At the same time, about $5 \%$ of current job stayers are newly hired in the previous period and this labor turnover will dampen the correlation between current wages and past productivity. The two effects together, make job stayers' and the aggregate wages "inertial" as in the data.

Regarding the magnitude of contemporaneous elasticities, the model generates about 0.8 and 0.4 for new hires and job stayers, respectively. In Bils (1985), Pissarides (2009), Haefke et al. (2013), and also Kudlyak (2014), the estimates of elasticities are correspondingly 
about 0.8-1.2 and 0.3-0.5. My model's results are consistent with these. Fundamentally, one of the key elements in the model is that firms provide long-term insurance to smooth workers' wages. Empirically, firm insurance has been examined extensively and favored in the literature. For instance, Beaudry and DiNardo (1991) find the wages pattern from PSID data more consistent with an implicit contract model than with a standard spot market model; Recently Guiso et al. (2005) use an Italtian matched employer-employee panel data to show that workers are fully insured from temporary shocks to firms' output, but only partially against permanent shocks. These features are also reflected in our model. ${ }^{60}$

In sum, two key elements in the model, firm insurance and financial frictions, are very important to account for cyclical wage behaviors in the data. The main reason is that when firms face financial friction, they adjust the wage profile and provide imperfect insurance to workers. The model performs better than those with no firm insurance or with full insurance. Moreover, as we have seen in the previous section, the mechanism of imperfect insurance is also able to explain the the differential wage dynamics across firms during the crisis period, and it is crucial to understand the effects of mitigating firms' financial constraints.

\section{Concluding Remarks}

Motivated by empirical evidence, I study the role of wage dynamics in a employment relationship in mitigating adverse consequences of poorly functioning credit markets. I focus on the aggregate implications of this mitigating effect. The results suggest that the aggregate mitigating effects are important and sizable. Consequently, one potential policy implication is that, in addition to ensuring sufficient financial market credit directly to the firms, the government could also help stabilize households' balance sheets and lift households' credit borrowing constraints, so that effectively the workers could be more willing to accept wage profile adjustments when the credit markets are too limited or too costly to firms. ${ }^{61}$

The current paper could be extended along several dimensions. For instance, it would be interesting to consider endogenous separations between firms and workers, and investigate employment and wage dynamics simultaneously. Empirically, more detailed data during the financial crisis period could help us understand better why small and large firms have differential wage dynamics. Additionally, one could explore more the interaction between labor market and financial friction. For example, a firm's financial condition may affect its

\footnotetext{
${ }^{60}$ Recall we have

$$
\frac{u^{\prime}(w(s ; S))}{1+\mu(s ; S)}=\frac{u^{\prime}\left(w\left(s^{\prime} ; S^{\prime}\right)\right)}{1+\mu\left(s^{\prime} ; S^{\prime}\right)} .
$$

For a given current productivity $z$, suppose the next period's productivity is $z^{\prime}=\rho z+\epsilon$, then the marginal utility in the next period does not depend on $\epsilon$, but it does depend on $z$. Roughly, we can view next period's $\epsilon$ as temporary shocks conditional on $z$. For more details on the econometric treatment of temporary and permanent firm shocks, see Guiso et al. (2005).

${ }^{61}$ As a very rough intuition, we could view worker's utility as $u(w+r A)$ by consuming wage income and interest gains, where $A$ is the value of household's net asset. If $A$ is large, then workers could bear more fluctuations in $w$.
} 
worker's expectation of future wage growth, and therefore has an impact on the worker's on-the-job search behavior; also, workers may lose firm-specific human capital with firm bankruptcies, which may have important macroeconomic implications. I leave these for future studies.

The message of this paper could be read more broadly. Here I explore that the repeated relationships between firms and workers may help firms mitigate adverse shocks from outside credit markets. This is in contrast to traditional implicit contract literature: firms provide insurance to workers since outside insurance/credit markets do not work well for workers. Many other repeated relationships may have similar functions: mutual insurance within a married couple ${ }^{62}$ trade credit between firms and their long-term suppliers, ${ }^{63}$ employee health insurance programs at Walmart/Home Depot, ${ }^{64}$ and credit card companies may offer unemployment insurance to their long-time customers. ${ }^{65}$ When outside markets (credit markets, insurance markets, etc.) are not functioning well because of informational frictions or moral hazard, repeated relationships may help and serve as an endogenous market. It would be interesting to explore the implications of these phenomena both at the micro-level and at the aggregate level.

${ }^{62}$ For example, see Kotlikoff, Laurence J and Spivak, Avia(1981, JPE).

${ }^{63}$ See Petersen, Mitchell A and Rajan, Raghuram G (1997, RFS) and the literature followed since then.

${ }^{64}$ See http://blog.walmart.com/providing-quality-health-benefits-for-our-associates.

${ }^{65}$ See, e.g., http://www.stretcher.com/stories/09/09may25b.cfm. 


\section{References}

Abowd, J. M., Kramarz, F., and Margolis, D. N. (1999). High wage workers and high wage firms. Econometrica, 67(2):251-333.

Acemoglu, D. and Shimer, R. (1999). Efficient unemployment insurance. The Journal of Political Economy, 107(5):893-928.

Alvarez, F. and Jermann, U. (2000). Efficiency, equilibrium, and asset pricing with risk of default. Econometrica, 68(4):775-797.

Arellano, C., Bai, Y., and Kehoe, P. J. (2012). Financial markets and fluctuations in uncertainty. Working Paper, University of Rochester.

Azariadis, C. (1975). Implicit contracts and underemployment equilibria. The Journal of Political Economy, 83(6):1183-1202.

Baily, M. N. (1974). Wages and employment under uncertain demand. Review of Economic Studies, 41(1):37-50.

Barattieri, A., Basu, S., and Gottschalk, P. (2014). Some evidence on the importance of sticky wages. American Economic Journal: Macroeconomics, 6(1):70-101.

Beaudry, P. and DiNardo, J. E. (1991). The effect of implicit contracts on the movement of wages over the business cycle: Evidence from micro data. The Journal of Political Economy, 99(4):66588.

Bellou, A. and Kaymak, B. (2012). Wages, implicit contracts, and the business cycle: Evidence from a european panel. Labour Economics, 19(6):898-907.

Benmelech, E., Bergman, N. K., and Enriquez, R. J. (2012). Negotiating with labor under financial distress. Review of Corporate Finance Studies, 1(1):28-67.

Benveniste, L. and Scheinkman, J. A. (1979). On the differentiability of the value function in dynamic models of economics. Econometrica, 47(3):727-32.

Bernanke, B. and Gertler, M. (1989). Agency costs, net worth, and business fluctuations. The American Economic Review, 79(1):14-31.

Bernanke, B., Gertler, M., and Gilchrist, S. (1999). The financial accelerator in a quantitative business cycle framework. Handbook of macroeconomics, 1:1341-1393.

Bils, M. (1985). Real wages over the business cycle: evidence from panel data. The Journal of Political Economy, 93(4):666-689.

Bils, M., Chang, Y., and Kim, S.-B. (2014). How sticky wages in existing jobs can affect hiring. Working Paper, University of Rochester.

Blasi, J. R., Kruse, D., and Bernstein, A. (2003). In the company of owners: The truth about stock options (and why every employee should have them). Basic Books.

Bronars, S. G. and Famulari, M. (1997). Wage, tenure, and wage growth variation within and across establishments. Journal of Labor Economics, 15(2):285-317.

Brown, C. and Medoff, J. (1989). The employer size-wage effect. Journal of Political Economy, 97(5):1027-59.

Browning, M. and Crossley, T. (2001). Unemployment insurance benefit levels and consumption changes. Journal of Public Economics, 80(1):1-23.

Buera, F. J., Kaboski, J. P., and Shin, Y. (2011). Finance and development: A tale of two sectors. American Economic Review, 101:1964-2002.

Buera, F. J. and Shin, Y. (2013). Financial frictions and the persistence of history: A quantitative 
exploration. Journal of Political Economy, 121(2):221-272.

Campello, M., Graham, J. R., and Harvey, C. R. (2010). The real effects of financial constraints: Evidence from a financial crisis. Journal of Financial Economics, 97(3):470-487.

Carlstrom, C. T. and Fuerst, T. S. (1997). Agency costs, net worth, and business fluctuations: A computable general equilibrium analysis. American Economic Review, 87(5):893-910.

Chetty, R. (2008). Moral hazard versus liquidity and optimal unemployment insurance. Journal of Political Economy, 116(2):173-234.

Chodorow-Reich, G. (2014). The employment effects of credit market disruptions: Firm-level evidence from the 2008-9 financial crisis. The Quarterly Journal of Economics, 129(1):1-59.

Chugh, S. K. (2013). Costly external finance and labor market dynamics. Journal of Economic Dynamics and Control, 37(12):2882-2912.

Clementi, G. L. and Palazzo, B. (2014). Entry, exit, firm dynamics, and aggregate fluctuations. Working Paper, NBER.

Cooley, T., Marimon, R., and Quadrini, V. (2004). Aggregate consequences of limited contract enforceability. Journal of Political Economy, 112(4):817-847.

Cooley, T. and Prescott, E. (1995). Frontiers of business cycle research. Princeton Univ Pr, NJ.

Cooley, T. F. and Quadrini, V. (2001). Financial markets and firm dynamics. American Economic Review, 91(5):1286-1310.

Core, J. E. and Guay, W. R. (2001). Stock option plans for non-executive employees. Journal of Financial Economics, 61(2):253-287.

Diamond, P. A. (1982). Aggregate demand management in search. The Journal of Political Economy, 90(5):881-894.

Gertler, M. and Gilchrist, S. (1994). Monetary policy, business cycles, and the behavior of small manufacturing firms. The Quarterly Journal of Economics, 109(2):309-340.

Gertler, M. and Hubbard, R. G. (1989). Financial factors in business fluctuations. Working Paper (w2758), NBER.

Gertler, M. and Trigari, A. (2009). Unemployment fluctuations with staggered nash wage bargaining. Journal of Political Economy, 117(1):38-86.

Gilchrist, S., Ortiz, A., and Zakrajsek, E. (2009). Credit risk and the macroeconomy: Evidence from an estimated dsge model. Working Paper, Boston University.

Gilchrist, S., Sim, J. W., and Zakrajšek, E. (2012). Missallocation and financial frictions: Some direct evidence from the dispersion in borrowing costs. Working Paper, NBER.

Gordon, D. (1974). A neo-classical theory of keynesian unemployment. Economic Inquiry, 12(4):431459.

Gruber, J. (1997). The consumption smoothing benefits of unemployment insurance. American Economic Review, 87(1):192-205.

Guiso, L., Pistaferri, L., and Schivardi, F. (2005). Insurance within the firm. Journal of Political Economy, 113(5):1054-1087.

Guiso, L., Pistaferri, L., and Schivardi, F. (2013). Credit within the firm. The Review of Economic Studies, 80(1):211-247.

Hadlock, C. J. and Pierce, J. R. (2010). New evidence on measuring financial constraints: Moving beyond the kz index. Review of Financial Studies, 23(5):1909-1940.

Haefke, C., Sonntag, M., and Van Rens, T. (2013). Wage rigidity and job creation. Journal of monetary economics, 60(8):887-899. 
Hall, B. H. and Hall, R. E. (1993). The value and performance of us corporations. Brookings Papers on Economic Activity, 24(1):1-50.

Hall, B. J. and Murphy, K. J. (2003). The trouble with stock options. Journal of Economic Perspectives, 17(3):49-70.

Hall, R. E. and Milgrom, P. R. (2008). The limited influence of unemployment on the wage bargain. American Economic Review, 98(4):1653-1674.

Hanka, G. (1998). Debt and the terms of employment. Journal of Financial Economics, 48(3):245282.

Harris, M. and Holmstrom, B. (1982). A theory of wage dynamics. The Review of Economic Studies, 49(3):315-333.

Hart, O. and Moore, J. (1994). A theory of debt based on the inalienability of human capital. The Quarterly Journal of Economics, 109(4):841-879.

Jappelli, T. (1990). Who is credit constrained in the us economy? The Quarterly Journal of Economics, 105(1):219-234.

Jermann, U. and Quadrini, V. (2012). Macroeconomic effects of financial shocks. The American Economic Review, 102(1):238-271.

Kaplan, G., Violante, G. L., and Weidner, J. (2014). The wealthy hand-to-mouth. Working Paper, National Bureau of Economic Research.

Khan, A. and Thomas, J. K. (2013). Credit shocks and aggregate fluctuations in an economy with production heterogeneity. Journal of Political Economy, 121(6):1055-1107.

King, R. G. and Rebelo, S. T. (1999). Resuscitating real business cycles. Handbook of macroeconomics, 1:927-1007.

Kiyotaki, N. and Moore, J. (1997). Credit cycles. Journal of political economy, 105(2):211-248.

Knight, F. (2002). Risk, uncertainty and profit. Beard Books.

Kocherlakota, N. (1996). Implications of efficient risk sharing without commitment. The Review of Economic Studies, 63(4):595.

Kudlyak, M. (2014). The cyclicality of the user cost of labor. Journal of Monetary Economics, 68:53-67.

Lee, Y. and Mukoyama, T. (2008). Entry, exit and plant-level dynamics over the business cycle. Working Paper, University of Virginia.

Macis, M. (2006). Wage dynamics and insurance. Unpublished Manuscript, University of Chicago.

Menzio, G. and Moen, E. (2010). Worker replacement. Journal of Monetary Economics, 57(6):623636.

Menzio, G. and Shi, S. (2010). Block recursive equilibria for stochastic models of search on the job. Journal of Economic Theory, 145(4):1453-1494.

Menzio, G. and Shi, S. (2011). Efficient search on the job and the business cycle. Journal of Political Economy, 119(3):468-510.

Michelacci, C. and Quadrini, V. (2009). Financial markets and wages. The Review of Economic Studies, 76(2):795-827.

Moen, E. (1997). Competitive search equilibrium. Journal of Political Economy, 105(2):385-411.

Moll, B. (2014). Productivity losses from financial frictions: Can self-financing undo capital misallocation? Working Paper, University of Chicago.

Monacelli, T., Quadrini, V., and Trigari, A. (2011). Financial markets and unemployment. Working Paper, NBER. 
Mortensen, D. T. and Pissarides, C. A. (1994). Job creation and job destruction in the theory of unemployment. The Review of Economic Studies, 61(3):397-415.

Moscarini, G. and Postel-Vinay, F. (2012). The contribution of large and small employers to job creation in times of high and low unemployment. The American Economic Review, 102(6):25092539 .

Oi, W. Y. and Idson, T. L. (1999). Firm size and wages. Handbook of labor economics, 3:2165-2214.

Petrosky-Nadeau, N. and Wasmer, E. (2013). The cyclical volatility of labor markets under frictional financial markets. American Economic Journal: Macroeconomics, 5(1):193-221.

Pissarides, C. A. (2009). The unemployment volatility puzzle: Is wage stickiness the answer? Econometrica, 77(5):1339-1369.

Rudanko, L. (2009). Labor market dynamics under long-term wage contracting. Journal of Monetary Economics, 56(2):170-183.

Rudanko, L. (2011). Aggregate and idiosyncratic risk in a frictional labor market. The American Economic Review, 101(6):2823-2843.

Schaal, E. (2012). Uncertainty, productivity and unemployment in the great recession. Working Paper, Federal Reserve Bank of Minneapolis.

Shimer, R. (2005). The cyclical behavior of equilibrium unemployment and vacancies. American Economic Review, 95(1):25-49.

Stokey, N., Lucas, R., and Prescott, E. (1989). Recursive methods in economic dynamics. Harvard University Press.

Tauchen, G. (1986). Finite state markov-chain approximations to univariate and vector autoregressions. Economics letters, 20(2):177-181.

Thomas, J. and Worrall, T. (1988). Self-enforcing wage contracts. The Review of Economic Studies, 55(4):541.

Thomas, J. P. and Worrall, T. (2007). Limited commitment models of the labour market. Scottish Journal of Political Economy, 54(5):750-773. 


\section{Appendix}

\subsection{Data Appendix}

\section{Aggregate Output, Employment, Wages}

I obtain time series from BLS for the following aggregate variables: Real Output for Nonfarm Business Sector, Compensation Index in 2009 dollar for Nonfarm Business Sector and Employment for Nonfarm Business Sector. All variables are quarterly data and seasonally adjusted. I use the CPI index for all urban consumers to deflate the compensation and then divide it by employment, to obtain real wage per worker. Real output per worker is from real output divided by employment. All variables are then taken logs, and hp-filtered (with smoothing parameter 1600).

\section{Debt Stock, Debt Changes, and Physical Capital}

Financial data is from the Flow of Funds Accounts of the Federal Reserve Board. Specifically, I use the flow measure of "Net increase in credit markets instruments of nonfinancial business" (FA144104005.Q). I deflate it by the price index for business value added from NIPA (Table 1.3.4). For the debt stock, I use the first available measure of nominal debt stock (1952.Q4) for Nonfinancial Noncorporate Business and Nonfinancial Corporate Business deflated by price index. Then I add flows to the previous-period stock and use recursion to obtain a series of stock measure. I do not directly use the balance sheet measure of debt stock, since that is not seasonally adjusted. For the construction of debt change to GDP ratio and also the debt stock to GDP ratio, I use the measure of business value added from NIPA (Table 1.3.5) which is consistent with our model. The Capital Stock is constructed using the equation $k_{t+1}=k_{t}$-Depreciation + Net New Investment. Specifically, depreciation is

measured as "Consumption of fixed capital in nonfinancial corporate business" plus "Consumption of fixed capital in nonfinancial noncorporate business". Investment is measured as "Capital expenditures in nonfinancial business". Both variables are deflated by the price index for business value added from NIPA. Initial capital stock is assumed to equal to the beginning-period investment divided by 0.1 . The average debt to asset ratio is then defined as the debt stock divided by the capital stock, which is consistent with our model construction.

\section{Compustat Variables}

The sample includes all U.S. firms in CRSP-Compustat merge file from 1960-2012. I include firms with fiscal year ending month in December $(\mathrm{fyr}=12)$, firms with non-missing SIC codes and I use additional sample selection rules as in the following table. I use the following variables from compustat after sample selections and possible mergers: book value of physical capital (Items 7 and 8), sales (Item 12), assets (Item 6), employment (item 29), gross debt (item 9+ item 34), cash and equivalents (item 1), physical investment (item 30 item 107 if any), operating income (Item 13), cash flows (item 14+item 18), dividends (item $19+$ item 21), equity (item 60), return to equity (item 18-item 19+item 50 if any, divided by item 60), staff expense (item 42), cost of goods sold (item 41), equity issuance (item 108 -item 115), Tobin's Q (item $6+24 * 25-60-74$ divided by item 6 ). These definitions are commonly used in empirical corporate finance.

\section{Sample Selections for Compustat Data}




\begin{tabular}{|c|c|c|}
\hline Sample Selections & \# of Obs left & Percent left \\
\hline all firm-year observations & 264582 & 100 \\
\hline drop all finance, public utility and foreign firms & 121560 & 45.9 \\
\hline drop if before 1986 (too few samples in those years) & 121543 & 45.9 \\
\hline drop if book asset, physical asset, gross debt, cash, sales missing & 120087 & 45.4 \\
\hline $\begin{array}{l}\text { drop if book value asset, physical asset, sales, physical inv, } \\
\text { employment in top or bottom } 1 \%\end{array}$ & 108101 & 40.9 \\
\hline $\begin{array}{l}\text { drop if Tobin's } \mathrm{Q}>10 \text {, Phy inv/Phy asset, sale/asset, } \\
\text { operating income/asset, op. income/Phy asset in top or bottom } 1 \%\end{array}$ & 95505 & 36.1 \\
\hline drop if the individual sample period is not consecutive & 88224 & 33.3 \\
\hline $\begin{array}{l}\text { drop if the growth of Phy inv, sales, asset, } \\
\text { Physical asset, employment in top or bottom } 1 \%\end{array}$ & 81619 & 30.8 \\
\hline drop if the individual sample periods smaller than 3 periods & 76477 & 28.9 \\
\hline
\end{tabular}

\section{SIPP Data Appendix.}

The main advantage of using SIPP data is that, among others, it provides a large nationally representative panel data with high frequencies. Specifically, I restrict to the sample of male, employed workers, age between 25 and 60, worked with full workweeks for each month when employed, with no change of employers when employed. I also do sample attrition by dropping observations with earnings in the top 1 percent and in the bottom 1 percent. SIPP also collects some information about the size of the firm where the worker works. Large firm means the number of employees is greater than 100 and small firm with less than 25 employees.

Table 1: Descriptive Statistics

\begin{tabular}{lccccc}
\hline \hline & \multicolumn{5}{c}{ Log earnings } \\
\cline { 2 - 6 } Small $(<25)$ & Obs & Mean & Std & Min & Max \\
\cline { 2 - 6 } & 107133 & 7.0529 & 0.8659 & -0.8132 & 10.1532 \\
medium & 63906 & 7.3387 & 0.7580 & -0.7832 & 9.9616 \\
Large $(>100)$ & 158166 & 7.5286 & 0.7568 & -0.8132 & 9.9231 \\
\hline \hline
\end{tabular}




\subsection{Illustrations for Model Intuition}

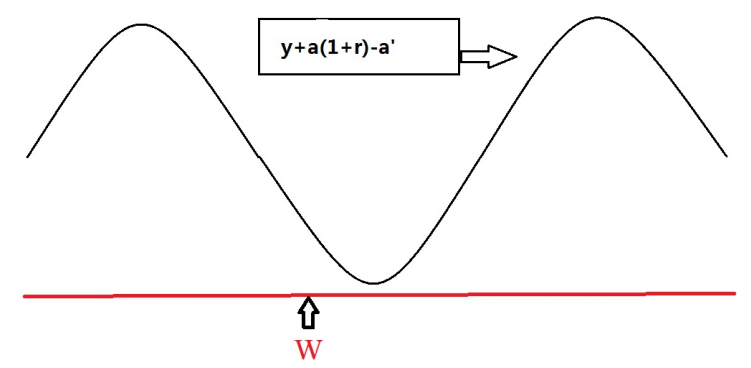

Figure 17: Perfect Worker Insurance

Notes: This graph shows firms may provide perfect insurance to workers when they are not financially constrained.

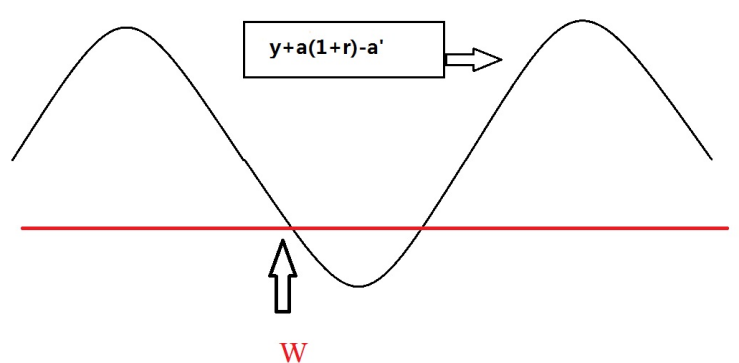

Figure 18: Hypothetical Case: Constraint Violated

Notes: This graph shows a hypothetical case when the firm's constraint was violated.

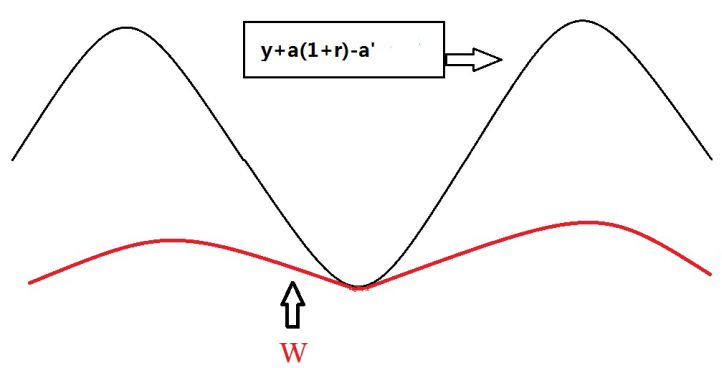

Figure 19: Imperfect Worker Insurance

Notes: This graph shows when firms are financially constrained, they may provide imperfect insurance to workers and tilt the wage profile. 


\subsection{Numerical Results Appendix}

\subsubsection{Calibration}

\begin{tabular}{lllll}
\hline \hline Pre-calibrated & & & \\
Risk aversion & $\sigma$ & 2 & \\
Discount factor & $\beta$ & 0.98 & \\
Risk free interest rate & $r$ & 0.005 & \\
Depreciation rate for physical capital & $\delta$ & 0.025 & \\
Matching function parameter & $\gamma$ & 1.60 & \\
Exogenous separation rate & $\rho$ & 0.05 & \\
& & & \\
Calibrated & & & (Reasons/Targets) \\
Production concavity & $\alpha$ & 0.295 & Capital Share \\
Persistence of idiosyncratic prod. & $\rho_{z}$ & 0.89 & Output process \\
Std. of idiosyncratic prod. & $\sigma_{z}$ & 0.18 & Output process \\
Entry cost & $\kappa$ & 2.74 & U rate 6\% \\
Unemployment benefit & $b$ & 0.82 & Replacement ratio $50 \%$ \\
Leverage constraint & $\lambda$ & 1.30 & Debt to asset ratio \\
\hline \hline
\end{tabular}

Table 2: Calibration: (model period: Quarter)

\begin{tabular}{lll}
\hline \hline Moments & Data & Model \\
\hline \hline Targeted & & \\
Transition Prob. $(\mathrm{U} \rightarrow \mathrm{E})$ & 0.834 & 0.82 \\
Aggregate labor share & 0.66 & 0.65 \\
Unemployment rate & 0.06 & 0.0602 \\
Output/asset $\widehat{\rho}(\mathrm{A})$ & 0.67 & 0.68 \\
Output/asset $\widehat{\sigma_{\epsilon}}(\mathrm{A})$ & 0.29 & 0.27 \\
Debt to Asset ratio & 0.23 & 0.231 \\
& & \\
Non-targeted & & \\
Operating income/asset mean & 0.078 & 0.082 \\
Operating income/asset $\widehat{\rho}(\mathrm{A})$ & 0.51 & 0.59 \\
Operating income/asset $\widehat{\sigma_{\epsilon}}(\mathrm{A})$ & 0.11 & 0.08 \\
Tobin's q & 1.79 & 1.66 \\
\hline \hline
\end{tabular}

Table 3: Calibration: compare data moments and model moments

Notes: $\widehat{\rho}$ is the annual persistence for a given variable and $\widehat{\sigma_{\epsilon}}$ is the standard deviation of the innovation for a given variable. The model period is a quarter and I convert the quarterly persistence and s.t.d into annual parameters using the following relations: ( $A$ is for annual basis and $Q$ for quarterly basis.) $\rho_{Q}=$ $\rho_{A}^{1 / 4} ; \sigma_{Q}^{2}=\frac{8\left(1-\rho_{Q}^{2}\right)}{2+3 \rho_{Q}+2 \rho_{Q}^{2}+\rho_{Q}^{3}} \frac{\sigma_{A}^{2}}{1-\rho_{A}^{2}}$. One issue is unobserved heterogeneity in the data from Compustat. The simulations produce independent and identically distributed firms. To remove the effects of heterogeneity from the autoregression, I include time dummies and remove firm fixed effects by differencing the data. 
8.3.2 Steady State Results.

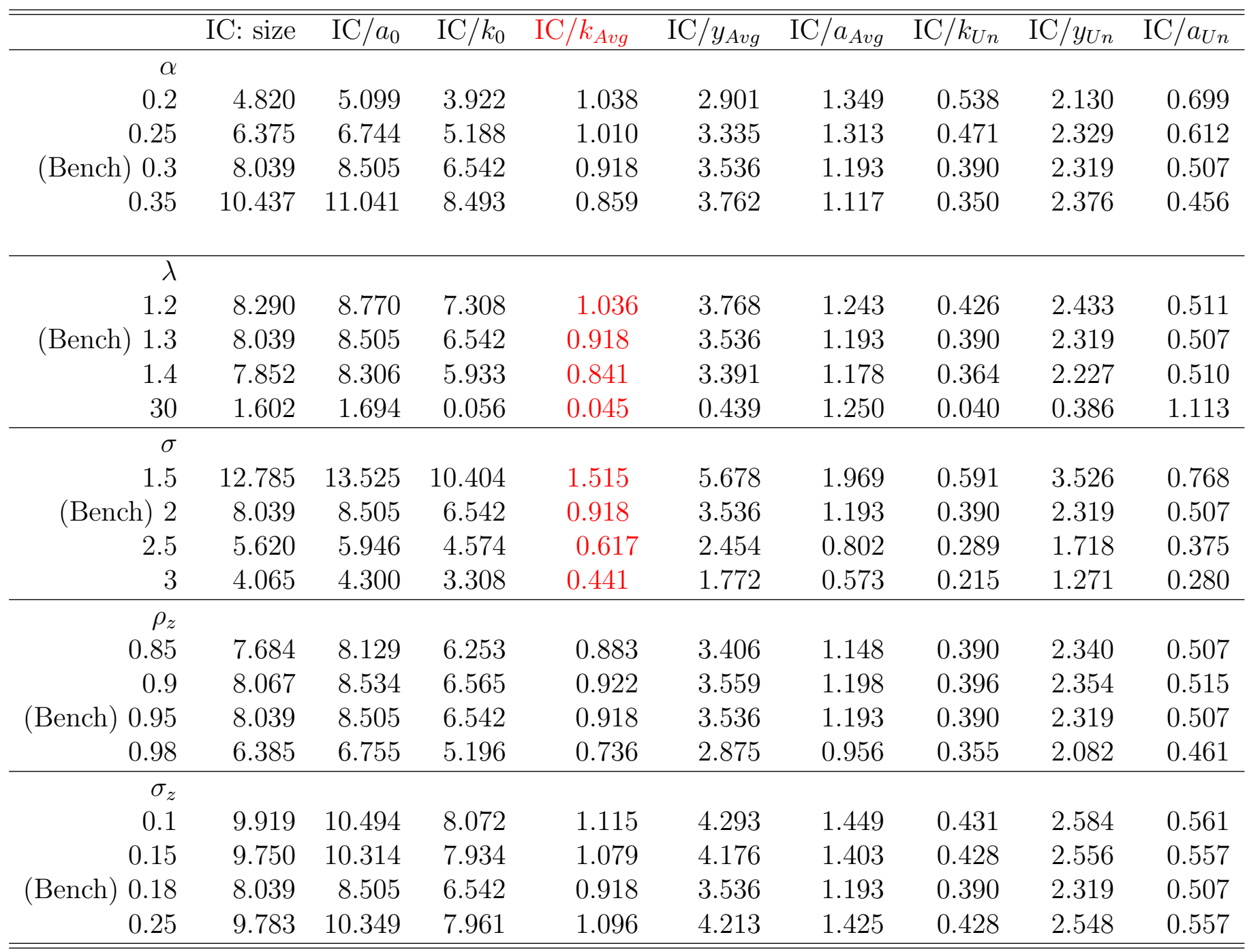

Notes: The internal credit(IC) is defined as $E_{0} \Sigma_{0 \leq t \leq T^{*}} \frac{(1-\rho)^{t}}{(1+r)^{t}}\left[w_{t}^{*}-w_{t}\right]$ (see the text for details). For each different parameter, I recalibrate such that the new economy has the same level of market tightness (and hence unemployment rate) as in the benchmark economy. I report the variables in the steady state of the corresponding economy. For the ratios, $a$ denotes firm net worth, $k$ is the firm's physical capital used for production and $y$ is the output. 0 stands for new entrants, $A v g$ stands for the average across the steady state economy and $U n$ stands for currently surviving and financially unconstrained firms.

Table 4: Steady State Comparison: Measuring the Size of Internal Credit in the Model 

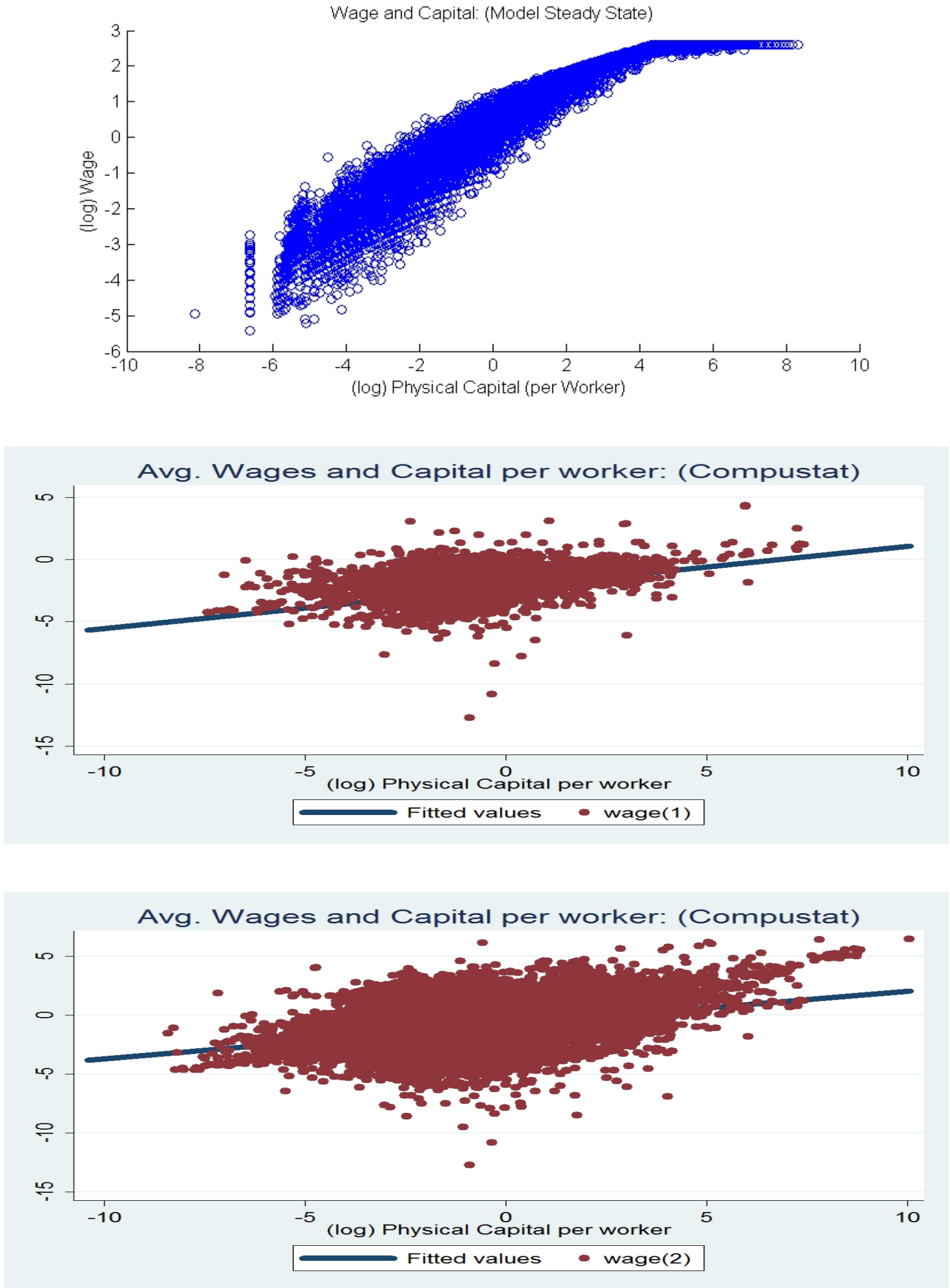

Figure 20: Firm Avg. wages and Physical capital per worker: Model and Data

Notes: This figure shows the positive relation between firms' average wages and physical capital (per worker), from the model (upper panel) and data (mid and lower panel). In the Compustat sample, Wage (1) is measured as the average labor compensation. Wage (2) is using Selling, General and Administration Cost whenever labor compensation is not available in wage (1). 


\begin{tabular}{|c|c|c|c|c|c|}
\hline \multicolumn{6}{|l|}{ Dep.Var. : $\Delta \log _{i, t}$} \\
\hline$\Delta \log _{i, t}$ & $0.2316^{* * *}$ & & & $0.0966^{* * *}$ & $0.1360^{* * *}$ \\
\hline & 0.0026 & & & 0.0037 & 0.0039 \\
\hline & 0.0000 & & & 0.0000 & 0.0000 \\
\hline $\log _{i, t-1}$ & & $-0.0288^{* * *}$ & & $-0.0201^{* * *}$ & $-0.0201^{* * *}$ \\
\hline & & 0.0003 & & 0.0004 & 0.0004 \\
\hline & & 0.0000 & & 0.0000 & 0.0000 \\
\hline \multirow{3}{*}{$\frac{D i v}{k}_{i, t-1}$} & & & $-0.2775^{* * *}$ & & $-0.2319^{* * *}$ \\
\hline & & & 0.0114 & & 0.0092 \\
\hline & & & 0.0000 & & 0.0000 \\
\hline $\mathrm{N}$ & 9513 & 9513 & 9513 & 9513 & 9513 \\
\hline$R^{2}$ & 0.4540 & 0.5240 & 0.0583 & 0.5552 & 0.5830 \\
\hline
\end{tabular}

Table 5: Regression of Wage Growth: from Model Generated Data

Notes: This table reports the regression results of wage growth rate $\left(\Delta \log _{i, t}\right)$ on firm size growth rate $\left(\Delta \log _{i, t}\right)$, firm size $\left(\log _{i, t-1}\right)$ and dividend payment to capital ratio $\left(\frac{D i v}{k}_{i, t-1}\right)$. I report the estimated coefficients, standard errors and the p-values. The sample is from model generated data. The model is simulated at the steady state, for 10,000 firms at the beginning and for 1000 periods. 


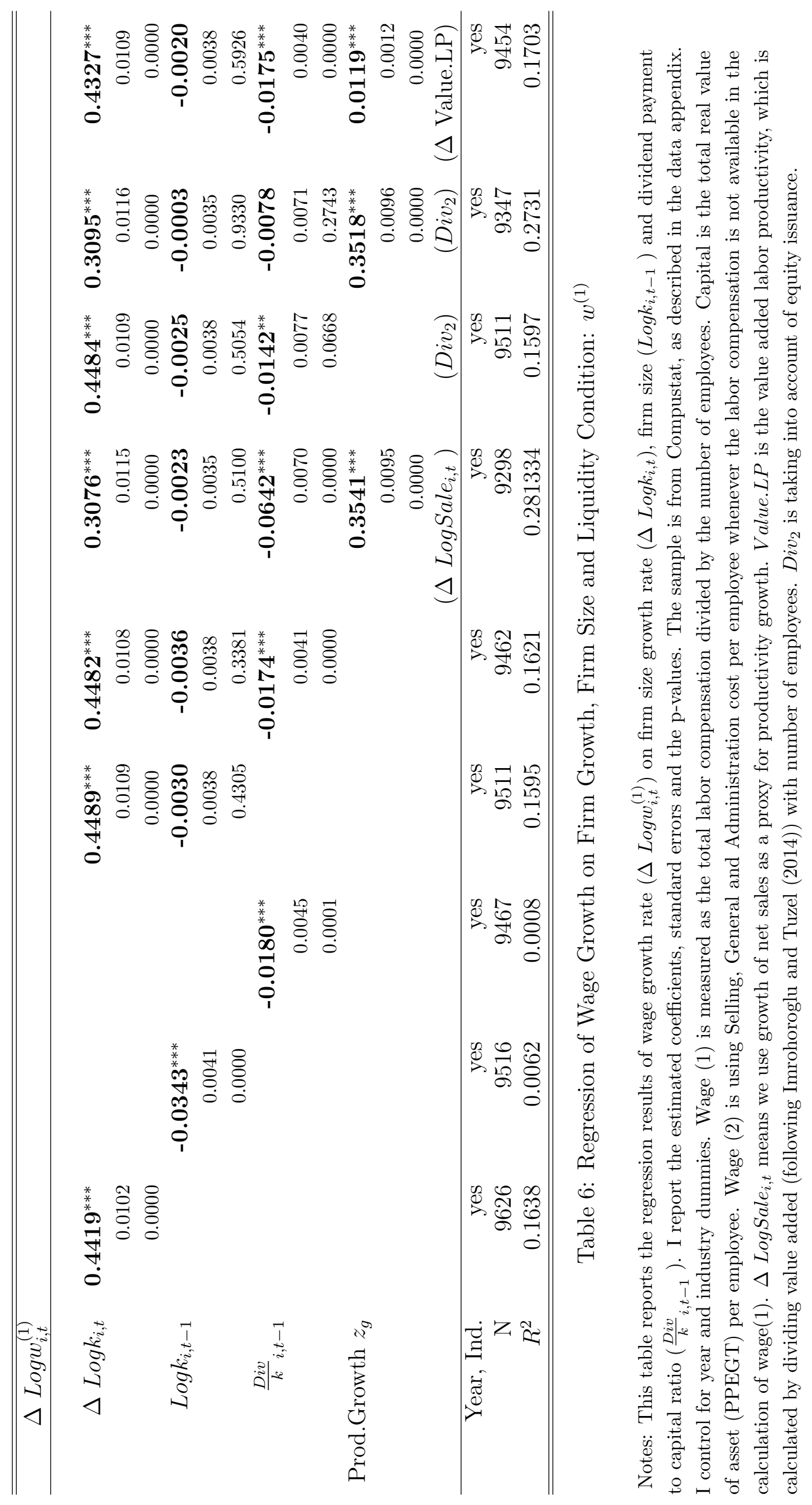




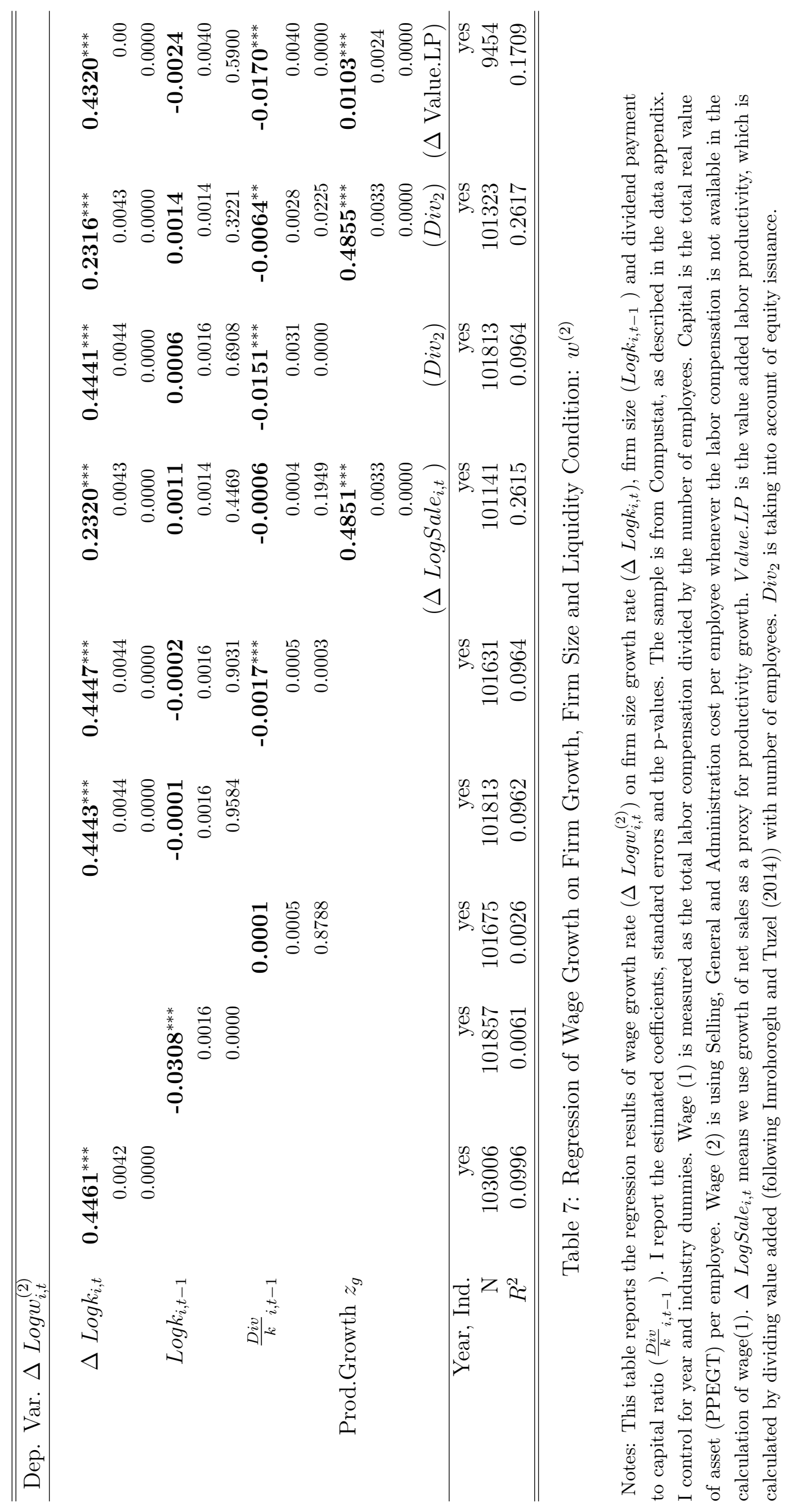




\subsubsection{For Studying 2008 Financial Crisis}
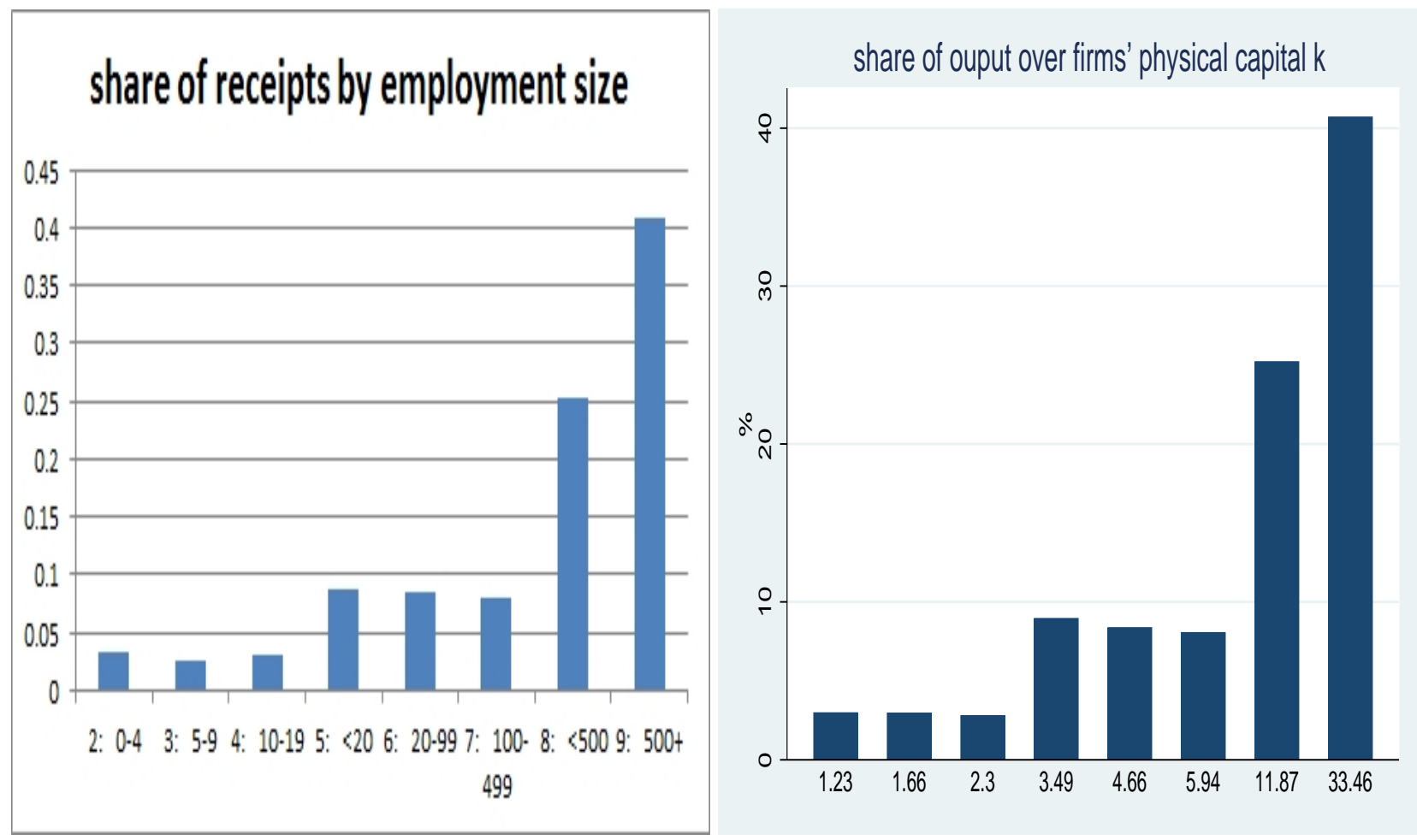

Figure 21: Distribution of Receipts and Output over Firm Sizes

Notes: The left panel displays the distribution of share of receipts over employment sizes in the data, from Statistics of U.S. Businesses, 2007. The panel in the right-hand side displays the distribution of share of outputs over physical capital in the model. I simulate the model at the steady state for 100,000 firms, incorporating entry and exit of firms. I use these distributions to help choose the thresholds for small firms and large firms in section 5 .

\begin{tabular}{|c|c|c|c|c|c|c|}
\hline & \multicolumn{2}{|c|}{ Output Share(\%) } & \multicolumn{2}{|c|}{ \#. of Firms (\%) } & \multicolumn{2}{|c|}{ Wage Share (\%) } \\
\hline & Data & Model & Data & Model & Data & Model \\
\hline Small & 17.63 & 17.63 & 61.86 & 63.53 & 18.78 & 18.48 \\
\hline Medium & 8.41 & 8.41 & 3.04 & 10.25 & 9.63 & 8.90 \\
\hline Large & 73.96 & 73.96 & 35.09 & 26.22 & 71.59 & 72.62 \\
\hline
\end{tabular}

Table 8: Comparison of firm size categories (Small, Medium and Large) in the model and in the data

Notes: This table shows the comparison of different firm size categories used in the model and in the data. The data is from Statistics of U.S. Businesses, 2007. The output share is chosen to be matched with data, but others are non-targeted. Each variable for a given category is presented in shares, relative to the summation across three categories. 


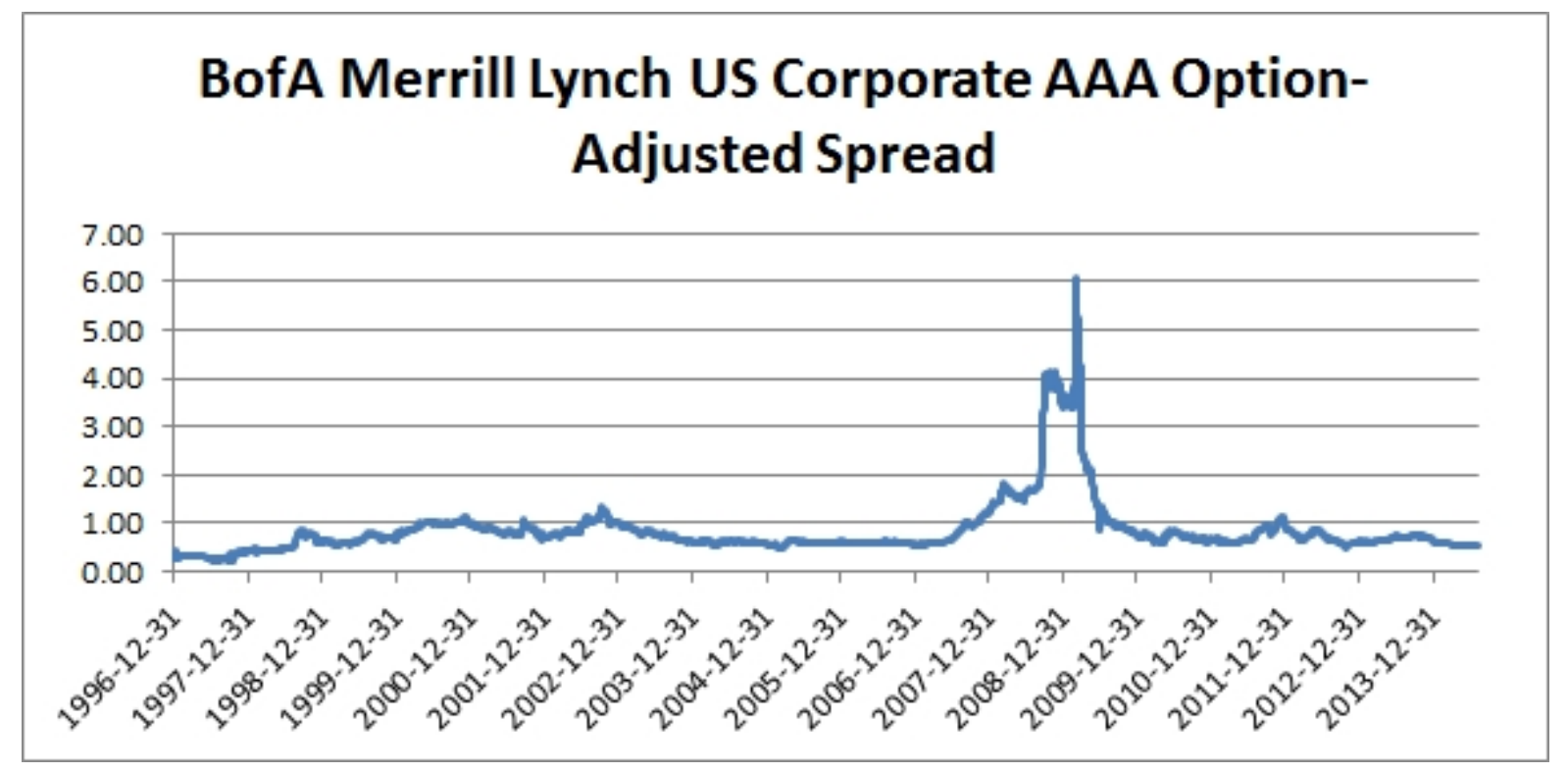

Figure 22: interest rate spread in 2001 and in 2008

\subsection{Empirical Analysis Appendix}

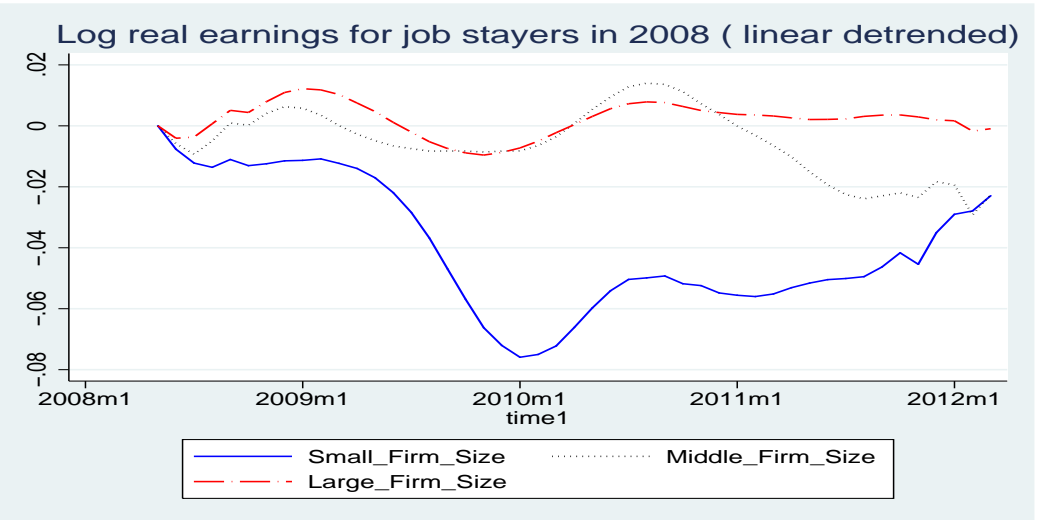

Figure 23: Earnings Dynamics for Small vs. Large Firms (smoothed and detrended) Notes: This figure shows job stayer's real earnings dynamics. The first month data point for each series is normalized to 0 for comparison purposes. I use five-months moving average smoothing. The three series are linearly detrended using the trend for large firms. 


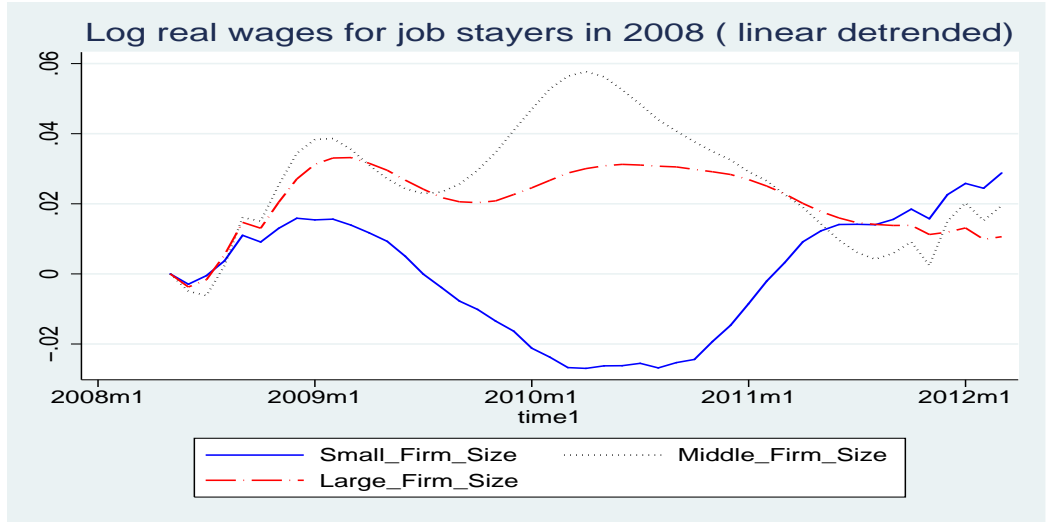

Figure 24: Real Wage Dynamics for Small vs. Large Firms (smoothed and detrended)

Notes: This figure shows job stayer's real wages dynamics. The first month data point for each series is normalized to 0 for comparison purposes. I use five-months moving average smoothing. The three series are linearly detrended using the trend for large firms.

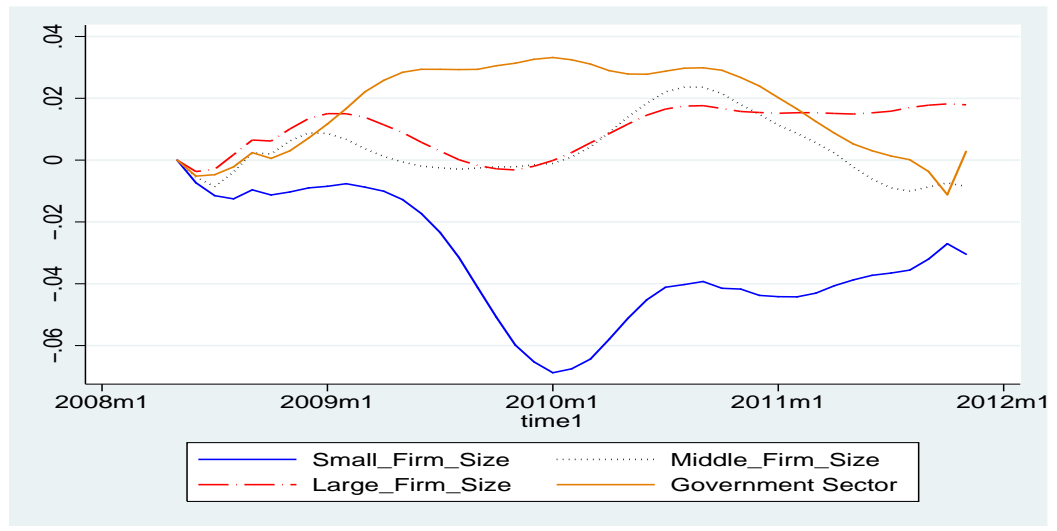

Figure 25: Earnings Dynamics for Small, Large Firms and the Government Sector (smoothed and detrended)

Notes: This figure shows job stayer's real earnings dynamics with smoothing and detrending. The first month data point for each series is normalized to 0 for comparison purposes. I use five-months moving average smoothing. The three series are linearly detrended using the trend for large firms. 


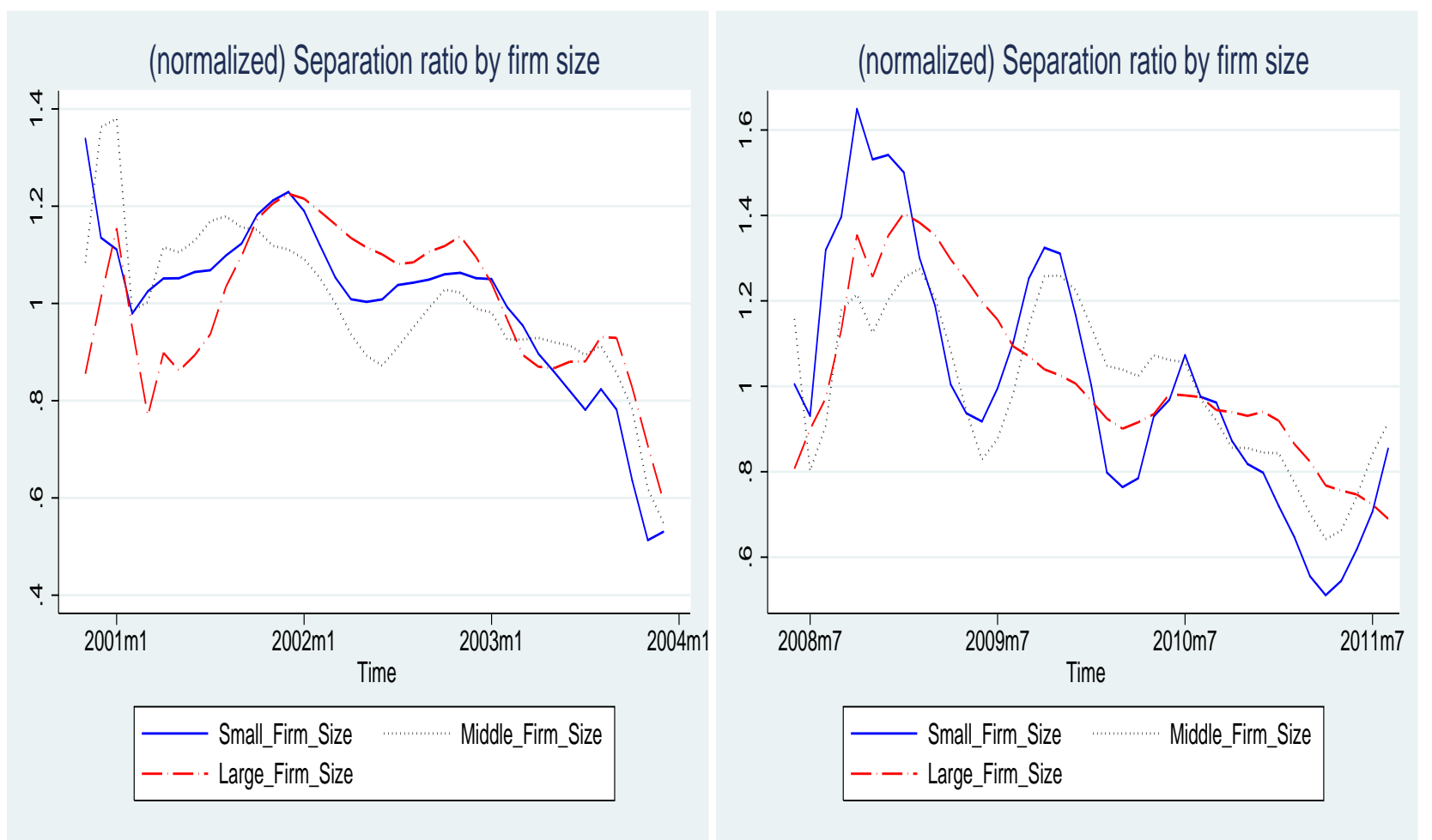

Figure 26: 2001 and 2008 separation rate by firm size

Notes: This figure shows the separation rates by firm size categories. Each separation rate time series is normalized to its sample mean for the purpose of comparison, since we care more about cyclical properties of these separation rates rather than their levels. (The average levels of separation rates across different firm sizes are roughly about $0.10-0.11$ for small firm monthly, 0.06-0.07 for medium firms and 0.02-0.03 for large firms monthly in the 2008 recession.)

\subsection{Appendix for Proofs and Numerical Computations}

\section{Model Solution and Transformed Value Function}

Recall the firm's optimization problem is:

$$
\begin{gathered}
J(z, a, v ; S)=\begin{array}{c}
\operatorname{Sup}_{\left\{k, w, a^{\prime}, v^{\prime}\left(z^{\prime}, a^{\prime}, s ; S^{\prime}\right)\right\}} d+\beta(1-\rho) E J\left(z^{\prime}, a^{\prime}, v^{\prime}\left(z^{\prime}, a^{\prime}, s ; S^{\prime}\right) ; S^{\prime}\right) \mid(s, S) \\
+\beta \rho a^{\prime}(1+r)
\end{array} \\
d=F(z, a ; S)-w-a^{\prime} \geq 0 \\
\quad \leq \lambda a, \lambda>1, \\
a^{\prime} \geq 0, w \geq 0, k \geq 0, \\
v=u(w)+\beta E\left\{\left[\rho V^{U}\left(S^{\prime}\right)+(1-\rho) v^{\prime}\left(z^{\prime}, a^{\prime}, s ; S^{\prime}\right)\right] \mid(s, S)\right\},
\end{gathered}
$$

Where $s=(z, a, v)$, and $F(z, a ; S) \equiv \operatorname{Sup}_{\{k\}} e^{z+X} f(k)-(r+\delta) k+a(1+r)$ subject to the constraint that $k \leq \lambda a, \lambda>1$ and $k \geq 0$.

Assume $z \in Z=\left\{z_{1}, \ldots, z_{N}\right\}, a \in A=\left[0, A^{\max }\right], v \in V=\left[\frac{u(b)}{1-\beta}, v^{\max }\right]$, where $v^{\max }$ is the maximal possible lifetime utility in the economy. Since we know $\beta(1+r)<1$, then the $v^{\text {max }}$ exists (e.g., the utility $u(c) \leq \alpha_{0}+\alpha_{1} c$, for some positive constant $\alpha_{0}$ and $\alpha_{1}$; then $\beta^{t} u\left(c_{t}\right) \leq \beta^{t}\left[\alpha_{0}+\alpha_{1} c_{t}\right] \leq$ $\beta^{t}\left[\alpha_{0}+\alpha_{1} A^{\max }(1+r)^{t}\right]$, so the lifetime utility will be bounded). Invoking standard arguments, we know $J$ is increasing and concave in $a$; similarly, $J$ is decreasing and concave in $v$. The standard contraction mapping theorem (Stokey et al. (1989)) applies and we use that in the numerical computation for value function iteration. 


\section{$J$ is Differentiable in $v$}

Moreover, we can show that $J$ is differentiable at int $V$ and this property can enable us to use first order conditions. To show it is differentiable, we want to apply the results in Benveniste and Scheinkman (1979). However, the difficulty here is that we have inequality constraint on the dividend and this makes the proof a little complex. Fix the states $(z, a)$ and note the optimal solution for $J$ is given by $\left(w^{*}(z, a, v), a^{\prime *}(z, a, v), v^{\prime *}\left(z^{\prime}, a^{\prime}, z, a, v ; S^{\prime}\right)\right)$, or shortly $\left(w^{*}(v), a^{\prime *}(v), v^{\prime *}\left(z^{\prime}, v\right)\right)$.

The basic idea is to construct a new function, defined in the interior of $V$, concave and differentiable, dominated by $J$ and coincides with $J$ at some point. To do this, take a small interval $\left[v_{1}, v_{2}\right]$ in the interior of $V$ and be around some point $v_{0}$. Find a small enough $\epsilon>0$ such that $\left(v_{0}-\epsilon, v_{0}+\epsilon\right) \subset\left[v_{1}, v_{2}\right]$. Define a new function $G(v)$ over the domain $\left(v_{0}-\epsilon, v_{0}+\epsilon\right)$ as follows:

For $\forall v \in\left(v_{0}-\epsilon, v_{0}\right]$, first define a new wage $w(v)$ such that

$$
v=u(w(v))+\beta \rho V^{U}\left(S^{\prime}\right)+\beta(1-\rho) E v^{\prime *}\left(z^{\prime}, v_{0}\right) .
$$

That is, the continuation utility part is the same as the optimal plan under $v_{0}$. Also let the new saving plan $a^{\prime}(v)$ defined as the same as $a^{\prime *}\left(v_{0}\right)$. Since $w(v) \leq w^{*}\left(v_{0}\right)$, we know the following constraint satisfied: $F(z, a ; S)-w(v)-a^{\prime}(v) \geq F(z, a ; S)-w^{*}\left(v_{0}\right)-a^{\prime *}\left(v_{0}\right) \geq 0$, where the second inequality comes from the fact that $w^{*}\left(v_{0}\right), a^{\prime *}\left(v_{0}\right)$ are feasible plans under $v_{0}$. So the new plan $\left(w(v), a^{\prime}(v), v^{\prime *}\left(z^{\prime}, v_{0}\right)\right)$ is feasible under $\forall v \in\left(v_{0}-\epsilon, v_{0}\right]$ for the problem of $J$. Now define $G(v)$ for $\forall v \in\left(v_{0}-\epsilon, v_{0}\right]:$

$$
G(v) \equiv F(z, a ; S)-w(v)-a^{\prime}(v)+\beta \rho a^{\prime}(v)(1+r)+\beta(1-\rho) E J\left(z^{\prime}, a^{\prime}(v), v^{\prime *}\left(z^{\prime}, v_{0}\right) ; S^{\prime}\right) \mid(s, S) .
$$

Then we must have:

$$
\begin{aligned}
G\left(v_{0}\right) & =J\left(v_{0}\right), \\
G(v) & \leq J(v), \text { for } \forall v \in\left(v_{0}-\epsilon, v_{0}\right] .
\end{aligned}
$$

since when $v=v_{0}$, the plan defined in $G$ is the same as the optimal one, so $G\left(v_{0}\right)=J\left(v_{0}\right)$; and when $v \in\left(v_{0}-\epsilon, v_{0}\right]$, the plan defined in $G$ is feasible but not necessarily optimal, hence $G(v) \leq J(v)$. Moreover, it is easy to check that $G(v)$ is concave in $v$ for $\forall v \in\left(v_{0}-\epsilon, v_{0}\right]$.

Now proceed to define $G$ over $\left(v_{0}, v_{0}+\epsilon\right)$. For $\forall v \in\left(v_{0}, v_{0}+\epsilon\right)$, define a new wage $w(v)$ such that $v=u(w(v))+\beta \rho V^{U}\left(S^{\prime}\right)+\beta(1-\rho) E v^{\prime *}\left(z^{\prime}, v_{0}\right)$. Again, the continuation utility part is the same as the optimal plan under $v_{0}$ and notice that

$$
w(v)=u^{-1}\left(v-\left(\beta \rho V^{U}\left(S^{\prime}\right)+\beta(1-\rho) E v^{\prime *}\left(z^{\prime}, v_{0}\right)\right)\right) .
$$

Define $a^{\prime}(v)$ as follows:

$$
\begin{aligned}
a^{\prime}(v) & =a^{\prime *}\left(v_{0}\right) \quad \text { if } F(z, a ; S)-w^{*}\left(v_{0}\right)-a^{\prime *}\left(v_{0}\right)>0 \\
& =F(z, a ; S)-w(v) \quad \text { if } F(z, a ; S)-w^{*}\left(v_{0}\right)-a^{\prime *}\left(v_{0}\right)=0 .
\end{aligned}
$$

Since $w^{*}\left(v_{0}\right)<w(v)=w^{*}\left(v_{0}\right)+\left(u^{-1}\right)^{\prime}\left(v_{0}-\left(\beta \rho V^{U}\left(S^{\prime}\right)+\beta(1-\rho) E v^{* *}\left(z^{\prime}, v_{0}\right)\right)\right) \epsilon+o(\epsilon)=w^{*}\left(v_{0}\right)+$ $\frac{1}{u^{\prime}\left(w^{*}\left(v_{0}\right)\right)} \epsilon+o(\epsilon)$, so when $F(z, a ; S)-w^{*}\left(v_{0}\right)-a^{\prime *}\left(v_{0}\right)>0$, then $F(z, a ; S)-w(v)-a^{\prime}(v)>0$ as long as $\epsilon$ is small. When $F(z, a ; S)-w^{*}\left(v_{0}\right)-a^{\prime *}\left(v_{0}\right)=0$, we also have $F(z, a ; S)-w(v)-a^{\prime}(v)=0$. So the new plan $\left(w(v), a^{\prime}(v), v^{\prime *}\left(z^{\prime}, v_{0}\right)\right)$ is feasible but not necessarily optimal under $\forall v \in\left(v_{0}, v_{0}+\epsilon\right)$ for the problem of $J$. Now define $G(v)$ for $\forall v \in\left(v_{0}, v_{0}+\epsilon\right)$ :

$$
G(v) \equiv F(z, a ; S)-w(v)-a^{\prime}(v)+\beta \rho a^{\prime}(v)(1+r)+\beta(1-\rho) E J\left(z^{\prime}, a^{\prime}(v), v^{\prime *}\left(z^{\prime}, v_{0}\right) ; S^{\prime}\right) \mid(s, S) .
$$


Then we must have:

$$
G(v) \leq J(v), \text { for } \forall v \in\left(v_{0}, v_{0}+\epsilon\right)
$$

Finally notice that $-w(v)$ is concave in $v$ and $a^{\prime}(v)$ concave in $v$ when $F(z, a ; S)-w^{*}\left(v_{0}\right)-$ $a^{\prime *}\left(v_{0}\right)=0$, and $J$ is concave in $a^{\prime}$, so we know $G(v)$ concave in $v$. Apply the theorem in Benveniste and Scheinkman (1979), we have $J$ is differentiable in $v$. Graphically, please see figure 2.

For the firm's problem, we state two properties here. These could help us understand better the mechanism as well as the wage dynamics when firms face financial frictions.

First recall the sequential problem is:

$$
\begin{aligned}
J(z, a, v)= & \max \quad\left\{w_{t}, a_{t}\right\} \quad \sum_{t \geq 0} \sum_{\theta^{t}} \pi\left(\theta^{t}\right)[\beta(1-\rho)]^{t-1}\left(F\left(z_{t}, a_{t}\right)-w_{t}-a_{t+1}\right) \\
& \left.+\sum_{t \geq 1} \beta^{t}(1-\rho)\right]^{t-1} \rho(1+r) a_{t+1} \\
\text { s.t. } \quad: \quad & F\left(z_{t}, a_{t}\right)-w_{t}-a_{t+1} \geq 0, \forall t \geq 0, \forall \theta^{t}, \\
v \quad= & \left.\sum_{t \geq 0} \sum_{\theta^{t}} \pi\left(\theta^{t}\right)[\beta(1-\rho)]^{t-1} u\left(w_{t}\right)+\sum_{t \geq 1} \sum_{\theta^{t}} \pi\left(\theta^{t}\right) \beta^{t}(1-\rho)\right]^{t-1} \rho V^{U}\left(S_{t}\right) \\
\equiv & \sum_{t \geq 0} \sum_{\theta^{t}} \pi\left(\theta^{t}\right)[\beta(1-\rho)]^{t-1} u\left(w_{t}\right)+C .
\end{aligned}
$$

Denote the lagrangian multiplier for the dividend constraint at time $t$ and $\theta^{t}$ as $\gamma_{t}\left(\theta^{t}\right)$ and use $\gamma_{t}$ as a shorthand whenever it is clear. Denote $\lambda$ as the multiplier for the promising constraint.

\section{Property 1}

Fix any path of realizations of productivity. When initial net worth is small and marginal return is high, e.g., $F_{a}^{\prime}\left(z, a_{t} ; S\right)>\frac{1}{\beta(1-\rho)}$, then we should have the dividend constraint multipliers $\gamma_{t}$ non-increasing over time.

The argument is as follows.It is easy to write the FOCs as follows:

$$
\begin{aligned}
\lambda u^{\prime}\left(w_{t}^{*}\right) & =1+\gamma_{t} \\
\lambda u^{\prime}\left(w_{t+1}^{*}\right) & =1+\gamma_{t+1} .
\end{aligned}
$$

Suppose $0 \leq \gamma_{t}<\gamma_{t+1}$ along the path of $\left(\theta^{t}, \theta^{t+1}\right)$. then we must have $w_{t}^{*}>w_{t+1}^{*}$, together with $F_{a}^{\prime}\left(z, a_{t+1} ; S\right)>\frac{1}{\beta(1-\rho)}$. We want to show this is impossible. We can construct a new feasible plan, particularly by modifying the wages along the path of $\left(\theta^{t}, \theta^{t+1}\right)$ and keep other wages not changing. We then change the savings accordingly and want to show that this feasible plan will bring a higher firm's profit. Then a contradiction is obtained.

We can reduce $w_{t}$ and increase $w_{t+1}$ to make the wage path more flatter: define $w_{t}=$ $w_{t}^{*}-\epsilon, w_{t+1}=w_{t+1}^{*}+\delta$, and choose $\epsilon, \delta$ such that

$$
\begin{aligned}
& \pi\left(\theta^{t}\right)[\beta(1-\rho)]^{t-1} u\left(w_{t}^{*}\right)+\pi\left(\theta^{t+1}\right)[\beta(1-\rho)]^{t} u\left(w_{t+1}^{*}\right) \\
= & \pi\left(\theta^{t}\right)[\beta(1-\rho)]^{t-1} u\left(w_{t}\right)+\pi\left(\theta^{t+1}\right)[\beta(1-\rho)]^{t} u\left(w_{t+1}\right), \\
= & \pi\left(\theta^{t}\right)[\beta(1-\rho)]^{t-1} u\left(w_{t}^{*}-\epsilon\right)+\pi\left(\theta^{t+1}\right)[\beta(1-\rho)]^{t} u\left(w_{t+1}^{*}+\delta\right) \\
= & \pi\left(\theta^{t}\right)[\beta(1-\rho)]^{t-1}\left[u\left(w_{t}^{*}\right)-\epsilon u^{\prime}\left(w_{t}^{*}\right)+o(\epsilon)\right] \\
& +\pi\left(\theta^{t+1}\right)[\beta(1-\rho)]^{t}\left[u\left(w_{t+1}^{*}\right)+\delta u^{\prime}\left(w_{t+1}^{*}\right)+o(\delta)\right],
\end{aligned}
$$


since $u^{\prime}\left(w_{t}^{*}\right)<u^{\prime}\left(w_{t+1}^{*}\right)$, we can restrict $\epsilon, \delta$ such that $\pi\left(\theta^{t+1}\right)[\beta(1-\rho)]^{t} \delta<\pi\left(\theta^{t}\right)[\beta(1-\rho)]^{t-1} \epsilon$. Since $\gamma_{t+1}>0$, we know the dividend constraint is binding at $t+1$ and $F\left(z_{t+1}, a_{t+1}^{*}\right)-w_{t+1}^{*}-a_{t+2}^{*}=0$ and it is not feasible to increase $w_{t+1}^{*}$ without changing $a_{t+1}^{*}$ and keeping $a_{t+2}^{*}$ the same. Recall for the period $t$ constraint is now slack: $F\left(z_{t}, a_{t}^{*}\right)-w_{t}-a_{t+1}^{*}=F\left(z_{t}, a_{t}^{*}\right)-\left(w_{t}^{*}-\epsilon\right)-a_{t+1}^{*}>0$. We could define a new $a_{t+1}=a_{t+1}^{*}+\epsilon$, and at the same time the plan $\left(w_{t}, a_{t+1}, w_{t+1}\right)$ is feasible. The gain in firm's profit (relative to the original plan) in period $t+1$ is:

$$
\begin{aligned}
& \{\beta(1-\rho)\}\left\{F\left(z_{t+1}, a_{t+1}\right)-F\left(z_{t+1}, a_{t+1}^{*}\right)+\beta \rho(1+r) \epsilon+\pi\left(\theta_{t+1} \mid \theta^{t}\right) \beta(1-\rho)\left\{\left(-w_{t+1}+w_{t+1}^{*}\right)\right\}\right. \\
= & \{\beta(1-\rho)\}\left\{F_{a}^{\prime}\left(z_{t+1}, a_{t+1}^{*}\right) \epsilon+\frac{\beta \rho(1+r)}{\beta(1-\rho)} \epsilon-\pi\left(\theta_{t+1} \mid \theta^{t}\right) \delta\right\},
\end{aligned}
$$

since $\beta(1-\rho) \pi\left(\theta_{t+1} \mid \theta^{t}\right) \delta<\epsilon<\beta(1-\rho) F_{a}^{\prime}\left(z_{t+1}, a_{t+1}^{*}\right) \epsilon$, then $F_{a}^{\prime}\left(z_{t+1}, a_{t+1}^{*}\right) \epsilon-\pi\left(\theta_{t+1} \mid \theta^{t}\right) \delta>0$ and we know there is a positive gain by deviation. Therefore, a contradiction is obtained and $\gamma_{t}$ must be non-increasing over time in the statement.

\section{Property 2}

The constraint $d=F(z, a ; S)-w-a^{\prime} \geq 0$ will become more tightened as $v$ increases. Formally, let $v_{2}=v_{1}+\epsilon, v_{1}<v_{2}, v_{1}, v_{2} \in$ int $V$, then it is impossible to have: $d^{*}\left(v_{1}\right)=0$ and $d^{*}\left(v_{2}\right)>0$.

A simple counter argument applies. Assume it's true that $d^{*}\left(v_{1}\right)=0$ and $d^{*}\left(v_{2}\right)>0$. Then since $d^{*}\left(v_{2}\right)>0$, we know the dividend constraint not binding and the savings is described by a first order equation:

$$
\beta \rho(1+r)+\beta(1-\rho) E \frac{\partial J}{\partial a^{\prime}}=1 .
$$

Now for $v_{1}$, consider the plan $\left(w\left(v_{1}\right), a^{\prime *}\left(v_{2}\right), v^{\prime *}\left(z^{\prime}, v_{2}\right)\right)$, with $w\left(v_{1}\right)$ defined by $v_{1}=u\left(w\left(v_{1}\right)\right)+$ $\beta \rho V^{U}\left(S^{\prime}\right)+\beta(1-\rho) E v^{\prime *}\left(z^{\prime}, v_{2}\right)$. We know $w\left(v_{1}\right)<w^{*}\left(v_{2}\right)$ and this plan will be feasible under $v_{1}$ : since $F(z, a ; S)-w\left(v_{1}\right)-a^{\prime *}\left(v_{2}\right)>F(z, a ; S)-w^{*}\left(v_{2}\right)-a^{\prime *}\left(v_{2}\right)>0$. And by

$$
\begin{aligned}
w\left(v_{1}\right) & =u^{-1}\left(v_{1}-\left(\beta \rho V^{U}\left(S^{\prime}\right)+\beta(1-\rho) E v^{\prime *}\left(z^{\prime}, v_{2}\right)\right)\right) \\
& =u^{-1}\left(v_{2}-\epsilon-\left(\beta \rho V^{U}\left(S^{\prime}\right)+\beta(1-\rho) E v^{\prime *}\left(z^{\prime}, v_{2}\right)\right)\right) \\
& =w^{*}\left(v_{2}\right)+\left(u^{-1}\right)^{\prime}\left(v_{2}-\left(\beta \rho V^{U}\left(S^{\prime}\right)+\beta(1-\rho) E v^{\prime *}\left(z^{\prime}, v_{2}\right)\right)\right)(-\epsilon)+o(\epsilon) \\
& =w^{*}\left(v_{2}\right)-\frac{1}{u^{\prime}\left(w^{*}\left(v_{2}\right)\right)} \epsilon+o(\epsilon) .
\end{aligned}
$$

Then we must have the following comparison:

$$
\begin{aligned}
J\left(v_{1}\right) \geq & F(z, a ; S)-w\left(v_{1}\right)-a^{\prime *}\left(v_{2}\right) \\
& +\beta \rho a^{\prime *}\left(v_{2}\right)(1+r)+\beta(1-\rho) E J\left(z^{\prime}, a^{\prime *}\left(v_{2}\right), v^{\prime *}\left(z^{\prime}, v_{2}\right) ; S^{\prime}\right) \mid(s, S) \\
= & \frac{1}{u^{\prime}\left(w^{*}\left(v_{2}\right)\right)} \epsilon-o(\epsilon)+F(z, a ; S)-w^{*}\left(v_{2}\right)-a^{\prime *}\left(v_{2}\right) \\
& +\beta \rho a^{\prime *}\left(v_{2}\right)(1+r)+\beta(1-\rho) E J\left(z^{\prime}, a^{\prime *}\left(v_{2}\right), v^{\prime *}\left(z^{\prime}, v_{2}\right) ; S^{\prime}\right) \mid(s, S) \\
= & \frac{1}{u^{\prime}\left(w^{*}\left(v_{2}\right)\right)} \epsilon-o(\epsilon)+J\left(v_{2}\right),
\end{aligned}
$$

Where the first inequality is because the new plan is feasible but not necessarily optimal under $v_{1}$ and the third equality is just using the definition of $J\left(v_{2}\right)$. However, for $J$ is a concave function and strict concave around $v_{2}$, we must have $0 \leq J\left(v_{1}\right)-J\left(v_{2}\right) \leq\left(v_{2}-v_{1}\right) *\left|J^{\prime}\left(v_{2}\right)\right|=\epsilon\left|J^{\prime}\left(v_{2}\right)\right|$, and the fact that $J^{\prime}\left(v_{2}\right)=\frac{1}{u^{\prime}\left(w^{*}\left(v_{2}\right)\right)}$. A contradiction is obtained and we are done.

\section{Legendre-Fenchel Transformation}


Now define the Pareto function $\Psi(z, a, \omega)$, that is, the weighted summation of two parties' valuations, for a given positive weight $\omega \geq 0, z \in Z, a \in A$, (mathematically, this is a LegendreFenchel Transform):

$$
\Psi(z, a, \omega) \equiv \operatorname{Sup}_{v \in V} \quad J(z, a, v)+\omega v .
$$

If we substitute the expression for the optimal problem of $J(z, a, v)$, then we can define

$$
\begin{aligned}
& \Psi(z, a, \omega ; S) \equiv \operatorname{Sup}_{v \in V} \operatorname{Sup}_{\left\{w, a^{\prime}, v^{\prime}\left(z^{\prime}, a^{\prime}, s ; S^{\prime}\right)\right\}} d+\beta(1-\rho) E J\left(z^{\prime}, a^{\prime}, v^{\prime}\left(z^{\prime}, a^{\prime}, s ; S^{\prime}\right) ; S^{\prime}\right) \mid(s, S) \\
& +\omega v+\beta \rho a^{\prime}(1+r) \\
& d=F(z, a ; S)-w-a^{\prime} \geq 0 \\
& a^{\prime} \geq 0 \\
& v=u(w)+\beta E\left\{\left[\rho V^{U}\left(S^{\prime}\right)+(1-\rho) v^{\prime}\left(z^{\prime}, a^{\prime}, s ; S^{\prime}\right)\right] \mid(s, S)\right\} .
\end{aligned}
$$

Again substitute the expression of $v$ into the optimization problem:

$$
\begin{aligned}
\Psi(z, a, \omega ; S) \equiv & \operatorname{Sup}_{\left\{k, w, a^{\prime}, v^{\prime}\left(z^{\prime}, a^{\prime}, s ; S^{\prime}\right)\right\}} \\
& d+\beta(1-\rho) E J\left(z^{\prime}, a^{\prime}, v^{\prime}\left(z^{\prime}, a^{\prime}, v ; S^{\prime}\right) ; S^{\prime}\right) \mid(s, S)+\beta \rho a^{\prime}(1+r) \\
& +\omega\left[u(w)+\beta E\left\{\left[\rho V^{U}\left(S^{\prime}\right)+(1-\rho) v^{\prime}\left(z^{\prime}, a^{\prime}, v ; S^{\prime}\right)\right] \mid(s, S)\right\}\right]
\end{aligned}
$$

with constraints:

$$
\begin{gathered}
d=F(z, a ; S)-w-a^{\prime} \geq 0, \\
a^{\prime} \geq 0 .
\end{gathered}
$$

Notice that we have used the fact that the optimization problem is bounded and sequential limits are equal to joint limits. Simplify the equation, we have:

$$
\begin{aligned}
\Psi(z, a, \omega ; S) \equiv & \operatorname{Sup}_{\left\{w, a^{\prime}, v^{\prime}\left(z^{\prime}, a^{\prime}, s ; S^{\prime}\right)\right\}} \\
& d+\beta(1-\rho) E J\left(z^{\prime}, a^{\prime}, v^{\prime}\left(z^{\prime}, a^{\prime}, v ; S^{\prime}\right) ; S^{\prime}\right) \mid(s, S)+\beta \rho a^{\prime}(1+r) \\
& +\omega\left[u(w)+\beta E\left\{\left[V^{U}\left(S^{\prime}\right)+(1-\rho) v^{\prime}\left(z^{\prime}, a^{\prime}, v ; S^{\prime}\right)\right] \mid(s, S)\right\}\right] \\
\equiv & \operatorname{Sup}_{\left\{w, a^{\prime}, v^{\prime}\left(z^{\prime}, a^{\prime}, s ; S^{\prime}\right)\right\}} \\
& d+\beta \rho a^{\prime}(1+r) \\
& +\omega\left[u(w)+\beta \rho V^{U}\left(S^{\prime}\right)\right] \\
& +\beta(1-\rho)\left(E J\left(z^{\prime}, a^{\prime}, v^{\prime}\left(z^{\prime}, a^{\prime}, v ; S^{\prime}\right) ; S^{\prime}\right) \mid(s, S)+\omega v^{\prime}\right) \\
\equiv & \operatorname{Sup}_{\left\{w, a^{\prime}\right\}} \\
& d+\beta \rho a^{\prime}(1+r) \\
& +\omega\left[u(w)+\beta \rho V^{U}\left(S^{\prime}\right)\right] \\
& +\operatorname{Sup}_{\left\{v^{\prime}\left(z^{\prime}, a^{\prime}, s ; S^{\prime}\right)\right\}} \beta(1-\rho)\left(E J\left(z^{\prime}, a^{\prime}, v^{\prime}\left(z^{\prime}, a^{\prime}, v ; S^{\prime}\right) ; S^{\prime}\right) \mid(s, S)+\omega v^{\prime}\right) \\
\equiv \quad & \operatorname{Sup}_{\left\{w, a^{\prime}\right\}} d+\beta \rho a^{\prime}(1+r) \\
& +\omega\left[u(w)+\beta \rho V^{U}\left(S^{\prime}\right)\right] \\
& +\beta(1-\rho)\left(E \Psi\left(z^{\prime}, a^{\prime}, \omega ; S^{\prime}\right)\right)
\end{aligned}
$$

with constraints:

$$
\begin{gathered}
d=F(z, a ; S)-w-a^{\prime} \geq 0, \\
a^{\prime} \geq 0 .
\end{gathered}
$$

Notice that $\omega$ is not changing over time and we can just set $\omega$ as an index for the function $\Psi$ as $\Psi(z, a ; \omega, S)$. We can limit the domain of $\omega$ such that in the optimal problem for $\Psi$, an interior solution exists, and because $J(z, a, v)$ is concave in $v$, then a first order condition equation is satisfied. 
Analyzing the relationship between functions of $J$ and $\Psi$ can give us a more clear picture and the computation could be facilitated by using the analysis results.

First, recall we have a set of FOCs and the envelop conditions as follows:

$$
\begin{gathered}
w:-(1+\mu)+\xi u^{\prime}(w)=0 \\
a^{\prime}:-(1+\mu)+\beta \rho(1+r)+\beta(1-\rho) E \frac{\partial J}{\partial a^{\prime}}=0 \\
v^{\prime}: \xi+\frac{\partial J}{\partial v^{\prime}}=0 \\
\frac{\partial J}{\partial a}=(1+\mu) F_{a}(a ; \lambda) \\
\frac{\partial J}{\partial v}=-\xi .
\end{gathered}
$$

For the optimization problem in $\Psi$, we can get an interior solution for the $v^{*}(z, a, \omega ; S)$ and also, we can have the following transformations by invoking the maximum theorem:

$$
\begin{aligned}
\Psi(z, a, \omega ; S) & \equiv \operatorname{Sup}_{v} J(z, a, v ; S)+\omega v \\
\frac{\partial \Psi}{\partial \omega} & =v^{*}(z, a, \omega ; S) \\
\frac{\partial J\left(z, a, v^{*}(z, a, \omega) ; S\right)}{\partial v} & =-\omega \\
J(z, a, v ; S) & =\Psi\left(z, a, \omega^{*} ; S\right)-\omega^{*} v \text { with } \frac{\partial \Psi}{\partial \omega^{*}}=v\left(z, a, \omega^{*} ; S\right) .
\end{aligned}
$$

The numerical solution for $\Psi$ and $J$ are displayed in figure 2 in the text, and we heavily use the last equation to compute $J$.

\section{Business Cycles}

We can modify the function $\Psi(z, a ; \omega, S)$ to get a nice formation for studying the whole economy across business cycles with exogenous stochastic process of $S$.

Recall that:

$$
\begin{aligned}
\Psi(z, a ; \omega, S) \equiv & \operatorname{Sup}_{\left\{w, a^{\prime}\right\}} \\
& F(z, a ; S)-w-a^{\prime}+\beta \rho a^{\prime}(1+r) \\
& +\omega\left[u(w)+\beta \rho E\left(V^{U}\left(S^{\prime}\right) \mid S\right)\right] \\
& +\beta(1-\rho) E \Psi\left(z^{\prime}, a^{\prime} ; \omega, S^{\prime}\right) \\
& F(z, a ; S)-w-a^{\prime} \geq 0 .
\end{aligned}
$$

Denote a function $\tilde{U}(S)$, which only depends on the aggregate state $S$ :

$$
\tilde{U}(S)=\beta \rho E\left(V^{U}\left(S^{\prime}\right) \mid S\right)+\beta(1-\rho) E\left[\tilde{U}\left(S^{\prime}\right) \mid S\right] .
$$

Also, we can define a new function $\tilde{\Psi}(z, a ; \omega, S)$ :

$$
\begin{aligned}
\tilde{\Psi}(z, a ; \omega, S) \equiv & \quad \operatorname{Sup}_{\left\{w, a^{\prime}\right\}} \\
& F(z, a ; S)-w-a^{\prime}+\beta \rho a^{\prime}(1+r) \\
& +\omega u(w) \\
& +\beta(1-\rho) E \tilde{\Psi}\left(z^{\prime}, a^{\prime} ; \omega, S^{\prime}\right) \\
& F(z, a ; S)-w-a^{\prime} \geq 0 .
\end{aligned}
$$

It is easy to verify that

$$
\Psi(z, a ; \omega, S)=\tilde{\Psi}(z, a ; \omega, S)+\omega \tilde{U}(S) .
$$


Similarly, we can define $\tilde{v}$ :

$$
\left.\tilde{v}=u(w)+\beta(1-\rho) E \tilde{v}^{\prime}\left(z^{\prime}, a^{\prime}, s ; S^{\prime}\right)\right] \mid(s, S) ;
$$

with the relation:

$$
v=\tilde{v}+\tilde{U}(S)
$$

and $\tilde{J}(z, a, \tilde{v})$ :

$$
\begin{gathered}
\tilde{J}(z, a, \tilde{v})=\operatorname{Sup}_{\left\{w, a^{\prime}, \tilde{v}^{\prime}\left(z^{\prime}, a^{\prime}, s ; S^{\prime}\right)\right\}} d+\beta(1-\rho) E \tilde{J}\left(z^{\prime}, a^{\prime}, \tilde{v}^{\prime}\left(z^{\prime}, a^{\prime}, s ; S^{\prime}\right) ; S^{\prime}\right) \mid(s, S) \\
+\beta \rho a^{\prime}(1+r) \\
d=F(z, a ; S)-w-a^{\prime} \geq 0 \\
\left.\tilde{v}=u(w)+\beta(1-\rho) E \tilde{v}^{\prime}\left(z^{\prime}, a^{\prime}, s ; S^{\prime}\right)\right] \mid(s, S)
\end{gathered}
$$

We can see $J(z, a, v ; S)=\tilde{J}(z, a, \tilde{v} ; S)$ with $v=\tilde{v}+\tilde{U}(S)$. Or put it another way, it is just simple change from the argument of $v$ to $\tilde{v}$, nothing essential changed.

It is also easy to check that, similarly to $\Psi$ and $J$, we have transformations between $\tilde{\Psi}(z, a ; \omega, S)$ and $\tilde{J}(z, a, \tilde{v})$.

$$
\begin{aligned}
\tilde{\Psi}(z, a ; \omega, S) & =\operatorname{Sup}_{\tilde{v}} \tilde{J}(z, a, \tilde{v} ; S)+\omega \tilde{v} \\
\frac{\partial \tilde{\Psi}}{\partial \omega} & =\tilde{v}^{*}(z, a, \omega ; S) \\
\frac{\partial \tilde{J}(z, a, \tilde{v}(z, a, \omega) ; S)}{\partial \tilde{v}} & =-\omega \\
\tilde{J}(z, a, \tilde{v} ; S) & =\tilde{\Psi}\left(z, a ; \omega^{*}, S\right)-\omega^{*} \tilde{v} \text { with } \frac{\partial \tilde{\Psi}}{\partial \omega^{*}}=\tilde{v}\left(z, a, \omega^{*} ; S\right) .
\end{aligned}
$$

Moreover, we have:

$$
\begin{aligned}
& \Psi(z, a ; \omega, S)=\tilde{\Psi}(z, a ; \omega, S)+\omega \tilde{U}(S) \\
& \frac{\partial \Psi}{\partial \omega}=\frac{\partial \tilde{\Psi}}{\partial \omega}+\tilde{U}(S) \\
& J(z, a, v ; S)=\tilde{J}(z, a, \tilde{v} ; S), \text { with } v=\tilde{v}+\tilde{U}(S) \\
& \frac{\partial \tilde{J}(z, a, \tilde{v}(z, a, \omega) ; S)}{\partial \tilde{v}}=\frac{\partial J\left(z, a, v^{*}(z, a, \omega) ; S\right)}{\partial v}, \text { with } v=\tilde{v}+\tilde{U}(S) \\
& v=\tilde{v}+\tilde{U}(S) ; \\
& J \Psi-\omega \frac{\partial \Psi}{\partial \omega} \\
&=\tilde{\Psi}+\omega \tilde{U}(S)-\omega\left[\frac{\partial \tilde{\Psi}}{\partial \omega}+\tilde{U}(S)\right] \\
&=\tilde{\Psi}+\omega \tilde{U}(S)-\omega[\tilde{v}+\tilde{U}(S)] \\
&=\tilde{\Psi}-\omega \tilde{v} \\
& \equiv \tilde{J}=\tilde{\Psi}-\omega \frac{\partial \tilde{\Psi}}{\partial \omega}
\end{aligned}
$$

The last equation could be utilized when we calculate individual firm's value function $J$ over business cycle. We could simply first compute $\tilde{J}(z, a, \tilde{v} ; S)$ by using $\tilde{\Psi}(z, a ; \omega, S)$; After we find the equilibrium value of $\tilde{U}(S)$, we then could get the value $J(z, a, v ; S)$ by using $J(z, a, v ; S)=$ $\tilde{J}(z, a, \tilde{v} ; S)$, with $v=\tilde{v}+\tilde{U}(S)$. 


\section{Computing Dynamic General Equilibrium across Business Cy- cles}

For the equilibrium value of $\tilde{U}(S)$ and $V^{U}(S)$, we consider the following analysis: by:

First, for entry firms, the free entry condition in the competitive labor market is given

$$
\begin{aligned}
V^{U}(S)=\quad & f\left(q^{-1}\left(\frac{c}{J\left(z_{0}, a_{0}, v\right)}\right)\right) v \\
& +(1-f)\left[u(b)+\beta E V^{U}\left(S^{\prime}\right) \mid S\right] .
\end{aligned}
$$

Suppose the aggregate state of the economy is given by: $\left(S_{1}, S_{2}, \ldots S_{N}\right)$. Notice that we could have aggregate productivity shocks and/or aggregate financial shocks in here. Write $V^{U}(S)$ in the form of a vector $\bar{V}^{U}$, with elements $V^{U}{ }_{i}$;

In computation, we follow several steps:

(1) Guess an initial vector of $\bar{V}^{U}$; and find the corresponding $\tilde{U}(S)$ by using

$$
\tilde{U}(S)=\beta \rho E\left(V^{U}\left(S^{\prime}\right) \mid S\right)+\beta(1-\rho) E\left[\tilde{U}\left(S^{\prime}\right) \mid S\right]
$$

or $\tilde{U}_{V e c}=\beta \rho \Pi_{i} \bar{V}^{U}+\beta(1-\rho) \Pi_{i} \tilde{U}_{V e c}$, where $\Pi_{i}$ is the row vector in the transition matrix for markov process of $S$

(2) For each $S_{i}$, Find a optimal $\omega\left(S_{i}\right)$ to maximizes the right hand side in the free-entry equation,

$$
\begin{aligned}
& f\left(q^{-1}\left(\frac{c}{J\left(z_{0}, a_{0}, v_{i} ; S_{i}\right)}\right)\right) v_{i}+\left(1-f_{i}\right) u(b) \\
& +\left(1-f_{i}\right) \beta \Pi_{i} \bar{V}^{U}
\end{aligned}
$$

by using $\tilde{J}=\tilde{\Psi}-\omega \frac{\partial \tilde{\Psi}}{\partial \omega}$, and $v=\tilde{v}+\tilde{U}(S)$, and $J(z, a, v ; S)=\tilde{J}(z, a, \tilde{v} ; S)$, with $v=\tilde{v}+\tilde{U}(S)$. Note $f_{i}$ is a shorthand for $f\left(q^{-1}\left(\frac{c}{J\left(z_{0}, a_{0}, v_{i}\right)}\right)\right)$.

(3) Denote $f\left(q^{-1}\left(\frac{c}{J\left(z_{0}, a_{0}, v_{i} ; S_{i}\right)}\right)\right) v_{i}+\left(1-f_{i}\right) u(b)=a_{i},\left(1-f_{i}\right) \beta=b_{i}$, then we have the following equation from the free-entry equation :

$$
V_{i}^{U}=a_{i}+b_{i} \Pi_{i} \bar{V}^{U}
$$

Denote the matrix

$$
\left[\begin{array}{c}
b_{1} \Pi_{1} \\
b_{i} \Pi_{i} \\
b_{j} \Pi_{j} \\
b_{n} \Pi_{n}
\end{array}\right]=H
$$

Then we have

$$
\begin{array}{r}
\bar{V}^{U}=\bar{a}+H \bar{V}^{U} \\
\Rightarrow \bar{V}^{U}=(I-H)^{-1} \bar{a}
\end{array}
$$

So we can update the vector $\bar{V}^{U}$ by using vector $\bar{a}$ in the step 2 results;

(4) iterate and until $\bar{V}^{U}$ converges. That is, we have solved the equilibrium for the economy along business cycles. In practice, it turns out this iteration is fast. 